\title{
ZUR STRUKTUR UND FUNKTION VON SYNONYMEN
}

\section{Einleitung}

Der Artikel behandelt die Synonyme im Licht der funktionell-strukturellen Sprachtheorie Coserius. ${ }^{1}$ Die Wahl der theoretischen Grundsätze wurde durch die Festellung diktiert, daß die bisherigen Erkenntnisse über die Synonymie widersprüchlich sind und daß auch schon über alle Feststellungen berechtigte Einsprüche erhoben wurden. Deshalb wird in dieser Arbeit auf der genannten theoretischen Grundlage, die verschiedene Gesichtspunkte des Problems verbindet, anstatt sie zu trennen (s. Punkt 2), ein Modell für die Analyse von Synonymen vorgestellt (3), das die klassischen Schwächen der Semantikforschung (zu geringe Menge tatsächlicher Daten, Subjektivität und Introspektion) durch eine empirische Untersuchung in einem Textkorpus zu ersetzen versucht. In die Analyse sind drei Inhaltsebenen einbezogen (Bezeichnung, Bedeutung und Sinn) und ihnen sind jeweils entsprechende Untersuchungsmethoden zugeordnet. Im Sinne des Modells wurden in der Arbeit Zorman 1997 zwei slowenische Synonympaare (kuverta - ovojnica und borba - boj) analysiert, die als Beispiele reiner (und totaler) Synonymie gelten können. Die Analyse wird aus Platzgründen an dieser Stelle nicht detailliert dargestellt, ${ }^{2}$ veranschaulicht werden nur ihre Tragweite und die Ergebnisse (4). Im letzten Teil (5) werden die Leistungen der vorgeschlagenen Methode bewertet und einige Annahmen dargestellt, die der weiteren Erforschung der Synonyme dienen könnten. Die objektive Behandlung der Synonymie unter unterschiedlichen Gesichtspunkten scheint einige Dogmen über Synonyme in Frage zu stellen.

1 Der Beitrag ist eine Zusammenfassung der Dissertation mit dem Titel "Nekateri strukturalnofunkcionalni odnosi med členi sinonimnih vrst v slovenščini" (Strukturelle und funktionelle Beziehungen zwischen Gliedern der Synonymenreihen im Slowenischen; in der Folge Zorman 1997), verteidigt an der Philosophischen Fakultät in Ljubljana am 26. 2. 1998 vor der Kommission Prof. Dr. J. Orešnik, Prof. Dr. A. Vidovič-Muha, Prof. Dr. M. Golden.

2 Der gesamte Verlauf der Analyse ist mit 99 repräsentativen Beispielen in Zorman 1997: 55-107 und 122-164 veranschaulicht. 


\section{Die Untersuchung der Synonymie nach Coseriu}

Synonyme werden gewöhnlich als Ausdrücke aufgefaßt, die die "gleiche oder ähnliche Bedeutung" haben. Der Unterschied in der Form wird damit zwar eine grundlegende Voraussetzung für die Synonymie, jedoch wird der Terminus "synonym" dabei auf zwei verschiedene Arten gebraucht: Im engeren Sinn wird er auf einzelne Wörter begrenzt, die als Stichwörter in konventionellen Wörterbüchern auftreten, im weiteren Sinn (sog. Isomorphismus) wird er jedoch nur als eine der Manifestationen der Bedeutungsgleichheit in der Sprache verstanden, ${ }^{3}$ die eigentlich auf allen Ebenen der Sprachstruktur auftreten kann - als synonym können Phoneme, Morpheme, Syntagmen, Sätze oder sogar ganze Texte betrachtet werden. ${ }^{4}$ Während einige Linguisten für das Synonymieverhältnis die Invarianz der grammatischen Merkmale voraussetzen (Synonyme müssen derselben Ebene der Sprachstruktur angehören), lassen andere zu, daß in dieses Verhältnis auch Einheiten verschiedener Sprachebenen treten.

Das Studium der Fachliteratur über die Synonymie stellt den Leser dringend vor die schwierige Frage: Wie ist es möglich, daß verschiedene Autoren zu so unterschiedlichen Erkenntnissen gelangen konnten? Die widersprechenden Feststellungen betreffen so grundlegende Fragen, wie sie schon allein die nach der Existenz von Synonymen ist, die von einigen befürwortet, von anderen hingegen verneint wird, ${ }^{5}$ die Frage, ob die Synonymie ein strukturelles Verhältnis oder ein Verhältnis ist, das nur in einem bestimmten Kontext auftreten kann, ${ }^{6}$ ob die Synonyme untereinander austauschbar sind und wir sie dann mit der Substitution aufdecken können, oder ob andere Kriterien dafür gefunden werden müssen, ${ }^{7}$ ob verschiedene Grade der Bedeutungsgleichheit unterschieden werden können ${ }^{8}$ usw.

Das Problem der Synonymie zeigt noch ein viel verwickelteres Bild, wenn die Forscher beginnen, sich mit der Frage zu beschäftigen, was überhaupt Bedeutung sei bzw. worin die Gleichheit oder Ähnlichkeit von Bedeutungen eigentlich zu suchen sei: Sind das die bezeichneten Gegenstände (Definitionen des Typs "Synonyme sind Wörter, die dieselbe Sache bezeichnen"), ${ }^{9}$ Konzepte oder Begriffe in den Köpfen der Sprecher, ${ }^{10}$ gleiche oder ähnliche Distribution, ${ }^{11}$ Wörterbuchdefinition, ${ }^{12}$ Extension, ${ }^{13}$

Siehe z. B. Koch 1963, Gauger 1972a: 447, Harris 1973: 1.

Z. B. Gabka 1967: 729.

Vgl. dazu z. B. Skalička 1941, Zvegincev 1963, Gauger 1972, Harris 1973, Schirn 1975, Bickmann 1978, Sparck Jones 1986 usw.

Vgl. Gauger 1972: 5 und Lyons 1975: 462.

Vgl. Ullmann 1967: 102 und Cooper 1974: 253.

Quinne 1976: 345 und Lyons 1975: 457.

S. z. B. Evens et al. 1980: 153.

Filipec 1961: 203, Gabka 1967: 728 u. a.

Zvegincev 1963: 132, Harris 1970: 786 u. a. 
Wahrheitswert, ${ }^{14}$ gleiche Implikationen von Sätzen, die sich nur in der Wahl des Synonyms unterscheiden, ${ }^{15}$ gleiche Regeln des Gebrauchs, ${ }^{16}$ gleiche Proposition ${ }^{17}$ oder das gleiche Illokutionspotential. ${ }^{18}$ Alle erwähnten Definitionsversuche sind schon auf berechtigte Einwände gestoßen ${ }^{19}$ und sind deshalb abzulehnen. Sie berechtigen jedoch zu der Annahme, daß jeder Forscher der Synonyme das eigene Objekt seiner Untersuchung auswählen muß, in dem er Ähnlichkeiten oder Unterschiede zu prüfen versucht. Die Erkenntnisse können dann natürlich nicht übereinstimmen.

Der vorliegende Artikel behandelt das Problem vom Gesichtspunkt der Sprachtheorie Coserius aus, die in bezug auf die Synonymie zumindest die folgenden drei Vorzüge hat: 1. Sie stellt eine kohärente Theorie für die Behandlung mehrerer Seiten desselben Problems dar, 2. Sie führt eine Unterscheidung zwischen der Funktionalität in der Sprache und der Funktionalität in der Norm ein, 3. Sie führt eine Unterscheidung zwischen der Architektur und der Struktur der Sprache ein.

\subsection{Bezeichnung, Bedeutung und Sinn des sprachlichen Zeichens}

Entscheidend für das Verstehen der Sprachtheorie von Coseriu ${ }^{20}$ ist die Unterscheidung der drei Ebenen des Sprachlichen:

a) das Sprechen im allgemein, das Sprechen als eine allgemein menschliche Tätigkeit;

b) die Einzelsprache;

c) der Text.

Den drei Ebenen des Sprachlichen entsprechen drei Ebenen des sprachlichen Inhalts bzw. drei semantische Ebenen: ${ }^{21}$

a) die Bezeichnung, die der Beziehung zwischen der außersprachlichen Realität und dem sprachlichen Zeichen beim Sprechen entspricht;

b) die Bedeutung, die durch die strukturelle Beziehungen zwischen einzelsprachlichen Inhalten (signifié) determiniert wird;

12 Katz \& Fodor 1963: $184 \mathrm{f}$.

13 Z. B. Montague (nach Lyons 1981: $157 \mathrm{ff}$.).

14 Mates 1950: 209, Quine 1960: 65 usw.; vgl. auch Cooper 1974.

15 Lyons 1975: 460.

16 Vgl. dazu Bickmann 1978: 2.

17 Hurford \& Heasley 1983: 104; vgl. auch Nida 1975: 106.

18 Vg1. Leech 1990: 20, Harris 1973: 151.

19 S. Zorman 1997: 15-24.

20 Weil bei uns nur wenige Werke Coserius zugänglich sind, wird seine Theorie in diesem und folgendem Punkt ausführlicher besprochen, als es zu erwarten wäre.

21 S. z. B. Coseriu 1973: 9 ff., Coseriu 1985: 42-48 oder Coseriu 1992: 262-264. 
c) der Sinn, der sich im Text aufgrund der beiden niedrigeren Schichten konstituiert.

Das Sprechen verläuft immer nach bestimmten historischen Traditionen einer Sprachgemeinschaft (Sprache) und immer individuell (es spricht ein Individuum in einer bestimmten Situation, was Coseriu einen Sprechakt nennt ${ }^{22}$ ). Der Untersuchung ist nur die Ebene des Sprechens bzw. solcher Sprechakte zugänglich, und zwar immer in der Form eines Textes. Jedoch müssen wir dabei zwischen der Funktion im Text und der Funktion in der Sprache bzw. zwischen den oben aufgeführten Ebenen des Sprachlichen unterscheiden, d. h. zwischen dem, was bei dem Sprechen universell, historisch (Resultat der Tradition und zugleich Grundlage für spätere sprachliche Tätigkeit) sowie individuell ist. Ein Sprechakt bezieht sich immer auf einen tatsächlichen Zustand, der außerhalb der Sprache besteht, und zwar mit Hilfe der Kategorien der Einzelsprache und jedesmal mit einer Textfunktion. Damit unterscheidet sich seine Auffassung von langue und parole von der orthodoxen strukturalistischen Interpretation dieser zwei Begriffe, wo das einzige Objekt der Beschreibung langue war, während parole meist nur als "Realisierung des Systems" begriffen wurde, sowie auch von den modernen pragmatischen Theorien, die die außersprachlichen Faktoren bei dem Gebrauch der Sprache zu erklären versuchen.

Universell, allgemein menschlich ist die Technik des Sprechens (Funktionen des Sprechens als solches ${ }^{23}$ und die Instrumente für das Erfüllen dieser Funktionen: lexikalische und grammatikalische Einheiten und deren Modifizierungs- und Kombinationsregeln innerhalb eines Satzes). Neben den verbalen Mitteln, die auf dieser Ebene die Funktion haben, daß wir etwas über etwas mit Hilfe sprachlicher Zeichen aussagen (der gemeinsame Name für die verwendeten Operationen, mit welchen diese Funktion ausgefüllt wird, ist die Determinierung), gehören hierher auch nichtverbale Mittel (Mimik, Gesten, Schweigen usw.) und die Umstände des Sprechens, in welchen auch das funktionell werden kann, was sonst in der Sprache nicht so ist. Diese Möglichkeit ist mit der Wahl gegeben. Die von den Umständen abhängigen Instrumente des Sprechens nennen sich "Umfelder". Das sprachliche Zeichen stellt beim Sprechen "eine Sache" dar (einen Tatbestand oder einen Denkinhalt) und den Bezug auf das Außersprachliche oder dieses Außersprachliche selbst nennt Coseriu "Bezeichnung". Die Bezeichnung kann bei zwei Zeichen identisch sein, ohne daß ihre Inhalte es wären (vgl. dazu das serbische Sprichwort: Beide sind Alkoholiker: der Arme ist ein Säufer, der Reiche aber ein Boheme). Hierbei handelt es sich um eine einzige Bezeichnung bzw. außersprachliche Realität, der mehrere verschiedene strukturelle Bedeutungen entsprechen - die Ausdruckspaare wie Säufer und Boheme sind nicht sprachlich synonym, sondern nur in der Bezeichnung äquivalent. Die Äquivalenz in der Bezeichnung nennt Coseriu 1973: 10 auch kognitive

22 Der Terminus ist hier nicht in dem aus der Pragmatik bekannten Sinn gebraucht, sondern im Sinn des Sprechens, Gesprächs.

23 S. Coseriu 1975: 256 


\section{ZUR STRUKTUR UND FUNKTION VON SYNONYMEN}

\section{Einleitung}

Der Artikel behandelt die Synonyme im Licht der funktionell-strukturellen Sprachtheorie Coserius. ${ }^{1}$ Die Wahl der theoretischen Grundsätze wurde durch die Festellung diktiert, daß die bisherigen Erkenntnisse über die Synonymie widersprüchlich sind und daß auch schon über alle Feststellungen berechtigte Einsprüche erhoben wurden. Deshalb wird in dieser Arbeit auf der genannten theoretischen Grundlage, die verschiedene Gesichtspunkte des Problems verbindet, anstatt sie zu trennen (s. Punkt 2), ein Modell für die Analyse von Synonymen vorgestellt (3), das die klassischen Schwächen der Semantikforschung (zu geringe Menge tatsächlicher Daten, Subjektivität und Introspektion) durch eine empirische Untersuchung in einem Textkorpus zu ersetzen versucht. In die Analyse sind drei Inhaltsebenen einbezogen (Bezeichnung, Bedeutung und Sinn) und ihnen sind jeweils entsprechende Untersuchungsmethoden zugeordnet. Im Sinne des Modells wurden in der Arbeit Zorman 1997 zwei slowenische Synonympaare (kuverta - ovojnica und borba - boj) analysiert, die als Beispiele reiner (und totaler) Synonymie gelten können. Die Analyse wird aus Platzgründen an dieser Stelle nicht detailliert dargestellt, ${ }^{2}$ veranschaulicht werden nur ihre Tragweite und die Ergebnisse (4). Im letzten Teil (5) werden die Leistungen der vorgeschlagenen Methode bewertet und einige Annahmen dargestellt, die der weiteren Erforschung der Synonyme dienen könnten. Die objektive Behandlung der Synonymie unter unterschiedlichen Gesichtspunkten scheint einige Dogmen über Synonyme in Frage zu stellen.

1 Der Beitrag ist eine Zusammenfassung der Dissertation mit dem Titel "Nekateri strukturalnofunkcionalni odnosi med členi sinonimnih vrst v slovenščini" (Strukturelle und funktionelle Beziehungen zwischen Gliedern der Synonymenreihen im Slowenischen; in der Folge Zorman 1997), verteidigt an der Philosophischen Fakultät in Ljubljana am 26. 2. 1998 vor der Kommission Prof. Dr. J. Orešnik, Prof. Dr. A. Vidovič-Muha, Prof. Dr. M. Golden.

2 Der gesamte Verlauf der Analyse ist mit 99 repräsentativen Beispielen in Zorman 1997: 55-107 und 122-164 veranschaulicht. 


\section{Die Untersuchung der Synonymie nach Coseriu}

Synonyme werden gewöhnlich als Ausdrücke aufgefaßt, die die "gleiche oder ähnliche Bedeutung" haben. Der Unterschied in der Form wird damit zwar eine grundlegende Voraussetzung für die Synonymie, jedoch wird der Terminus "synonym" dabei auf zwei verschiedene Arten gebraucht: Im engeren Sinn wird er auf einzelne Wörter begrenzt, die als Stichwörter in konventionellen Wörterbüchern auftreten, im weiteren Sinn (sog. Isomorphismus) wird er jedoch nur als eine der Manifestationen der Bedeutungsgleichheit in der Sprache verstanden, ${ }^{3}$ die eigentlich auf allen Ebenen der Sprachstruktur auftreten kann - als synonym können Phoneme, Morpheme, Syntagmen, Sätze oder sogar ganze Texte betrachtet werden. ${ }^{4}$ Während einige Linguisten für das Synonymieverhältnis die Invarianz der grammatischen Merkmale voraussetzen (Synonyme müssen derselben Ebene der Sprachstruktur angehören), lassen andere zu, daß in dieses Verhältnis auch Einheiten verschiedener Sprachebenen treten.

Das Studium der Fachliteratur über die Synonymie stellt den Leser dringend vor die schwierige Frage: Wie ist es möglich, daß verschiedene Autoren zu so unterschiedlichen Erkenntnissen gelangen konnten? Die widersprechenden Feststellungen betreffen so grundlegende Fragen, wie sie schon allein die nach der Existenz von Synonymen ist, die von einigen befürwortet, von anderen hingegen verneint wird, ${ }^{5}$ die Frage, ob die Synonymie ein strukturelles Verhältnis oder ein Verhältnis ist, das nur in einem bestimmten Kontext auftreten kann, ${ }^{6}$ ob die Synonyme untereinander austauschbar sind und wir sie dann mit der Substitution aufdecken können, oder ob andere Kriterien dafür gefunden werden müssen, ${ }^{7}$ ob verschiedene Grade der Bedeutungsgleichheit unterschieden werden können ${ }^{8}$ usw.

Das Problem der Synonymie zeigt noch ein viel verwickelteres Bild, wenn die Forscher beginnen, sich mit der Frage zu beschäftigen, was überhaupt Bedeutung sei bzw. worin die Gleichheit oder Ähnlichkeit von Bedeutungen eigentlich zu suchen sei: Sind das die bezeichneten Gegenstände (Definitionen des Typs "Synonyme sind Wörter, die dieselbe Sache bezeichnen"), ${ }^{9}$ Konzepte oder Begriffe in den Köpfen der Sprecher, ${ }^{10}$ gleiche oder ähnliche Distribution, ${ }^{11}$ Wörterbuchdefinition, ${ }^{12}$ Extension, ${ }^{13}$

Siehe z. B. Koch 1963, Gauger 1972a: 447, Harris 1973: 1.

Z. B. Gabka 1967: 729.

Vgl. dazu z. B. Skalička 1941, Zvegincev 1963, Gauger 1972, Harris 1973, Schirn 1975, Bickmann 1978, Sparck Jones 1986 usw.

Vgl. Gauger 1972: 5 und Lyons 1975: 462.

Vgl. Ullmann 1967: 102 und Cooper 1974: 253.

Quinne 1976: 345 und Lyons 1975: 457.

S. z. B. Evens et al. 1980: 153.

Filipec 1961: 203, Gabka 1967: 728 u. a.

Zvegincev 1963: 132, Harris 1970: 786 u. a. 
Wahrheitswert, ${ }^{14}$ gleiche Implikationen von Sätzen, die sich nur in der Wahl des Synonyms unterscheiden, ${ }^{15}$ gleiche Regeln des Gebrauchs, ${ }^{16}$ gleiche Proposition ${ }^{17}$ oder das gleiche Illokutionspotential. ${ }^{18}$ Alle erwähnten Definitionsversuche sind schon auf berechtigte Einwände gestoßen ${ }^{19}$ und sind deshalb abzulehnen. Sie berechtigen jedoch zu der Annahme, daß jeder Forscher der Synonyme das eigene Objekt seiner Untersuchung auswählen muß, in dem er Ähnlichkeiten oder Unterschiede zu prüfen versucht. Die Erkenntnisse können dann natürlich nicht übereinstimmen.

Der vorliegende Artikel behandelt das Problem vom Gesichtspunkt der Sprachtheorie Coserius aus, die in bezug auf die Synonymie zumindest die folgenden drei Vorzüge hat: 1. Sie stellt eine kohärente Theorie für die Behandlung mehrerer Seiten desselben Problems dar, 2. Sie führt eine Unterscheidung zwischen der Funktionalität in der Sprache und der Funktionalität in der Norm ein, 3. Sie führt eine Unterscheidung zwischen der Architektur und der Struktur der Sprache ein.

\subsection{Bezeichnung, Bedeutung und Sinn des sprachlichen Zeichens}

Entscheidend für das Verstehen der Sprachtheorie von Coseriu ${ }^{20}$ ist die Unterscheidung der drei Ebenen des Sprachlichen:

a) das Sprechen im allgemein, das Sprechen als eine allgemein menschliche Tätigkeit;

b) die Einzelsprache;

c) der Text.

Den drei Ebenen des Sprachlichen entsprechen drei Ebenen des sprachlichen Inhalts bzw. drei semantische Ebenen: ${ }^{21}$

a) die Bezeichnung, die der Beziehung zwischen der außersprachlichen Realität und dem sprachlichen Zeichen beim Sprechen entspricht;

b) die Bedeutung, die durch die strukturelle Beziehungen zwischen einzelsprachlichen Inhalten (signifié) determiniert wird;

12 Katz \& Fodor 1963: $184 \mathrm{f}$.

13 Z. B. Montague (nach Lyons 1981: $157 \mathrm{ff}$.).

14 Mates 1950: 209, Quine 1960: 65 usw.; vgl. auch Cooper 1974.

15 Lyons 1975: 460.

16 Vgl. dazu Bickmann 1978: 2.

17 Hurford \& Heasley 1983: 104; vgl. auch Nida 1975: 106.

18 Vg1. Leech 1990: 20, Harris 1973: 151.

19 S. Zorman 1997: 15-24.

20 Weil bei uns nur wenige Werke Coserius zugänglich sind, wird seine Theorie in diesem und folgendem Punkt ausführlicher besprochen, als es zu erwarten wäre.

21 S. z. B. Coseriu 1973: 9 ff., Coseriu 1985: 42-48 oder Coseriu 1992: 262-264. 
c) der Sinn, der sich im Text aufgrund der beiden niedrigeren Schichten konstituiert.

Das Sprechen verläuft immer nach bestimmten historischen Traditionen einer Sprachgemeinschaft (Sprache) und immer individuell (es spricht ein Individuum in einer bestimmten Situation, was Coseriu einen Sprechakt nennt ${ }^{22}$ ). Der Untersuchung ist nur die Ebene des Sprechens bzw. solcher Sprechakte zugänglich, und zwar immer in der Form eines Textes. Jedoch müssen wir dabei zwischen der Funktion im Text und der Funktion in der Sprache bzw. zwischen den oben aufgeführten Ebenen des Sprachlichen unterscheiden, d. h. zwischen dem, was bei dem Sprechen universell, historisch (Resultat der Tradition und zugleich Grundlage für spätere sprachliche Tätigkeit) sowie individuell ist. Ein Sprechakt bezieht sich immer auf einen tatsächlichen Zustand, der außerhalb der Sprache besteht, und zwar mit Hilfe der Kategorien der Einzelsprache und jedesmal mit einer Textfunktion. Damit unterscheidet sich seine Auffassung von langue und parole von der orthodoxen strukturalistischen Interpretation dieser zwei Begriffe, wo das einzige Objekt der Beschreibung langue war, während parole meist nur als "Realisierung des Systems" begriffen wurde, sowie auch von den modernen pragmatischen Theorien, die die außersprachlichen Faktoren bei dem Gebrauch der Sprache zu erklären versuchen.

Universell, allgemein menschlich ist die Technik des Sprechens (Funktionen des Sprechens als solches ${ }^{23}$ und die Instrumente für das Erfüllen dieser Funktionen: lexikalische und grammatikalische Einheiten und deren Modifizierungs- und Kombinationsregeln innerhalb eines Satzes). Neben den verbalen Mitteln, die auf dieser Ebene die Funktion haben, daß wir etwas über etwas mit Hilfe sprachlicher Zeichen aussagen (der gemeinsame Name für die verwendeten Operationen, mit welchen diese Funktion ausgefüllt wird, ist die Determinierung), gehören hierher auch nichtverbale Mittel (Mimik, Gesten, Schweigen usw.) und die Umstände des Sprechens, in welchen auch das funktionell werden kann, was sonst in der Sprache nicht so ist. Diese Möglichkeit ist mit der Wahl gegeben. Die von den Umständen abhängigen Instrumente des Sprechens nennen sich "Umfelder". Das sprachliche Zeichen stellt beim Sprechen "eine Sache" dar (einen Tatbestand oder einen Denkinhalt) und den Bezug auf das Außersprachliche oder dieses Außersprachliche selbst nennt Coseriu "Bezeichnung". Die Bezeichnung kann bei zwei Zeichen identisch sein, ohne daß ihre Inhalte es wären (vgl. dazu das serbische Sprichwort: Beide sind Alkoholiker: der Arme ist ein Säufer, der Reiche aber ein Boheme). Hierbei handelt es sich um eine einzige Bezeichnung bzw. außersprachliche Realität, der mehrere verschiedene strukturelle Bedeutungen entsprechen - die Ausdruckspaare wie Säufer und Boheme sind nicht sprachlich synonym, sondern nur in der Bezeichnung äquivalent. Die Äquivalenz in der Bezeichnung nennt Coseriu 1973: 10 auch kognitive

22 Der Terminus ist hier nicht in dem aus der Pragmatik bekannten Sinn gebraucht, sondern im Sinn des Sprechens, Gesprächs.

23 S. Coseriu 1975: 256 
Synonymie. Die Gleichheit beruht in solchen Fällen auf dem bezeichneten Tatbestand bzw. Denkinhalt - sie ist außersprachlich gegeben. Unter bestimmten Bedingungen sind nur Beziehungen zwischen Bedeutungen strukturierbar, während die konkrete Bezeichnung eine Sache der Wahl ist, ein Faktum der Rede. Sie ist nicht konstant, sondern variabel - dieselbe Sache kann Sitz, Lehnstuhl, Fauteuil oder Stuhl genannt werden; Buch, Untersuchung, Abhandlung oder Erörterung; derselbe Mensch Informator, Benachrichtiger, Spitzel oder Spion; waghalsiger Fahrer oder neues Opfer einer gefährlichen Straße. Man muß sich aber dessen bewußt sein, daß der Sprachinhalt (signifié) nicht mit den Klassen von Designata (der bezeichneten Sachen) zusammenfällt. Das ermöglicht uns, die Abweichungen zwischen der Intension und Extension oder Denotation bzw. zwischen der virtuellen und aktuellen Bedeutung zu verstehen: Die aktuelle Bedeutung bildet sich aufgrund der lexikalischen Funktion des Wortes mit Hilfe von Instrumenten für die Aktualisierung und Kombination der Wörter im Satz.

Der Begriff der Bezeichnung wird außer von Coseriu auch von anderen Sprachwissenschaftlern gebraucht, jedoch in einem etwas anderen Sinn. In der Semiotik ist die Bezeichnung ein neutraler Terminus für dasjenige, wofür ein bestimmtes Zeichen steht; noch häufiger wird in diesem Sinn der Terminus "das Bezeichnete" gebraucht. ${ }^{24}$ Obwohl verschiedene Abweichungen möglich sind, bleiben die Autoren gewöhnlich im Rahmen des semiotischen Dreiecks von Ogden und Richards und teilen die Überzeugung, daß Wörter Sachen mittels Begriffen bezeichnen. Hier haben wir mit einer anderen Art von Bezeichnung zu tun als bei Coseriu, denn die Konzeptualisten versuchen Konzepte aufzudecken, die mit Wörtern im abstrakten Sprachsystem verbunden sind. Die Bezeichnung von Coseriu muß auch von zwei anderen semantischen Begriffen getrennt werden, die für die Beziehung des sprachlichen Ausdrucks und der Sache gebraucht werden: Referenz und Denotation. Der Terminus "Referenz" wird in der logischen Semantik für die Beziehung zwischen dem sprachlichen Ausdruck und dem Ding, der Handlung usw., die außerhalb der Sprache existieren, gebraucht. Nach Searle ist das der Teil des Sprechakts, in welchem die Beziehung zwischen dem sprachlichen Zeichen und seinem Denotat hergestellt wird. Es geht hierbei um die Identifikation des individuellen Vertreters jener Menge von Sachen, die z. B. vom Lexem denotiert wird, um die Identifikation eines konkreten Objektes oder einer Sache mit Hilfe von sprachlichen Mitteln. Vom Gesichtspunkt der philosophischen Semantik aus verändert sich die Bedeutung des Ausgesagten nicht, wenn für die Identifikation ein anderer sprachlicher Ausdruck gebraucht wird (Dicker mit roter Krawatte und kräftigerer Mann mit roter Krawatte kann sich in einer bestimmen Situation des Sprechens auf dieselbe Person beziehen, über die wir etwas aussagen wollen). Demgegenüber ist die Bezeichnung von Coseriu die primäre Strukturierung von Erfahrungen mit Wörtern, das Einreihen von Sachen in eine bestimmte Klasse. Die Auswahl der Bezeichnung kann auch ein latent vorhandenes 
Synonymie. Die Gleichheit beruht in solchen Fällen auf dem bezeichneten Tatbestand bzw. Denkinhalt - sie ist außersprachlich gegeben. Unter bestimmten Bedingungen sind nur Beziehungen zwischen Bedeutungen strukturierbar, während die konkrete Bezeichnung eine Sache der Wahl ist, ein Faktum der Rede. Sie ist nicht konstant, sondern variabel - dieselbe Sache kann Sitz, Lehnstuhl, Fauteuil oder Stuhl genannt werden; Buch, Untersuchung, Abhandlung oder Erörterung; derselbe Mensch Informator, Benachrichtiger, Spitzel oder Spion; waghalsiger Fahrer oder neues Opfer einer gefährlichen Straße. Man muß sich aber dessen bewußt sein, daß der Sprachinhalt (signifié) nicht mit den Klassen von Designata (der bezeichneten Sachen) zusammenfällt. Das ermöglicht uns, die Abweichungen zwischen der Intension und Extension oder Denotation bzw. zwischen der virtuellen und aktuellen Bedeutung zu verstehen: Die aktuelle Bedeutung bildet sich aufgrund der lexikalischen Funktion des Wortes mit Hilfe von Instrumenten für die Aktualisierung und Kombination der Wörter im Satz.

Der Begriff der Bezeichnung wird außer von Coseriu auch von anderen Sprachwissenschaftlern gebraucht, jedoch in einem etwas anderen Sinn. In der Semiotik ist die Bezeichnung ein neutraler Terminus für dasjenige, wofür ein bestimmtes Zeichen steht; noch häufiger wird in diesem Sinn der Terminus "das Bezeichnete" gebraucht. ${ }^{24}$ Obwohl verschiedene Abweichungen möglich sind, bleiben die Autoren gewöhnlich im Rahmen des semiotischen Dreiecks von Ogden und Richards und teilen die Überzeugung, daß Wörter Sachen mittels Begriffen bezeichnen. Hier haben wir mit einer anderen Art von Bezeichnung zu tun als bei Coseriu, denn die Konzeptualisten versuchen Konzepte aufzudecken, die mit Wörtern im abstrakten Sprachsystem verbunden sind. Die Bezeichnung von Coseriu muß auch von zwei anderen semantischen Begriffen getrennt werden, die für die Beziehung des sprachlichen Ausdrucks und der Sache gebraucht werden: Referenz und Denotation. Der Terminus "Referenz" wird in der logischen Semantik für die Beziehung zwischen dem sprachlichen Ausdruck und dem Ding, der Handlung usw., die außerhalb der Sprache existieren, gebraucht. Nach Searle ist das der Teil des Sprechakts, in welchem die Beziehung zwischen dem sprachlichen Zeichen und seinem Denotat hergestellt wird. Es geht hierbei um die Identifikation des individuellen Vertreters jener Menge von Sachen, die z. B. vom Lexem denotiert wird, um die Identifikation eines konkreten Objektes oder einer Sache mit Hilfe von sprachlichen Mitteln. Vom Gesichtspunkt der philosophischen Semantik aus verändert sich die Bedeutung des Ausgesagten nicht, wenn für die Identifikation ein anderer sprachlicher Ausdruck gebraucht wird (Dicker mit roter Krawatte und kräftigerer Mann mit roter Krawatte kann sich in einer bestimmen Situation des Sprechens auf dieselbe Person beziehen, über die wir etwas aussagen wollen). Demgegenüber ist die Bezeichnung von Coseriu die primäre Strukturierung von Erfahrungen mit Wörtern, das Einreihen von Sachen in eine bestimmte Klasse. Die Auswahl der Bezeichnung kann auch ein latent vorhandenes 
Wissen über Sachen evozieren und damit Inferenzen, Konnotationen bzw. Evokationen auf einer anderen Inhaltsebene. Die Denotation (ähnlich auch die Extension des Prädikats) ist die Beziehung zwischen dem Lexem (nicht aber dem in einer bestimmten Sprechsituation gebrauchten Ausdruckes) und der ganzen Klasse der Individuen, auf die das Lexem anwendbar ist. ${ }^{25}$ Das Lexem Vogel denotiert eine besondere Klasse von Lebewesen, in welche sowohl prototypische Vertreter als auch solche gehören, die davon schon sehr abweichen. Wiederum geht es also um den Unterschied zwischen dem Gebrauch in der Sprechsituation und der Rolle im sprachlichen System.

Die Reihenfolge der Analyse (Bezeichnung, Bedeutung) entspricht nicht der tatsächlichen sprachlichen Reihenfolge. Coseriu 1971: 219 meint, daß die tatsächliche Reihenfolge gerade umgekehrt sei - sekundär sei die Bezeichnung, die sich in der sprachlichen Verständigung auf der Grundlage einer entsprechenden strukturellen Bedeutung eines sprachlichen Zeichens ergibt (die "Sache" diktiert die Wahl). Das Zeichen kann hinsichtlich der Bezeichnung polyvalent sein, wobei wir es anstatt mit der Identität der Bezeichnung mit der Identität der Bedeutung zu tun haben. Obwohl das sprachliche Zeichen für die Bezeichnung von verschiedenen Sachen dienen kann, hat es jedoch immer nur eine Bedeutung. Die Bedeutung ist nicht die Synthese von Bezeichnungsmöglichkeiten, sondern ein einzelsprachlicher Inhalt, bestimmt durch die strukturellen Beziehungen zu den Inhalten anderer Zeichen in dem gleichen System. Diese Auffassung der Bedeutung stimmt mit dem Begriff valeur bei de Saussure überein und die Werte der sprachlichen Einheiten sind relationell bestimmt. Für Coseriu ist die sprachliche Einheit eine konzeptuelle Einheit, definiert durch die Oppositionen und Funktionen (als Einheit existiert sie nur, wenn sie zu einer anderen Einheit in Opposition steht; der Unterschied auf der Ebene der Form ist in der Sprache nur dann funktionell, wenn ihm auch ein Unterschied auf der Inhaltsebene entspricht (Coseriu 1992: 172 f.)). Bei einer solchen Auffassung muß die Beschreibung der Bedeutung selbstverständlich strukturell sein, jedoch weicht Coseriu in dieser Hinsicht von anderen strukturellen Beschreibungen semantischer Konfigurationen ab. Als Kriterium für die Beschreibung übernimmt er die Funktionalität auf der Ebene langue. In Betracht zieht er nicht alles, was wichtig sein könnte, sondern nur das, was nicht fehlen darf. Aus der lexikalischen Struktur schließt er alles aus, was auf dieser Ebene fakultativ, unsystematisch oder außersprachlich ist. Coseriu 1970: 8-47 verlangt die Unterscheidung zwischen der Kenntnis der Sachen und der Kenntnis der Wörter, der Primärsprache und der Metasprache, der Synchronie und der Diachronie, der Technik der Rede und der wiederholten Rede, der Architektur und der Struktur der Sprache, dem System und der Norm, den Bedeutungsbeziehungen und den Bezeichnungsbeziehungen. Terminologien, die Kenntnis der Sachen, Assoziationen zwischen den Sachen (Rind - Pflug) sowie die Meinungen über diese (dumm wie ein Esel) gehören nicht in die strukturelle Beschreibung der semantischen Konfigurationen. Die sprachliche Strukturierung fällt nicht immer mit den Strukturen der objektiven 
Wirklichkeit zusammen - für dieselbe Sache können in der Sprache mehrere Benennungen zur Verfügung stehen oder nur eine für mehrere Sachen. Aus der Beschreibung müssen auch Fälle von metasprachlichem Gebrauch und Einheiten der wiederholten Rede (erstarte Ausdrücke, Phrasen und Redewendungen, die ähnlich wie Zitate gebraucht werden und deren Einzelteile nicht gemäß den geltenden Regeln kombiniert oder ersetzt werden können) weggelassen werden. Jede Struktur muß in ihrer eigenen Synchronie gesehen werden (obwohl ein Sprachzustand niemals ausschließlich "synchronisch" ist, denn es gibt.immer auch Formen, die die Sprecher "noch verwenden" und Formen, welche sie gerade "anfangen zu verwenden") und innerhalb der funktionellen Sprache, der sie angehört (die sprachliche Einheit steht nur innerhalb eines Systems in Opposition zu anderen Einheiten). So "gesäuberte" Beziehungen, d. h. ausschließlich Beziehungen zwischen den Bedeutungen einer einzigen Technik des Sprechens, lassen sich strukturieren. Die Strukturen können paradigmatisch (oppositionell) oder syntagmatisch (kombinatorisch) $\operatorname{sein} .{ }^{26}$ Die paradigmatischen Strukturen sind primär, wenn ihre Begriffe sich gegenseitig implizieren, ohne daß der eine Begriff im Verhältnis zum anderen primär wäre ('alt' 'jung'), und sekundär, wenn die Implikation zwischen ihren Begriffen nur in eine Richtung verläuft (die Definition des Inhalts 'Haus' ist unabhängig von dem Inhalt 'Häuschen', während die Definition des Inhalts 'Häuschen' notwendigerweise den Inhalt 'Haus' einschließt). Primäre Strukturen sind das Wort- bzw. Bedeutungsfeld und die Wortklasse, sekundäre aber die Modifikation, Entwicklung und Komposition. Coseriu gebraucht diese Termini auf seine eigene Weise ohne Rücksicht auf den üblichen Gebrauch in der Sprachwissenschaft. Das, was traditionell Ableitung bzw. Derivation genannt wird, sind bei ihm verschiedene Strukturen, und zwar entweder die Modifikation, Komposition oder die Entwicklung. Coseriu geht hier nämlich ausschließlich von Beziehungen zwischen Inhalten aus und läßt die Form außer Betracht. Vorsicht ist auch hinsichtlich der Inhaltsebene geboten, auf welcher wir eine gewisse Erscheinung beobachten: Dieselbe Erscheinung ist, auf der Ebene der Bezeichnung gesehen, z. B. eine Spezifizierung, auf der Ebene der Bedeutung hingegen eine Komposition (z. B. Tierarzt).

Ein Wortfeld ist nach Coseriu eine paradigmatische Struktur, die aus lexikalischen Einheiten besteht, die sich eine gemeinsame Bedeutungzone ${ }^{27}$ teilen und in unmittelbarer Opposition zueinander stehen. Es handelt sich um lexikalische Einheiten, zwischen denen man an einem gewissen Punkt der chaîne parlée die Wahl hat, bzw. die Einheit, die man gewählt hat, und die Einheiten, die von der Wahl ausgeschlossen sind. Ein Lexem, dessen Inhalt mit dem eines ganzen Wortfeldes identisch ist, ist ein Archilexem. Die Methode, nach welcher man ein Wortfeld konstruiert, ist die Methode der unmittelbaren Oppositionen: Zwischen zwei Lexemen identifiziert man die unterscheidenden Züge, die diese Begriffe in Opposition zueinander stellen, und man 
konstruiert das Wórtfeld schrittweise, indem man neue Oppositionen aufstellt. Eine Wortklasse ist eine Klasse von Lexemen, die durch ein Klassem determiniert werden; dieses ist ein unterscheidender Zug, der mehreren Wortfeldern gemein ist (z. B. 'belebt', 'unbelebt'). Die Klassen zeigen sich in den grammatischen oder lexikalischen Kombinationen der Lexeme. Zu derselben Klasse gehören Lexeme, bei denen dieselben lexikalischen und/oder grammatischen Kombinationen zugleich möglich sind. Für die Substantive kann man Klassen aufstellen wie 'lebende Wesen', 'Sachen' und innerhalb der Klasse 'lebende Wesen' Klassen wie 'menschliche Wesen', 'Tiere' usw. Die Modifikation ist eine inhaltliche Beziehung zwischen Lexemen, die keine spezifische Funktion des modifizierten primären Begriffes impliziert (am häufigsten handelt es sich um Quantifikation, jedoch bleibt das Wesen der Modifikation nach Coseriu 1970: 52 noch zu bestimmen). Dieser Struktur entsprechen z. B. Deminutiva, Kollektiva, Verben mit Präfixen: 'Haus' - 'Häuschen', 'hinfallën'-'ausfallen' usw. Die Entwicklung ist eine grammatikalische Determination, die eine bestimmte Funktion eines primären Begriffes im Satz impliziert, und zwar einen Wechsel der Wortart ('Nation' - 'national'). Ein schon entwickelter Begriff kann der Ausgangspunkt einer neuen Entwicklung sein, und die Entwicklung kann mit der Modifikation kombiniert werden ('gehen'- 'durchgehen'- 'Durchgang'). Die Komposition impliziert immer das Vorhandensein von zwei Basiselementen, die in grammatischer Beziehung zueinander stehen. Je nachdem, was für Elemente man kombiniert, ist die Komposition entweder generisch (pronominal; eines der Elemente ist generisch: 'lesen' - 'Leser') oder spezifisch (nominal; beide Elemente sind Lexeme: 'Kauf-mann').

Die syntagmatischen Strukturen sind Solidaritäten zwischen Lexemen, die durch ihren Sprachwert motiviert sind (Coseriu 1971: 209-211). Solidarität ist die Beziehung zwischen zwei Lexemen (determinierend und determiniert), wobei das eine in seiner Gesamtheit oder teilweise im anderen als unterscheidender Zug enthalten ist. Wir unterscheiden drei Typen von Solidaritäten: Affinität, Selektion und Implikation. Bei der Affinität funktioniert die Klasse der determinierenden Lexeme als unterscheidender Zug in den determinierten Lexemen; z. B. die Klasse 'menschliche Wesen' und lateinisch 'senex'. Bei der Selektion funktioniert das Archilexem der determinierenden Lexeme als unterscheidender Zug in den determinierten Lexemen; z. B. die Beziehung zwischen 'Schiff', 'Zug' und 'fahren': Das Archilexem 'Fahrzeug' in 'Schiff' und 'Zug' funktioniert als unterscheidender Zug in 'fahren'.

Die Implikation ist die Beziehung, bei der als unterscheidender Zug im determinierten Lexem das ganze determinierende Lexem auftritt. Semantische Solidaritäten müssen von lexikalischen Clichées und von durch die Kenntnis der Sachen determinierten Solidaritäten unterschieden werden. Die Tatsache, daß bestimmte Adjektive häufiger mit bestimmten Nomina gebraucht werden (weißes Schaf : grünes Schaf), gehört nicht in den Rahmen der Bedeutungsbeziehungen, denn sie wird von der Kenntnis der Sachen ausgelöst und ist nicht sprachlich determiniert. Zwischen weiß und Schaf besteht keine solche Beziehung wie z. B. zwischen blond und Haare, wo blond schon 'Haare' impliziert und auch nur für Haare gebraucht wird. 
Die Ebene des Textes ist in der Sprachwissenschaft schon mehr als 20 Jahre anerkannt und hat heute als besondere Ebene schon ihren berechtigten Platz mit Bezug auf die niedrigeren Ebenen der sprachlichen Strukturierung gefunden. Weniger klar ist jedoch das Verhältnis zwischen Rede, Sprache und Text. Bekannt ist, was den Text als Text begründet (siehe z. B. die Kriterien in Beaugrande \& Dressler 1992). Das Verhältnis zwischen der Rede und der Sprache ist üblicherweise nur das Verhältnis zwischen dem Konkreten und dem Abstrakten, dem Individuellen und dem Sozialen, die Rede wird aber gewöhnlich nicht von dem Text unterschieden. Verschiedene Autoren haben sich mit diesem Problem auf unterschiedliche Weise auseinandergesetzt. Filipec 1961 z. B. bestimmt aus praktischen Gründen bei der Behandlung der Synonymie (Unterschiede zwischen den Synonymen im System und Text) als grundlegende Opposition das Verhältnis Text (d. h. Resultat der Rede) Sprache, Coseriu hingegen unterstreicht die Notwendigkeit, zwischen Sprechen, Sprache und Text zu unterscheiden (z. B. 1974: 21-57, 1985: 5-48). Die Ebene des Textes ist als besondere Ebene durch die grammatikalischen Erscheinungen gerechtfertigt, die über den Satz hinausgehen (z. B. Topikalisierung, Ellipse, Wiederaufnahme und viele andere), sowie auch durch Abweichungen von den Regeln einer Einzelsprache, die annehmbar sind im Text, situationelle Bedingtheit des Sinnes des Ausgesagten, übersprachliche Tradition bei der Gestaltung bestimmter Arten von Texten (z. B. wissenschaftlicher Abhandlungen), spezifische Tradition bei bestimmten Arten von Texten in verschiedenen Sprachgemeinschaften (z. B. Telefongespräch) u. ä. Der Sinn ist jene Art von Inhalt, die auf der Ebene des Textes auftritt. Für das Verfassen von Texten sind drei Stufen der Kompetenz (Coseriu 1985: 41 ff.) notwendig: 1. elokutionelle (das Wissen darüber, wie man spricht: daß man sich beim Sprechen z. B. auf Sachen und Kontexte beziehen kann); 2. idiomatische (die Beherrschung einer bestimmten Sprache) und 3. expressive (das Wissen, wie man bestimmte Texte gestaltet, das Wissen, wie Texte gebildet werden müssen, um ihre Funktion zu erfüllen). Jede Stufe der Kompetenz wird anders bewertet. Die elokutionelle Stufe wird auf der Grundlage der Kongruenz beurteilt: Das Sprechen muß klar, kohärent und folgerichtig sein, vor allem was die allgemeinen Denkprinzipien und die Kenntnis der Sachen in einer Sprachgemeinschaft angeht. Verstöße gegen das Gebot der Kongruenz sind annehmbar, wenn sie der Text erlaubt (bestimmte Textarten können zulassen, daß wir eine bestimmte Sache anders benennen als üblich; hierher gehört $\mathrm{z}$. B. der moderne Roman). Das Maß für die Übereinstimmung mit den Regeln einer bestimmten Sprache ist die Korrektheit und für das Einschätzen der expressiven Stufe der Kompetenz die Angemessenheit (was der Erwartung hinsichtlich der Art des Textes entspricht, ist angemessen). Das sprachliche Zeichen hat auf jeder der drei erwähnten Ebenen eine andere Funktion und die Funktionen im Text z. B. müssen wir von den Funktionen in der Sprache unterscheiden. Die Funktion des Textes ist als Funktion des Sprechens in einer bestimmten Situation und mit einer bestimmten Absicht definiert (ebd. 45).

Der Inhalt, der der Funktion des sprachlichen Zeichens auf der Ebene des Textes entspricht, ist der Sinn, nach Coseriu definiert (ebd. 47) als Gesamtheit der Funktionen des Textes, Gesamtheit dessen, was wir gerade durch den Text und nur im Text 
verstehen, die Gesamtheit der Inhalte, die nur als Textinhalte gegeben sind. In den Texten tritt ein doppeltes semiotisches Verhältnis auf: Die sprachlichen Zeichen, die den Text konstruieren, bedeuten und bezeichnen etwas, was die Leser oder Zuhörer verstehen können, wenn sie diese Zeichen und die Regeln für ihre Verwendung kennen. Auf dieser Ebene kann jemand alles verstehen, ohne zu begreifen, was dieses auf einer anderen semiotischen Ebene bedeutet. Hier benötigt der Text eine Interpretation, der Sinn muß "aufgedeckt" werden. Bei der Analyse des Aufbaus bzw. des Erkennens des Sinns im Text geht Coseriu (ebd. 51-109) von Bühlers Organon-Modell aus: Das sprachliche Zeichen steht im Kommunikationsprozeß in Beziehung zu Sachen und sachlichen Zuständen, Sender und Empfänger - es hat eine Darstellungs-, Kundgabeund Appellfunktion, ist zugleich Symbol, Symptom und Signal. Zu diesen drei Verhältnissen fügt er noch eine ganze Reihe anderer Relationen hinzu, die nach seiner Meinung.konstitutiv für den Sinn sind. Diese Relationen sind:

1. Relationen mit anderen Zeichen (assoziative Relationen in materieller oder inhaltlicher Hinsicht mit einzelnen Zeichen, Gruppen von Zeichen und ganzen Zeichensystemen);

2. Relationen mit Zeichen in anderen Texten;

3. Relationen zwischen Zeichen und Sachen (Nachahmung durch die Substanz des Zeichens (Onomatopöie, Synästhesie) sowie Nachahmung durch die Form des Zeichens);

4. Relationen zwischen Zeichen und Kenntnis der Sachen (s. oben über die Wahl der Bezeichnung);

5. Relationen zwischen Zeichen und sog. Umfeldern (Kontext, Situation, Redeuniversum).

Während die von Bühler identifizierten Funktionen auch dem virtuellen Zeichen eigen sind (Zeichen im Sprachsystem), tritt das sprachliche Zeichen in die unter Punkt 1-5 angeführten Relationen nur im Text ein (aktuelles Zeichen). Die Gesamtheit der Funktionen eines Zeichens, die durch die Relationen in einem Text gegeben sind, nennt Coseriu Evokation. Der Sinn entsteht aus der Kombination der Bühlerschen Funktionen und der Evokation (ebd. 102). Bei der Evokation handelt es sich um eine Zeichenfunktion, bei dem Sinn jedoch um eine Textfunktion. Coseriu leitet den Begriff der Evokation aus dem ab, was unter Konnotation von der Glossematik behandelt wird $^{28}$ (Beziehungen zu Zeichensystemen, Punkt 1 oben). Dazu fügt er noch weitere Möglichkeiten für ein derartiges Funktionieren des Zeichens hinzu (Punkt 2-5) und verändert den Terminus, um die Verwirrung zu vermeiden, die bei der Auffassung von Konnotation herrscht. Die Konnotationen im Sinne Hjelmslevs sind nur dann möglich, wenn das Zeichen außerhalb des Systems gebraucht wird, zu dem es gehört, ${ }^{29}$ wobei

29 In der vorliegenden Arbeit ist als solches System die funktionelle Sprache im Sinn der Definition unter Punkt 2.3 unten gedacht. 
auch kollektive Vorstellungen über einzelne Sprachen und Sprecher dieser Sprachen teilnehmen können. Coserius Auffassung des Sinnes unterscheidet sich von dem Verständnis desselben Terminus in der Philosophie und Semantik, wo große Unterschiede zwischen den einzelnen Autoren zu beobachten sind, und auch von zwei anderen semantischen Begriffen - der Referenz und der Bedeutung. Die Ansichten sind keineswegs einheitlich. Nach Lyons 1981: 58 ist z. B. der Sinn die Relation zwischen den Ausdrücken; einen ähnlichen Inhalt, der bei Coseriu Sinn genannt wird, untersucht er ebd. 171 ff. unter der Äußerungsbedeutung. Anders Ducrot: Die Bedeutung ist der semantische Wert des Satzes, der Sinn jedoch die semantische Wirkung der Äußerung (vgl. z. B. 1988: 13, 19, 58, 110, 111, und auch 49).

Der Sinn, den wir in einem Text erkennen, ist davon abhängig, was wir als Funktion des Textes annehmen. Darin versteckt sich die Antwort auf die Frage, ob die wissenschaftlichen Termini absolut synonym sind oder nicht: Wenn wir annehmen, daß die Funktion der sprachlichen Zeichen in einem wissenschaftlichen Text ausschließlich objektiv ist, daß sie nur im Sinne verwendet werden, den Coseriu (ebd. 49) "Sich-einfach-auf-eine-empirische-Wirklichkeit-Beziehen" bzw. "Keinen-darüberhinausgehenden-Sinn-Haben" nennt, dann können wir wissenschaftliche Termini aus verschiedenen Quellen als absolute Synonyme ansehen. Wenn wir jedoch zulassen, daß das sprachliche Zeichen auch im wissenschaftlichen Text noch andere Funktionen hat, dann ist die Antwort natürlich eine andere.

Mit der Untergliederung der Inhaltsebene in die drei semantischen Ebenen umfaßt Coseriu alle Beziehungen, die bei der Beschreibung der Synonymie relevant sind:

a) Die Beziehung zwischen dem sprachlichen Zeichen und der Sache wird von konzeptuellen Theorien der Bedeutung und der wahrheitsfunktionalen Semantik untersucht, die die Bedeutung als mentale Repräsentation von etwas, was in der Welt existiert, auffassen. Jedoch gibt es einen wesentlichen Unterschied zwischen diesen Theorien und der Bezeichnung nach Coseriu: Während die erwähnten Richtungen den Inhalt meist vom Standpunkt des Sprachsystems her betrachten, ist die Bezeichnung nach Coseriu ein Faktum der Rede, eine konkrete und variable Aufführung von etwas in eine bestimmte Klasse von Sachen (Coseriu 1970: $44 \mathrm{f}$.);

b) Die Beziehung eines Zeichens zu anderen sprachlichen Zeichen ist durch die Tatsache bestimmt, daß das Synonymieverhältnis zumindest zwei Zeichen voraussetzt. Diesem Verhältnis entspricht der Bedeutungsbegriff von Coseriu. Ähnliche Ansichten über Bedeutung werden auch von anderen Anhängern der paradigmatischen Semantik, die aus der europäischen sprachwissenschaftlichen Tradition hervorgegangen ist, befürwortet, es gibt aber zwischen ihnen und Coseriu entscheidende Unterschiede hinsichtlich der Terminologie und der Strukturierung bzw. semantische Konfiguration des Wortschatzes. Coseriu berïcksichtigt auf diesem Niveau der Inhaltsanalyse im Gegensatz zu anderen Autoren streng das Kriterium der Funktionalität auf der Ebene der Sprache und eliminiert alles, was über diese Ebene hinausgeht (außersprachlich ist) oder auf ihr fakultativ, relationell ist (1970: $7 \mathrm{f}$.); 
c) Auf das Verhältnis zwischen dem sprachlichen Zeichen und dem Text bzw. Kontext weisen die Semantiker hin, die die Kontextabhängigkeit der Synonymie betonen, ${ }^{30}$ von anderen Gesichtspunkten aus wird aber dieses Verhältnis auch von Stilistikern und Pragmatikern erforscht. Im Gegensatz zu den anderen Ansätzen, die sich auf die Sprache im Gebrauch oder in ihrer kommunikativen Funktion beziehen, gelingt es Coseriu, in diesem Bereich systematisch die Abhängigkeit des Sinnes von den niedrigeren Ebenen des Sprachinhaltes zu erklären.

\subsection{Die Funktionalität im System und in der Norm}

Coseriu erweitert die Saussuresche Dichotomie langue - parole mit dem Aspekt der Norm. ${ }^{31}$ Coseriu 1975: 62: Die Sprache im weiteren Sinne ist nicht allein funktionelles System, sondern ebenso normale Realisierung. Der Erforschung ist nur das wirkliche Sprechen zugänglich, in Form des konkreten Sprechakts, welcher zugleich eine Neuschöpfung (er enthält individuelle, gelegentliche und augenblickliche Varianten) und eine Wieder-Schöpfung von schon vorgegebenen Mustern und Strukturen ist, die in einer Gemeinschaft normal und traditionell sind. Das, was wir als Wiederholen früherer Vorlagen zählen können, stellt die erste Stufe der Abstraktion bei der Erforschung der Sprache dar, zu welcher wir mit der Eliminierung von allem Individuellen und Gelegentlichen kommen. Das Sprachsystem stellt die zweite Stufe der Abstraktion dar, auf welcher wir auch das eliminieren missen, was in der Norm Gewohnheit, Tradition ist, aber ohne funktionellen Wert, denn in das System gehören nach Definition nur funktionelle Oppositionen. Das Sprachsystem können wir uns als System von Wegen vorstellen, von denen einige von der Norm geöffnet sind, andere aber versperrt.

Da neben dem funktionellen System immer auch eine normale Realisierung besteht, bleibt die Wahl in der Norm fast nie indifferent. Bei der Verwendung der Synonyme, die vom System aus eine einzige Invariante darstellen (ebd. 79), heißt das, $\mathrm{da} ß$ von allen Varianten, die das System zuläßt, jedesmal nur eine normal ist, während die übrigen entweder einen bestimmten Stilwert erhalten oder aber unnormal sind. Die Begriffe, die sich hier ausschließen, sind normal : unnormal, und nicht etwa korrekt : unkorrekt, was ein übliches Kriterium bei dem Verstehen der Norm in der Sprachwissenschaft ist. Bei der Norm im Sinne Coserius geht es nicht darum, wie wir etwas sagen sollten, sondern darum, wie wir sprechen, folglich um die Norm, die objektiv in der Sprache selbst enthalten ist. Die individuelle Realisierung kann beim Sprechen mit der Norm zusammenfallen oder von ihr abweichen - das Individuum kennt die Norm oder kennt sie nicht, es kann sie wiederholen oder verwerfen. Eine Neuheit im Vergleich mit anderen strukturalistischen Schulen, die die Existenz der Norm in der Sprache anerkannt haben, stellt Coserius Einreihung der funktionell

\footnotetext{
30 Z. B. Lyons 1975: 462.

31 S. die bekannten Aufsätze mit dem Titel System, Norm und Rede in Coseriu 1971: 53-72 und 1975: 11-101.
} 
irrelevanten, jedoch normalen und konstanten Elemente in die Sprache. Sowohl die Vertreter der Prager Schule wie auch Hjelmslev haben sie zur Rede gezählt und das bedeutete, daß das Studium der Synonyme zur Stilistik gehörte. Da die Norm immer einen von ihnen vorzieht, herrschte bei der Erforschung des Sprachsystems die Meinung vor, daß es eigentlich keine Synonyme gebe.

\subsection{Die Architektur und Struktur der Sprache}

Bei Coserius Auffassung von Sprache, wie sie oben beschrieben wurde, kommt die Sprache als System von Isoglossen aufgrund des Sprachmaterials (Summe von konkreten Sprechakten) zustande. Die Grenzen einer Sprache richten sich wiederum nach dem in Betracht gezogenen Sprachmaterial und genauso wird auch die hinzukommende Norm festgestellt. Wir können z. B. die Sprache eines bestimmten Autors beschreiben, einer Gemeinschaft in Raum oder Zeit, geschriebene oder gesprochene Sprache usw. Die historische Sprache (z. B. das heutige Slowenisch) ist ein Diasystem - die Summe von Sprachsystemen, zwischen denen Koexistenz und Interferenz herrscht. In der Synchronie verschiedener Techniken der Rede, die lexikalische und grammatikalische Einheiten und deren Modifizierungs- und Kombinationsregeln innerhalb eines Satzes umfassen (Coseriu 1970: 27), sind folgende Unterschiede festzustellen: Unterschiede der geographischen Ausdehnung (diatopische Unterschiede), Unterschiede zwischen sozial-kulturellen Schichten der Sprachgemeinschaft (diastratische Unterschiede) und Unterschiede zwischen den Typen der Ausdrucksmodalität (diaphasische Unterschiede, z. B. Unterschiede zwischen der gesprochenen und geschriebenen Sprache, Unterschiede zwischen verschiedenen "biologischen" Gruppen innerhalb derselben soziokulturellen Schicht, Unterschiede zwischen Literatur- und Umgangssprache usw.) Dieses Diasystem ist keine strukturelle und funktionelle homogene Einheit und wir können es auf diese Weise auch nicht beschreiben, denn es wird in der Rede nie realisiert. Der Untersuchung ist es nur in der Form der sog. funktionellen Sprache zugänglich, die als homogene "Technik der Rede in einem einzigen Sprachraum, auf einer einzigen ,Sprachebene' und in einem einzigen Sprachstil" definiert ist, d. h. als syntopische, synstratische und synphasische Technik der Rede (ebd. 33). Die Neuheit in der strukturalistischen Betrachtung der Sprache stellt die Unterscheidung zwischen der Architektur und der Struktur der Sprache dar (ebd. 32-37), die Coseriu nach Flydal 1951 übernimmt und später weiterentwickelt: Die Beziehungen zwischen Elementen der verschiedenen koexistenten Techniken der Rede in einer historischen Sprache gehören in die Architektur der Sprache, die Beziehungen zwischen den Begriffen einer bestimmten Technik der Rede (einer funktionellen Sprache) aber in die Struktur der Sprache. In der Struktur der Sprache bestehen Oppositionen und jede dieser Oppositionen müssen wir innerhalb der funktionellen Sprache beschreiben, der sie angehört. Die Beziehungen zwischen den Einheiten in der Architektur der Sprache sind keine Oppositionen, sondern Diversitäten. Die Unterschiede zwischen den einzelnen Techniken der Rede innerhalb einer Sprache sind ähnlich wie zwischen verschiedenen 
Sprachen (z. B. in der Phonologie, Grammatik, Wortschatz), nur daß der Grad der Diversität geringer ist. Weil wir die Besonderheiten einer Sprache nicht mit dem Maß einer anderen messen können, müssen wir bei der Beschreibung immer innerhalb eines einziges Systems bleiben. Die Besonderheiten der Dichtersprache oder Dialekte dürfen wir nicht als Abweichungen von einer normalen, normierten Alltagssprache bewerten, sondern als Charakteristika einer funktionellen Sprache innerhalb einer historischen Sprache. Im System dieser Sprache sind das völlig neutrale Wörter, eine besondere Wirkung tritt jedoch auf, wenn wir diese außerhalb des Systems verwenden, dem sie angehören. Eine Folge für die Behandlung der Synonymie: Auf der beschriebenen Grundlage können wir nicht mehr zwischen Oppositionen wie neutrale und stilistische Synonyme unterscheiden, die wir aufgrund spezifischer Merkmale weiter als gegensätzliche Paare klassifizieren könnten (geschrieben - gesprochen, mundartlich hochsprachlich, veraltet - neu usw.). Hier haben wir es nicht mit Oppositionen zu tun, bei denen demselben signifié unterschiedliche signifiants entsprächen, sondern mit Einheiten verschiedener Systeme, bei welchen hinsichtlich des Verhältnisses signifié signifiant einem analogen signifiant unterschiedliche signifiés (oder umgekehrt) entsprechen können. Zu einer ähnlichen Erkenntnis, obwohl auf der Grundlage anderer Annahmen, kommt auch Lyons 1975: 460 in dem Kapitel über die Synonymie, wenn er über die "kognitive" und "emotive" Bedeutung nachdenkt: "Es erscheint jedenfalls vorteilhaft, den Terminus ,Synonymie' auf das zu beschränken, was viele Semantiker mit ,kognitiver' Synonymie beschrieben haben." Damit aber beseitigt er einen großen Teil dessen, was Coseriu unter die Diversitäten einreiht.

\section{Methoden der Untersuchung verschiedener Inhaltsebenen und ein Modell der Synonymanalyse}

\subsection{Untersuchungsmethoden auf den drei Inhaltsebenen}

\subsubsection{Bezeichnung}

Aus der oben eingeführten Unterscheidung zwischen drei semantischen Ebenen geht hervor, daß wir auf der Ebene der Bezeichnung die Instrumente des Sprechens untersuchen, auf der Ebene des Sinnes das Produkt des Sprechens (Text), auf der Ebene der Bedeutung jedoch das Funktionieren des Zeichens im System. Die Methode der Untersuchung der Bezeichnung muß neben den Möglichkeiten der Identifizierung der Bezeichnung auch Möglichkeiten für die Beschreibung der Faktoren der Wahl leisten. Als Identifizierungsverfahren der Bezeichnung nennt Coseriu 1973: 11 die Paraphrase.

Paraphrasiert werden können verschiedene sprachliche Einheiten: ein einzelnes Wort oder nur eine bestimmte Verwendungsweise des Wortes (Lexikographie), Syntagma, Satz, Text. Der Satz ist eine grundlegende Einheit der Paraphrasierung schon seit den 60er Jahren dieses Jahrhunderts, als sich die Sprachwissenschaftler darüber bewußt wurden, daß auch die Analyse der Bedeutung der lexikalischen 
Einheiten im entsprechenden syntaktischen Rahmen verlaufen muß. Der Satz wird auf diesem Niveau der Analyse in Zorman 1997 zwar als Einheit der Verständigung gesehen, vernachlässigt wird jedoch seine Funktion im Text.

Paraphrasieren ist nach Wunderlich 1980: 72 ein fundamentales Verfahren der sprachlichen Kommunikation, mit welchem der Sprecher seine sprachlichen Formulierungen erklärt, assoziative Verbindungen (z. B. Konnotation) verhindert, die komplexe Wirklichkeit mit zusätzlichen Gesichtspunkten erhellt, seine impliziten Annahmen ausdrückt und den Proze $ß$ des Verstehens beim Hörer steuert. In verschiedenen Situationen des Gebrauches und in verschiedenen Arten von Texten kann das Paraphrasieren unterschiedliche Funktionen ausfüllen (z. B. Erklärung, Verallgemeinerung, Begrenzung, Schluß usw.). In der Sprachwissenschaft hat sich dieses Verfahren zu einer Technik entwickelt, die in syntaktischen und semantischen Untersuchungen zur Erhellung der Wirkungen, Funktionen und Bedeutungen sprachlicher Formulierungen allgemein gebraucht wird. In der vorliegenden Arbeit wird die Paraphrase nur als Methode der semantischen Analyse behandelt, nicht aber als semantische oder textlinguistische Frage, stilbildendes oder rhetorisches Mittel. Ungeheuer 1969: 212 unterscheidet in diesem Sinne zwischen kommunikativer und extrakommunikativer Verwendung der Paraphrase. Obwohl in beiden Fällen diese als Instrument für die Erklärung oder Präzision gebraucht wird, ist der innere Mechanismus jedoch ein anderer. Während bei der kommunikativen Verwendung beide Sätze der paraphrastischen Relation gleich wichtig sind, ist bei der Paraphrase als Teil des metasprachlichen Instrumentariums die abgeleitete kanonische Formulierung wichtiger. Die kanonische Form wird durch Umformung der Originalformulierung aufgrund der Paraphrasierungsregeln erreicht. In die Paraphrase sind nur verifizierbare Elemente eingebaut und die Erkenntnisse können wir wegen der Relation zwischen beiden Formulierungen auf die Originalformulierung applizieren. Bei der Nachahmung der Paraphrase als "dem Ausdrücken desselben mit anderen Worten" treten Unterschiede in Hinsicht darauf auf, was "dasselbe" sein solle: ein Gedanke, Redethema, Proposition... Am breitesten anerkannt ist die Definition der Paraphrase auf der Grundlage der Implikation (eng. entailment; die Beziehung zwischen den Sätzen, äquivalent zur hyponymen Relation zwischen den Wörtern): Für die Paraphrasen werden dieselbe Menge von Implikationen verlangt. Die paraphrastische Relation muß symmetrisch sein (die Sätze müssen sich gegenseitig implizieren, d. h., wenn einer wahr ist, muß der andere auch wahr sein). ${ }^{32}$ In diesem Fall kann "dasselbe" in beiden Sätzen Proposition genannt und als "tatsächlicher Sachverhalt" verstanden werden. ${ }^{33}$ Der Begriff "Proposition" ist im gewissen Sinne ahnlich dem, was Coseriu unter Bezeichnung versteht, und er ist für die Untersuchung einiger Arten von Satzbedeutung sehr wichtig. Bei der Analyse jener Art des Inhalts, welche zur Ebene der Bezeichnung gehört, können wir ihn jedoch vermeiden, denn er ist keinesfalls klar.

33 Hurford \& Heasley 1983: 19, vgl. auch Lyons, Semantik I (1980: 154). 
In Übereinstimmung mit der Vereinfachung in der linguistischen Semantik können wir einfach den Wahrheitswert des Satzes beurteilen. ${ }^{34}$ Die Sätze drücken dann dasselbe (d. h. dieselbe Proposition) aus, wenn wir uns keine Bedingungen vorstellen können, unter welchen einer von ihnen wahr und der andere falsch wäre. Die Semantik und Pragmatik unterscheiden verschiedene Arten der logischen Schlußfolgerung hinsichtlich der Beziehung zwischen dem sprachlichen und außersprachlichen. Auf die Relevanz dieses Verhältnisses für die Synonymie haben schon Mel'čuk und Žolkovskij (z. B. 1970) hingewiesen. In Hinblick auf dasselbe Verhältnis können wir die Paraphrasen in mehrere Arten unterteilen. Wunderlich 1980: 81-83 z. B. unterscheidet 6 Arten von Paraphrasen: lexikalische, stilistische, kontextuelle bzw. pragmatische, idiomatische, syntaktische und syntaktisch-semantische. Nach Coseriu ist jedoch die Möglichkeit für die Beobachtung dieses Verhältnisses an anderer Stelle vorgesehen (Determinierung und Umfelder). Wir können es bei dem Paraphrasieren außer Betracht lassen.

Mit dem Paraphrasierungsverfahren entdecken wir nämlich lexikalische Varianten ("verschiedene Bedeutungen desselben Wortes", die von dem Kontext und der Situation abhängig sind), sie sind aber eine Folge der sprachlichen Determinierung und der Bestimmungen der Umfelder (die umstandsbedingten Instrumente der Sprechtätigkeit). Die Arten der Determinierung und Umfelder beschreibt Coseriu in dem berühmten Aufsatz Determinación y entorno (dt. Übersetzung in Coseriu 1975: 253-290). Unter Determinierung versteht er Operationen, mit welchen das sprachliche Zeichen als Element des Sprachsystems beim Sprechen so aktualisiert bzw. umgeformt wird, daß es sich auf etwas Konkretes bezieht. Dieses können wir durch vier Arten von Operationen erreichen: Aktualisierung, Diskrimination, Delimitierung und Identifizierung. Die Redeinstrumente für diese Operationen nennen sich nominale Determinatoren (Aktualisatoren, Diskriminatoren, Delimitatoren, Identifikatoren). Die Aktualisierung ist die Umformung der potentiellen Bezeichnung (des Namens für eine Sache, die in der Sprache besteht) in eine wirkliche Bezeichnung (das sprachliche Zeichen richten wir auf ein bestimmtes "Objekt", das natürlich nicht unbedingt ein natürlich existierendes Objekt sein braucht). Bei diesem Prozeß integriert sich die aktuelle "Erkenntnis" mit dem vorherigen "Wissen" (ebd. 264). Die Aktualisierung kann implizit oder explizit sein. Manche Sprachen haben dafür besondere Aktualisatoren ( $\mathrm{z}$. B. bestimmter Artikel) vorgesehen, obwohl wir die Aktualisierung nicht mit der Individualisierung gleichsetzen dürfen. In den Sprachen ohne einen Artikel kommt die Aktualisierung implizit durch die Umgebung oder durch die bloße Tatsache des Sprechens vor. Die Umsetzung der virtuellen in eine aktuelle Bezeichnung verlangt manchmal eine weitere Bestimmung in all den Fällen, wo nicht von "Seienden im allgemeinen" die Rede ist, sondern von irgendeiner Gruppe einzelner Seiender (die Menschen, alle Menschen, dieser Mensch...). Die Operation dafür ist die Diskrimination, mit welcher sich die bezeichneten Seienden als Exemplare einer Klasse oder Vertreter eines Typs darstellen. Auch die Diskrimination kann implizit sein, 
oder sie kann durch die Umfelder zustandekommen, oder sie kann bestimmte Redeinstrumente verlangen (die sog. Diskriminatoren). Die Diskrimination teilt sich auf mehrere Untertypen auf: Quantifizierung, Selektion und Situierung. Durch die Quantifizierung kommt die Zahl bzw. die Zählbarkeit der bezeichneten Gegenstände zustande. Die Selektion bedeutet eine Trennung zwischen den bezeichneten Objekten und dem Rest ihrer Klasse oder ihres Typs (möglich ist die Partikularisierung oder Individualisierung, die entsprechenden Redeinstrumente sind verschiedenartig, dabei sind auch die Umfelder von Bedeutung). Bei der Situierung werden z. B. die bezeichneten Objekte mit Hilfe deiktischer Elemente in Bezug zu den räumlichzeitlichen Gegebenheiten der Rede gesetzt. Mit diesen zwei Verfahren (Aktualisierung und Diskrimination) formen wir die Polyvalenz einer möglichen Bezeichnung in eine monovalente wirkliche Bezeichnung um, welche wir dann mit der Delimitierung und Identifizierung weiter begrenzen können. Die Delimitierung teilt sich in die Explizierung, Spezialisierung und Spezifizierung. Die Explikatoren betonen eine besondere Eigenschaft des Genannten oder Bezeichneten (z. B. der weite Ozean). Die Spezialisatoren markieren die extensiven oder intensiven Grenzen, innerhalb derer das jeweils Determinierte intern gesehen wird, d. h. ohne dessen Vergleichung mit anderen unter dieselbe Benennung passenden Determinierbaren (die morgendliche Sonne, Goethe als Dichter). Die Spezifikatoren jedoch beschränken die Bezugsmöglichkeiten eines sprachlichen Zeichens, indem sie ihm seiner Bedeutung nicht-zugehörige Züge anfügen (blonder Junge, die Wasservögel, der Bundespräsident). Die distinktiven Spezifikatoren, auf Virtuelle angewandt, begrenzen innerhalb der jeweiligen Klassen andere, kleinere Klassen (Mann : weißer Mann), auf Aktuelle angewandt, präsentieren sie die bezeichneten Gegenstände als Klassen zugehörig (ein blonder Junge gehört zur Klasse 'blonder Junge', die ihrerseits Glied der Klasse 'Junge' ist). Formal analoge Mittel wie für die distinktive Spezifizierung können funktionell anders als informative Spezifikatoren oder Identifikatoren im Verfahren der Identifizierung gebraucht werden. Die Identifizierung ist der Vorgang, bei dem die Bedeutung einer vieldeutigen Form spezifiziert wird, damit sie vom jeweiligen Zuhörer auch sicher verstanden wird (vgl. z. B. Papierblatt : Sägeblatt). Die Identifikatoren können okkasionell (Córdoba, Argentinien), üblich (frz. pomme de terre) oder konstant sein (New York). Wenn die letzten zwei Arten nicht explizit ausgedrückt sind, verläuft die Identifizierung auf der Grundlage der Umfelder. Die Delimitierung und Identifizierung sind Operationen, die die Integrierung von aktueller Kenntnis und vorhergehendem Wissen sichern, zugleich aber ermöglichen, daß wir beim Sprechen ständig kreativ sein können, obwohl wir im Rahmen der Einzelsprache bleiben. In jedem Redeakt wird mehr ausgedrückt und mehr verstanden als tatsächlich gesagt. Die Möglichkeit, daß wir uns trotzdem verständigen, geben nichtsprachliche Arten des Ausdrückens und äußere Umstände, die den Redeakt begleiten und von Coseriu Umfelder genannt werden.

Die Umfelder nehmen Einfluß auf die Bestimmung des Zeichens und können manchmal die sprachlichen Determinatoren ersetzen, orientieren jedes Gespräch, geben ihm einen Sinn und können sogar den Wahrheitswert des Geäußerten bestimmen. Coseriu versteht unter Umfelder ähnliche Elemente, wie sie bei modernen 
Theorien des Kontextes im weitesten Sinne des Wortes untersucht werden. Die Umfelder werden in vier Typen unterteilt: Situation, Region, Kontext und Redeuniversum. Die Situation bilden äußere Umstände und Beziehungen in Zeit und Raum, die nur dadurch entstehen, daß jemand an einer bestimmten Stelle im Raum und zu einem gewissen Zeitpunkt spricht, also das, wodurch hier und dort, jetzt und damals, $i c h$ und $d u$ entstehen. Die Situierung mit sprachlichen Determinatoren ist ganz von dieser Situation abhängig und hat nur in bezug auf diese Sinn. Die Region ist der Raum, der ein in bestimmten Bedeutungssystemen funktionierendes Zeichen einschließt. Die Grenzen dieses Raums sind durch die Tradition des Sprechens und durch die Erfahrungen der Sprecher mit den bezeichneten Wirklichkeiten bestimmt. Er wird in drei Untertypen aufgeteilt: Zone, Bereich und Umgebung. Die Zone ist die Region, in der ein Zeichen allgemein bekannt ist und üblicherweise verwendet; die Grenzen der Zone sind sprachlicher Natur. Der Bereich ist die Region, in der ein bestimmter Gegenstand ein vertrautes Element der alltäglichen Lebenswelt, der Erfahrungen oder der Bildung der Sprecher ist; die Grenzen sind allgemein-kulturell, nicht sprachlich. Die Umgebung ist schließlich eine sozial oder kulturell bestimmte Region, wie z. B. Familie, Schule, die Berufsgemeinschaften usw., die über besondere Zeichen für Gegenstände verfügen. Eine Umgebung kann einerseits ein spezifisches Zeichen für ein Gegenstand eines viel weiteren Bereichs haben, anderseits kann sie besondere Zeichen für Gegenstände haben, die nur ihr angehören, folglich funktioniert sie wie die Zone oder der Bereich oder wie die Zone und der Bereich zugleich. In verschiedenen Umgebungen sind auch verschiedene Erkenntnisformen derselben Wirklichkeit möglich (vgl. z. B. Salz : Natriumchlorid). Der Kontext des Sprechens ist die gesamte ein Zeichen umgebende Wirklichkeit. Coseriu unterscheidet drei Arten des Kontextes: den einzelsprachlichen, Rede- und Außer-Rede-Kontext. Den einzelsprachlichen Kontext stellt die Sprache selbst dar, in der gesprochen wird. Dieses konkretisiert sich und bedeutet etwas erst in bezug auf das gesamte sprachliche System. Jedes Zeichen funktioniert in komplexen Systemen formeller und semantischer Oppositionen und Assoziationen mit anderen Zeichen, die zwar nicht ausgesprochen wurden, jedoch in das sprachliche Wissen der Sprecher gehören. Als einzelsprachlicher Kontext kann auch eine andere Sprache funktionieren, welche die Sprecher beherrschen, nicht nur die, die sie zu einem bestimmten Zeitpunkt sprechen. Den Rede-Kontext stellt das dar, was dem jeweils betrachteten Textsegment vorausgeht, und auch das, was ihm folgt (die Determinatoren, die hinter einem Zeichen stehen, funktionieren genauso als kontextuelle Elemente: das Haus meines Vaters : das Haus Österreich). Der Rede-Kontext kann unmittelbar (s. z. B. letztes Beispiel) oder mittelbar sein (ganzer Text; im umfangreichen, schriftlichen Text kann sich der Sinn des bereits Ausgesagten auch mit dem verändern, was ganz am Ende ausgesagt wird, z. B. im letzten Kapitel). Der Rede-Kontext kann auch positiv oder negativ sein: Er besteht aus dem, was der Sprecher nicht gesagt hat; die absichtliche Verwendung des negativen Rede-Kontextes stellt einen besonderen Fall der Wahrheitsverfälschung dar. Den Außer-Rede-Kontext konstruieren alle nicht-sprachlichen Umstände. Der Sprecher 
kann sie direkt wahrnehmen oder sie sind ihm zumindestens bekannt. Unterarten dieses Kontextes sind:

- physikalischer (Dinge, denen Zeichen unmittelbar anhaftet),

- empirischer (alles, was der Sprecher kennt, obwohl er das nicht sieht),

- natürlicher (die Gesamtheit der möglichen empirischen Kontexte),

- praktischer oder okkasioneller (die "Gelegenheit" des Sprechens - mit wem, wo und wann, was zu grammatikalischen, semantischen und stilistischen Funktionen des Ausgesagten beiträgt: ein schöner Tag bedeutet im Winter etwas anderes als im Sommer),

- historischer (er kann aktuell oder bekannt aus der Vergangenheit sein sowie universell oder partikulär, wenn er durch die Vergangenheit einer Person, Familie, einer Nation bestimmt wird - in solchem Kontext funktionieren, z. B. rufe den Doktor und Königin Mutter), und

- kultureller Kontext (alles, was zur kulturellen Tradition einer Gemeinschaft gehört, eigentlich nur eine besondere Art des geschichtlichen Kontextes).

Den Außer-Rede-Kontext kann der Sprecher mit Hilfe des Rede-Kontextes schaffen, zumindest kann er mit bestimmten Arten rechnen, als wären sie schon bekannt. Die geschriebene Sprache verfügt nur über bestimmte Umfelder, andere Umfelder (z. B. okkasioneller Außer-Rede-Kontext) muß sie durch den Rede-Kontext schaffen. Bei künstlerischen Texten liegt die Meisterschaft darin, wie die Umfelder erzeugt sind. Unter dem Redeuniversum versteht Coseriu das universelle System von Bedeutungen, zu dem ein Text gehört und durch das er seine Gültigkeit und seinen Sinn erhält (z. B. Mythologie, Mathematik, Literatur; die Reduktion des Objekts auf das Subjekt ist sinnvoll innerhalb der Philosophie, nicht jedoch in der Grammatik; die Vermischung verschiedener Redeuniversen ist aus schlechten Witzen bekannt). Die Interpretation des Textes bedeutet nach Coseriu die Bestimmung der Umfelder, Kommentare zu den Texten sind nötig, wenn die Interpretation in anderen Kontexten verläuft, als sich der Autor vorgestellt hatte.

Auf der semantischen Ebene der Bezeichnung wird, wie schon bemerkt, neben der Identifizierung der Bezeichnung auch die Wahl der Bezeichnung beobachtet. Mit der Wahl hat jede Behandlung der Synonyme im Kontext zu tun, ungeachtet dessen ob es eine stilistische, semantische, textlinguistische, pragmatische oder noch irgendeine andere ist. Der größte Teil dieser Erkenntnisse kann mit den Ansichten Coserius konfrontiert und auch entsprechend erklärt werden, obgleich Coseriu diese auf verschiedene Ebenen des Sprachinhalts verteilt. Nach Coseriu müssen wir auf der Ebene der Bezeichnung nur die konkrete Realisierung untersuchen, während alle anderen Möglichkeiten, die der Sprecher nicht gewählt hat, zu der Ebene der Bedeutung gehören. Die konkrete Auswahl müssen wir von drei Gesichtspunkten aus betrachten: des Typs, der Norm und des Systems. Beim Typ stellen wir Präferenzen hinsichtlich der Oppositionsklassen und lexikalische Unterscheidungen in einer Sprache fest. Der Norm sind insbesondere zwei Abhandlungen dieses Autors mit 
gleichen Titel gewidmet: Sistema, norma y halba (dt. in Coseriu 1975: 11-101) und Sistema, norma e "parola" (dt. in Coseriu 1971: 53-72), er behandelt sie aber auch z. B. in Coseriu 1970: 37-44. Die Norm erlaubt seiner Meinung nach weniger als das System, deshalb treten in ihr Oppositionen zwischen Varianten auf, die im System eine einzige Invariante darstellen (1975: 79). Der augenfälligste Fall dafür sind die Synonyme: Das System läßt Möglichkeiten zu, die die Norm nicht zuläßt, denn wir haben es neben dem funktionellen System immer auch mit einer normalen Realisierung zu tun. Die Möglichkeiten des funktionellen Systems nutzen am liebsten Dichter. Die Norm fällt mit dem System zusammen, wenn dieses nur eine Möglichkeit anbietet, genauso kann aber auch die individuelle Realisierung mit der Norm zusammenfallen. Wenn das System eine Reihe von fakultativen Realisierungsvarianten zuläßt, wird der Unterschied zwischen der Norm und dem System evident, denn in der Norm wird auch das funktionell, was im System nicht so ist. Die Norm läßt manchmal nicht das zu, was im System existieren kann (hinsichtlich der Farbe sprechen wir von Weiß- und Schwarzbrot, das jedoch in Wirklichkeit nicht schwarz, sondern grau oder braun ist) oder es können einige Suffixe im System völlig austauschbar sein, obwohl die Norm trotzdem eines von ihnen bevorzugt. Diese Art der Norm erkennen wir mit der Beschreibung der entsprechenden funktionellen Sprache durch die Eliminierung von allem, was im Sprechen gelegentliche Variannten sind, denn die Norm umfaßt nur die kollektive Realisierung des Systems. Das bedeutet, daß wir von den Daten über die relative Häufigkeit der Wahl zwischen Synonymen auf die Präferenzen in der Norm schließen dürfen und Abweichungen von ihnen bestimmen können. Das System verlangt eine Einordnung des Ausgewählten in die funktionelle Sprache und die Identifizierung dessen, was zugleich in demselben System existiert. Im Wortschatz entspricht das System der begrifflichen Einteilung der Welt sowie besonderen Weise der formalen Realisierung dieser Klassifizierung, denn die Strukturen der Sprache fallen nicht immer mit den Strukturen der objektiven Wirklichkeit zusammen.

Wenn wir Coserius Ansichten auf die Bezeichnung synthetisieren, welche er in verschiedenen Werken vorgestellt hat, können wir in Übereinstimmung mit seinen Annahmen das folgende Arbeitsverfahren für die Untersuchung der Bezeichnung entwickeln:

1. Identifizierung der funktionellen Sprache,

2. Identifizierung der lexikalischen Variante mit Hilfe der Paraphrasierung,

3. Beschreibung der nominalen Determinatoren,

4. Beschreibung der Umfelder.

Der statistische Vergleich der Angaben aus dem 1. Schritt erlaubt uns, Schlüsse über Präferenzen im System zu ziehen, für die Feststellung der Norm muß aber auch der funktionelle Wert der Faktoren der Auswahl berücksichtigt werden, die Gegenstand der Beschreibung im 2. und 4. Schritt sind. Die Operationen, die Gegenstand der Beschreibung im 3. Schritt sind, sind von entscheidender Bedeutung für das Interpretieren im 2. und 4. Schritt (Monosemieren, Klassifizieren in eine Klasse, Integrieren des Wissens). 


\subsubsection{Bedeutung}

Auf der Ebene der Bedeutung beschreiben wir die Relationen in absentia - die Beziehungen des Zeichens $\mathrm{zu}$ anderen Zeichen desselben Systems, welche der Sprecher zu einem bestimmten Zeitpunkt des Sprechens nicht gewählt hat. Bei der Beschreibung müssen wir jedoch immer im Rahmen einer einzigen funktionellen Sprache bleiben. Die Einheiten, die von diesem Gesichtspunkt aus verschiedenen Systemen angehören, sind zwar übersetzbar, nicht aber gleichwertig (vgl. Koch 1963: 79). Für die Untersuchung auf der Ebene der Bedeutung werden in der strukturellen Sprachwissenschaft zwei Methoden verwendet: die Kommutation und Distribution.

Die Kommutation, wie sie von Hjelmslev ausführlich begründet wurde, diente bei der Analyse der Bedeutung in Zorman 1997 für: 1. die Ausscheidung der Elemente der wiederholten Rede (diese gehören nach Coseriu 1970: 28 nicht in die strukturelle Beschreibung des synchronischen Systems, denn sie stehen durch keine konstitutive Teile in Opposition zu anderen Einheiten. Bei den Elementen der wiederholten Rede können mehrere Elemente auf der Ebene des signifiant ein einziges Element auf der Ebene des signifié darstellen. Wir erkennen sie daran, daß sie nicht kommutierbar sind, obwohl sie teilweise mit Satz-, Syntagma- oder Wortäquivalenten austauschbar sind); 2. für die Identifizierung von Invarianten im Sprachsystem, die der einzige Gegenstand der strukturellen Beschreibung sein können. Hjelmslev (z. B. 1980: 62 ff., besonders noch 65) bestimmt die Invarianten auf der Grundlage der Reversibilität: Wenn die Veränderung auf der Ausdrucksebene keine Veränderungen auf der Inhaltsebene (oder umgekehrt) hervorruft, handelt es sich um eine Invariante. Wenn bei lexikalischen Einheiten der Unterschied in der Form keinen Unterschied im Inhalt auslöst, bedeutet das, daß wir es mit Varianten zu tun haben, die vom Gesichtspunkt des Systems aus eine einzige Invariante darstellen. Der Unterschied zwischen ihnen ist im System nicht funktionell, zwei Einheiten auf der Ebene des Ausdrucks entspricht dabei eine einzige Einheit auf der Inhaltsebene. Der Vorgang der Kommutation wird in einer empirisch gegebenen Einheit des Ausdrucks angewandt, die nicht von der Länge her begrenzt ist.

Die Kommutation wird also als Verfahren für die Identifizierung der Einheiten im System gebraucht. Bei der Identifizierung der Bedeutung, die durch das strukturelle Verhältnis zu anderen Einheiten desselben Systems bestimmt wird, hilft jedoch die Methode der Distribution (Coseriu 1970: 56). Die distributionelle Semantik ist eine Variante der Gebrauchstheorie der Bedeutung. Ihre angesehensten Befürworter sind Wittgenstein, Meillet und Firth, Kritiker dagegen de Mauro, Chomsky, Naert usw. Die Sprache wird dabei als Werkzeug bzw. Instrument aufgefaßt, welches wir nur verwenden können, wenn wir die Art der Verwendung kennen. Nach dieser Theorie existiert die Bedeutung des sprachlichen Zeichens als eine abstrakte konzeptuelle Einheit nicht, sie wird nur durch seinen Gebrauch bestimmt. Auf die Erforschung der Synonymie wurde sie in verschiedenen Varianten z. B. von Dubois 1964, Apresjan 1966, Eckert 1968 und Battaglia 1991 appliziert, jedoch entspricht keiner dieser Versuche den theoretischen Grundannahmen von Coseriu. 
Eine eigene Version der distributionellen Semantik hat auch H. J. Heringer entwickelt. Er hat sie in einem Vortrag im Linguistischen Kreis der Philosophischen Fakultät in Ljubljana im Jahre 1992 vorgestellt. Die Grundidee, die der distributionellen Semantik nach Heringer zugrunde liegt, basiert auf der Annahme, daß sich die Bedeutung von Wörtern historisch in Texten konstituiert und sich somit aus diesen ableiten lassen müßte. Der beschreibende Linguist sollte nicht aus seiner eigenen Kenntnis schöpfen und die Beschreibung sollte der Variabilität und Dynamik der Bedeutung gerecht werden, die sich in verschiedenen kommunikativen Verwendungen in Sätzen oder Satzausschnitten zeigen. Die Bedeutung eines Wortes ist dabei keine Entität, die allein durch ein Synonym oder eine Periphrase erklärt werden könnte, sondern man kann sie sich als einen semantischen Hof vorstellen, um den sich andere Ausdrücke mehr oder weniger eng herumlagern, je nachdem wie relevant sie für seine Bedeutung sind. Die Struktur der Bedeutung sollte daher aus einem umso größeren Korpus von Texten eruiert werden. Heringer stellte in dem erwähnten Vortrag das Verfahren der computergestützten Distributionsanalyse dar, das die kontextuelle Umgebungen aller Vorkommen eines Wortes im Korpus analysiert. Aus den analysierten Daten erstellt der Computer ein sog. Kondensat aus den Kontexten des untersuchten Wortes. Das Kondensat aus der Distribution wird durch die Errechnung des mittleren Wertes aus der Häufigkeit der umgebenen Nachbarwörter und deren Distanz zum untersuchten Wort erstellt. Das Ergebnis, d. h. jene Wörter, die am charakteristischsten für die Distribution des untersuchten Wortes im Korpus sind, wird anschließend graphisch oder in tabellarischer Form dargestellt. Die Interpretation des Kondensats ist dem untersuchenden Linguist überlassen. Heringer erlaubte freundlicherweise die Verwendung des entsprechenden Programms der Distributionsanalyse auch zum Zwecke der Dissertation Zorman 1997. Mit Bezug auf die Rolle der Distribution bei Coseriu war das Ziel der Interpretation in Zorman 1997 nicht die Beschreibung des Wortinhalts, sondern nur die Identifikation des Platzes der lexikalischen Einheit im Sprachsystem, folglich der paradigmatischen und syntagmatischen Relationen, die sie in Opposition mit anderen Einheiten in der lexikalischen Struktur der Sprache stellen. Das Korpus in Zorman 1997 war leider zu klein für die Distributionsanalyse nach einzelnen funktionellen Sprachen, deshalb wurden die lexikalischen Einheiten nur im System der Schriftsprache analysiert. Die Erkentnisse können ausschließlich als eine Illustration der vorgeschlagenen Vorgehensweise dienen. Wenn wir die Tatsache in Betracht ziehen, daß es sich um ein Kondensat aus den Rede-Kontexten handelt, wird klar, daß wir die paradigmatischen Relationen, die als Relationen in absentia definiert sind, aus dem Kondensat nicht direkt ablesen können. Auf Grund der aufgedeckten Solidaritäten kann man jedoch die Wortklasse und das Bedeutungsfeld der untersuchten Lexeme identifizieren und die Bedeutungsfelder dann auf Grund von Wörterbuchangaben für die entsprechenden Lexeme konstruieren. Der gesamte Vorgang der Identifizierung der Bedeutungsverhältnisse der Synonyme mit der Analyse der Distribution in den Texten wird an 
anderer Stelle erörtert, ${ }^{35}$ deshalb wird er hier aus der weiteren Darstellung ausgeschlossen.

Beim Funktionieren der sprachlichen Einheiten sind neben den oppositionellen auch assoziative Beziehungen relevant, was schon F. de Saussure festgestellt hatte. ${ }^{36}$ Obwohl die Beschreibung der assoziativen Beziehungen nicht zur strukturellen Beschreibung gehört, müssen bei der einzelsprachlichen Beschreibung auch materielle und semantische Eigenschaften erkannt werden, die im Text ebenso funktionell werden können. Hierher gehört das Beobachten der Motiviertheit des sprachlichen Zeichens (Relationen zwischen Zeichen und Sachen) sowie der Verhältnisse zu anderen Zeichen oder Gruppen von Zeichen, die $u$. a. auch die kategorielle und instrumentale Bedeutung bestimmen. Coseriu 1973: $9 \mathrm{f}$. unterscheidet nämlich: Die lexikalische Bedeutung, die dem Was der sprachlichen Erfassung der Welt entspricht (die Bedeutung, die bei warm, Wärme unverändert bleibt und diese Gruppe z. B. von kalt, Kälte unterscheidet), die kategorielle Bedeutung, die dem Wie der Erfassung der Welt entspricht (die Bedeutung der Verbalkategorien, die Bedeutung, die bei warm und kalt identisch, und bei warm und Wärme unterschiedlich ist; diese Art von Bedeutung kommt in traditionellen Definitionen von Wortarten zum Ausdruck, nach welchen das Adjektiv z. B. eine Eigenschaft ausdrückt, das Substantiv eine Person oder Sache usw.; dariber Lyons in Semantik II (1983: 68 f.)), und die instrumentale Bedeutung, d. h. die Bedeutung der Morpheme ( $e$ in Tisch-e hat z. B. die Bedeutung 'pluralisierend'). Diese drei Arten der Bedeutung hat jede lexikalische Einheit, während die anderen zwei Arten (strukturelle bzw. syntaktische und ontische Bedeutung) nur dem Satz eigen sind.

Auf der Ebene der Bedeutung wurde bei jedem analysierten Beispiel die Durchführbarkeit der Kommutation überprüft, während die Distributionsanalyse wegen der oben beschriebenen Methode, welche eine genügend große Zahl von Belegen aus Texten erfordert, nur für alle funktionelle Sprachen gemeinsam durchführbar war, d. $h$. nur für den Zustand in der heutigen slowenischen Schriftsprache. Auf dieser Ebene wurden also die eigentlichen lexikalischen Einheiten und ihre Stelle im lexikalischen System identifiziert sowie die kategorielle Bedeutung und mögliche Assoziationen zwischen den Wörtern beschrieben.

\subsubsection{Sinn}

Die höchste Einheit des Sinns ist nach Coseriu 1985: 123 nicht der Text, sondern die gesamte Tätigkeit eines Autors. Dem können wir vom Gesichtspunkt der Wahl des Ausdrucks ohne Bedenken zustimmen. In Zorman 1997 war eine solche Vorgehensweise bei der Beschreibung des Sinns trotzdem nicht möglich. Die Einschränkungen waren auf der einen Seite vom Material gegeben, das für die Analyse zur Verfügung stand, auf der anderen vom Umfang der Arbeit (es geht um eine ansehnliche Zahl der Vorkommen desselben Wortes größtenteils in verschiedenen

35 In Vorbereitung.

36 Vgl. Coseriu 1970: 8 und $15 \mathrm{f}$. oder 1992: $139 \mathrm{ff}$. 
Texten verschiedener Autoren). Die Analyse war deshalb auf den Text beschränkt und sie hat nicht die Absicht, den eigentlichen Sinn eines bestimmten Textes völlig zu erklären. Der Sinn ist nach Coseriu ${ }^{37}$ mit der rein sprachlichen Analyse sowieso nicht greifbar und die Erklärung des Sinns ist größtenteils auf den Beitrag des untersuchten Wortes beschränkt, der unter dem Kriterium der Angemessenheit und in bezug auf die Norm und Funktion des Textes für die Aktualisierung des latent vorhandenen Evokationsvermögens durch die Wahl gegeben ist. Die Aufdeckung des Sinns ist eine Interpretation und jede Interpretation ist unbedingt subjektiv. Allgemein gültige Techniken der Textinterpretation gibt es nicht und nach der Überzeugung Coserius ${ }^{38}$ müssen wir bei jeder Interpretation damit rechnen, daß wir nicht alles verstanden haben oder daß wir weniger verstanden haben als andere. Die Liste der Möglichkeiten für die Integrierung des Außersprachlichen in die sprachliche Nachricht (s. unten Tabelle 9-12) ist als offene Liste gedacht, welche jederzeit vervollständigt werden kann.

\subsection{Analysemodell mit einem Kommentar zu den einzelnen Kategorien}

In das Analysemodell sind relevante Kategorien aus allen drei Inhaltsebenen eingeschlossen. Die tatsächliche Beschreibung, die den besprochenen theoretischen Forderungen zu folgen versucht, ist jedoch mit gewissen Schwierigkeiten verbunden. Die größte darunter liegt darin, daß die slowenische Sprache sowie die Textsorten noch nicht entsprechend beschrieben sind. Die Analyse der einzelnen Kategorien mußte deshalb oft den verfügbaren Fachkenntnissen angepaßt werden.

Funktionelle Sprache: Die Definition nach Coseriu ist oben unter Punkt 2.3 angeführt. Da eine ausführliche Beschreibung der sprachlichen Varietäten bei uns noch immer fehlt, ist die Bestimmung dieser Kategorie im Analyseverfahren der einzelnen Beispiele schwierig. Als homogene Einheit dürfen wir nach Coseriu nur die Sprache behandeln, welche von Autoren benützt wird, die von demselben geographischen Gebiet ausgehen, den gleichen sozialen Status besitzen und sich in der gleichen Redeposition hinsichtlich des Addressaten, der Sprechsituation und des Redethemas befinden. Bei der Bestimmung dieser Sprache müßten wir zugleich alle drei Faktoren berücksichtigen, nämlich die diaphasischen und diastratischen Unterschiede innerhalb des Dialekts oder diatopische und diastratische innerhalb des Stils. Es ist klar, daß eine solche Vorgehensweise hinsichtlich des derzeitigen Forschungsstands unmöglich ist. Ein Kompromiß wird so hergestellt, daß bei der Bestimmung dieser Kategorie nur die Varietäten in bezug auf den Anwendungsbereich berücksichtigt werden, die in einem gewissen Sinn der synstratischen Technik Coserius entsprechen. Aufmerksamkeit wird auch der Mannigfaltigkeit der realisierten funktionellen Sprachen im Rahmen desselben Textes gewidmet. Die Bestimmung der syntopischen Technik, die die Aufdeckung des regionalen Ursprungs des Autors verlangen würde, wird 
vernachlässigt, angenommen ist die in der slowenischen Sprachwissenschaft überwiegende Annahme über die einheitliche Hochsprache, die nur zweckmäßig untergliedert ist. Die diaphasischen Unterschiede sind bis zu einem gewissen Grad im Rahmen der Kategorien Region und Redeuniversum berücksichtigt.

Paraphrase: Durch die Paraphrasierung sind die aktualisierten Bezeichnungen vorgestellt, den Ausgangspunkt stellen (wenn möglich) die paraphrastischen Bedeutungsangaben der entsprechenden Wörter im Wörterbuch der slowenischen Schriftsprache (Slovar slovenskega knjižnega jezika; in der Folge SSKJ) dar. Genutzt werden verschiedene Arten der Paraphrasierung, die oben unter Punkt 3.1.1 erörtert wurden. Das Verhältnis zwischen dem Sprachlichen und Außersprachlichen ist, wie schon gesagt, dabei vernachlässigt worden.

Explikatoren: Angeführt sind die sprachlichen Mittel, die die Eigenschaften des Benannten beschreiben.

Spezialisatoren: Angeführt sind Spezialisatoren für die Begrenzung innerhalb der Klassen der Sachen.

Spezifikatoren: Angeführt sind Spezifikatoren, die Besonderheiten aufdecken.

Identifikatoren: Angeführt sind Identifikatoren, die die Mehrdeutigkeit begrenzen.

Region: Regionen sind in der sprachwissenschaftlichen Literatur in der Art, die dem Verständnis von Coseriu entsprechen würde, nicht klassifiziert, ebenso fehlt eine systematische Beschreibung der diesbezüglichen Besonderheiten für das Slowenische. Deshalb ist die Bestimmung problematisch und die Beurteilung bleibt der Kompetenz des Forschers überlassen. Dabei können bis zum gewissen Grad die entsprechenden Wörterbuchangaben hilfreich sein. Auf der Bestimmung der Art der Region wird aus den genannten Gründen verzichtet.

Rede-Kontext: Analysiert wird nur der unmittelbare positive Rede-Kontext mit Ausnahme der Determinatoren; auf die Wirkung des mittelbaren oder negativen Kontextes wird bei der Beschreibung des Sinns hingewiesen.

Thematischer Kontext: Coseriu 1975 zählt den thematischen Kontext zum Rede-Kontext, in Zorman 1997 ist er jedoch als gesonderte Kategorie dargestellt, weil der Umfang der Arbeit keine längeren Textabschnitten aufzuführen erlaubt.

Redeuniversum: Die Schwierigkeiten bei der Bestimmung sind gleicher Natur wie bei der Region (siehe oben). Selbstverständlich wurden sowohl Region als auch Redeuniversum nur in den Beispielen behandelt, wo sie tatsächlich funktionell sind.

Präferenzen und Norm: Aus den Daten über die relative Häufigkeit der Auswahl zwischen den Synonymen werden die Präferenzen in den einzelnen funktionellen Sprachen festgestellt, obwohl bei einem so kleinem Korpus, wie es das bearbeitete ist, solche Feststellungen wahrscheinlich unzuverlässig sind. Die Daten über die Präferenzen sind also in erster Linie illustrativer Natur und sie sind nicht direkt für das Erkennen der Norm einer funktionellen Sprache verwendbar. Die Norm können wir erst bei Beachtung des Kriteriums der Funktionalität erkennen - was der Norm einer 
funktionellen Sprache entspricht, hat die Funktion der Redundanz, und was von ihr abweicht, ist nach Coseriu 1992: 208 "funktioneller Luxus", der bei der Interpretation des Textes dem Addressaten das Verstehen erleichtert. Auf der Grundlage dieser Erklärung müssen wir beim Feststellen der Norm neben den Daten über die Frequenz auch die Funktion auf der Ebene des Sinns berücksichtigen. In bezug auf den Typ sind die in die Behandlung eingefaßten funktionellen Sprachen in der slowenistischen Fachliteratur nach den Kriterien Coserius noch nicht ausreichend beschrieben. Ein Versuch einer derartigen Analyse stellt der Beitrag Pogorelec 1986 dar, der nach Havránek vier sprachliche Varietäten von zwei für die vorliegende Erörterung geeigneten Gesichtspunkten behandelt: Ein- bzw. Mehrdeutigkeit des Wortschatzes sowie das koventionelle bzw. freie Verhältnis der Bezeichnung zu dem Bezeichnetem. Die behandelten Varietäten sind die Alltagssprache, die Fachsprache und die wissenschaftliche Sprache. Leider ist in dem Beitrag nicht die Rede von der Zeitungsprache, deshalb wird diese nach denselben Kriterien auf der Grundlage der Feststellungen der Analyse und bei Beachtung der Beschreibung des publizistischen Stils von Mistrík 1975: 110 bewertet.

Kommutierbarkeit: Die Durchführbarkeit der Kommutation ist mit $+/$ - bewertet. Wenn die Kommutation undurchführbar ist, ist zwischen den Elementen der wiederholten Rede und funktionellen Oppositionen zu unterscheiden.

Instrumentale Bedeutung: Ist nur in Fällen beschrieben, wenn sie die Funktion der Bezeichnung und der lexikalischen Bedeutung auf der Ebene des Sinns unterstützt.

Text: Bestimmt ist die Art des Textes (Textsorte, Texttyp, Textgattung usw.). Als theoretische Grundlage dafür dienten die Werke Mistrík 1975 (Beschreibungen der wissenschaftlichen, fachlichen, publizistischen, rhetorischen und administrativen Genres), Košir 1988 (publizistische Textgattungen), Kmecl 1976 (literarischeTextgattungen) und Schiffrin 1994 (Verzeichnisse). Hilfreich war auch die Arbeit Toporišič \& Gjurin 1981 (eine Sammlung von Mustertexten verschiedener Textsorten in der slowenischen Sprache). Für alltagssprachliche Textsorten stehen leider ähnliche ausführliche Beschreibungen nicht zur Verfügung, jedoch sind die Beschreibungen einiger Arten solcher Texte (z. B. Benachrichtigung, Anzeige, Exempel) auch bei Mistrík und Kmecl oder woanders in der Fachliteratur zu finden. Die Bestimmung der Art des Textes ist nötig, um die zukommende Norm und Funktion festzustellen. Die Schwierigkeiten bei der Zuordnung konkreter Texte zu den Gattungen sind in der Textlinguistik zur Genüge bekannt und eine entsprechende Texttypologie bleibt noch immer aufzustellen. Deshalb waren auch bei den analysierten Beispielen mehrere Fälle fragwürdig.

Textnorm: Ist bestimmt auf der Grundlage der Beschreibungen der einzelnen Textgattungen in der oben aufgeführten Fachliteratur. Die Norm ist bei Košir und Kmecl deskriptiv umrissen und wird in solcher Form auch zitiert. Mistrík führt die Beschreibung in Form von Modellen an, in welchen die formativen Gattungsmittel mit Hilfe von Qualifikatoren gekennzeichnet sind. Zu solchen Mitteln zählt er: physische Mittel (Extension, horizontale und vertikale Gliederung des Textes), sprachliche bzw. 
Redemittel (sie sind durch den Qualifikator $\mathrm{P}$ (parole) gekennzeichnet und in lexikalische (L), syndetische (S) und sog. Mittel des stilistischen Verfahrens (M), s. die Erklärung weiter unten unterteilt). Zu den formativen Mitteln gehören noch die sog. komplementäre Mittel (okkasionelle Mittel und die Addresse) usw. In bezug auf die Zielsetzung der vorliegenden Arbeit galt die Aufmerksamkeit bei der Beschreibung der Norm hauptsächlich zwei Arten der Redemittel: den lexikalischen Mitteln (L) und den Mitteln des stilistischen Verfahrens (M). Bei den lexikalischen Mitteln beurteilt Mistrík die Stufe der potentiellen Polyvalenz der Wörter und ordnet jede Gattung in eine der drei Stufen ein:

$\mathrm{L}_{1}$ bedeutet, daß Mehrdeutigkeit nicht zulässig ist - hierher gehören Texte mit eindeutigen Wörtern, deren Bedeutung nicht kontextabhängig ist, z. B. Dissertation, administrative Textgattungen...

$\mathrm{L}_{2}$ bedeutet, daß im Text mehrdeutige Wörter verwendet werden können (z. B. lexikalisierte Metaphern), die jedoch aufgrund des Kontextes auch eindeutig verstanden werden können. Wörter sind hier keine Termini, sondern Appelativa. In diese Gruppe gehören populärwissenschaftliche Texte und gewisse Texte des publizistischen Stils.

$\mathrm{L}_{3}$ bezeichnet, daß die Wörter im großen Maße metaphorisch gebraucht werden. Die Stufe L3 finden wir überwiegend in literarischen Textgattungen.

Die Mittel des stilistischen Verfahrens (ebd. 33 ff.) liegen den modernen Begriffen der Themenentfaltung und Textfunktion nahe:

$\mathrm{M}_{1}$ ist eine Information oder Beschreibung,

$\mathbf{M}_{2}$ ist ein erörterndes stilistisches Verfahren,

$\mathrm{M}_{3}$ ist ein explikatives stilistisches Verfahren.

Das stilistische Verfahren beeinflußt nach Mistrík auch die Art der Kohäsion sowie die Stufe der Objektivität des Textes usw. Von der Stufe der Objektivität des Textes ist jedoch (wenigstens teilweise) die Wirkung der Auswahl zwischen den potentiell vorhandenen Bezeichnungen abhängig. Ein nützliches zusätzliches Mittel für die Beobachtung der Auswahl von diesem Blickwinkel aus ist auch die Untergliederung in informative und interpretative Textgattungen bei Košir (ebd. 57-67) bzw. Stil- und Modalqualifikatoren von Mistrik (ebd. 40 ff.), z. B.:

$\mathrm{J} a$ publizistisch analytischer Stil (Analyse von Gründen, Erscheinungen, Agitations- und Erziehungsfunktion);

Js publizistischer Berichterstatterstil (referiert, konstatiert);

$\mathrm{J} b$ publizistisch belletristischer Stil (umfaßt die Bestandteile des künstlerischen Ausdrückens);

$\mathrm{Nv}$ fachlich (und wissenschaftlich) erklärender Stil (erhellt, erklärt, analysiert);

No fachlich (und wissenschaftlich) beschreibender Stil (konstatiert);

Ao administrativ benachrichtender Stil (wie $\mathrm{J} s$ ). 
Die Modalqualifikatoren dienen der Aufteilung auf objektive und subjektive Textgattungen:

$x$ oder die Abwesenheit des Indexes zeigt, daß die Gattung objektiv ist, der Autor ist in ihr nicht anwesend,

y hat einen ähnlichen Inhalt wie die Bezeichnung "expressiv" beim Wort: Die Gattung ist subjektiv, der Autor ist im Text anwesend, engagiert, seine Absicht (z. B. Ironie, Humor, Zorn, Suggestion...) ist bemerkbar.

Angemessenheit der Wahl: Mit Bezug auf die oben beschriebenen Kriterien der Textnorm ist sie mit $+/$ - bewertet. + bezeichnet, daß die Wahl der Norm des Textes entspricht, - jedoch, daß sie von ihr abweicht. Die Abweichung kann absichtlich sein oder sie ist eine Folge des Nichtkennens der Norm. Die Angemessenheit der Wahl beeinflußt die Aktualisierung der latent vorhandenen Möglichkeiten für die Evokation. Das Übereinstimmen mit der Norm ist redundant, die Funktion der Abweichung wird beim Sinn festgestellt.

Evokationen: Beschrieben sind die im jeweiligen Text gegebenen Möglichkeiten für die Evokation.

Sinn: Die Beschreibung ist auf einen Beitrag des untersuchten Ausdrucks zum Sinn des Textes beschränkt. In Fällen, wo dieser Ausdruck in einer redundanten Funktion auftritt, ist der Sinn des Textes nicht völlig geklärt.

\section{Analyse der Synonyme nach dem beschriebenen Modell}

\subsection{Untersuchte Einheiten}

Für die Untersuchung in Zorman 1997 wurden zwei Paare slowenischer Ausdrücke gewählt, die als Beispiele für "reine (und totale) Synonyme" im Sinne Lyons 1975: 458 gelten können: kuverta - ovojnica (reine, aber nicht totale Synonyme) und $b o r b a$ - $b o j$ (reine und totale, d. h. absolute Synonyme).

Kuverta und ovojnica haben nach Angaben des Wörterbuches der slowenischen Schriftsprache (SSKJ) nur teilweise gleiche Bedeutungsangaben, beide sind stilistisch neutral und gleich frequent. Kuverta bedeutet 'Papier, gebogen und so geklebt, daß eine Tüte, gewöhnlich für Briefe, entsteht' (in verschiedener phraseologischen Verbindungen kann es auch noch 'Geld', 'Gehalt' oder 'Bestechungsgeld' bedeuten). ${ }^{39}$ Ovojnica ist dagegen mehrdeutig. ${ }^{40} \mathrm{Die}$ erste Bedeutung stimmt völlig mit der von kuverta überein, die restlichen zwei sind spezifisch für dieses Lexem: "was man um etwas herumtut, meist als Schutz (z. B. Verpackung)' und 'dünne Gewebeschicht, die etwas umgibt, verbindet'. Modifiziert mit verschiedenen Attributen, wird es in Fachausdrücken gebraucht, z. B. in der Anatomie (mišična/možganska ovojnica 
'Muskel-/Hirnhaut', sklepna ovojnica 'Gelenkkapsel'), Biologie (celična ovojnica 'Zellhaut' usw.), der Mathematik ('Linie, die eine Familie von Kurven umgibt') sowie der Zoologie (pasja trakulja 'Bandwurm beim Hund') und der Embryologie. In die Synonymenreihe von kuverta und ovojnica gehören weiter die Wörter zalepka (ein absolutes Synonym) und omot, ovojka, ovoj, zavitek, die nur teilweise die gleiche Bedeutung haben wie kuverta. Ovojnica hat dazu noch eine Reihe von terminologischen Synonymen in der Anatomie: sklepna ovojnica heißt auch gožva, mišična ovojnica ist fascija, možganska ovojnica ist mrena usw.

Borba und boj sind laut Angaben derselben Quelle (I, 164 und 173 f.) mehrdeutige Wörter, deren Wörterbuchdefiniton absolut übereinstimmt. Sie heißt: 1. 'bewaffneter Kampf', 2. 'Zusammenstoß verschiedener Auffassungen', 3. 'Bestrebung für das Erreichen einer bestimmten Absicht'. Zwischen ihnen gibt es nur einen Frequenzunterschied (boj wird häufiger gebraucht) sowie gewisse phraseologische und terminologische Unterschiede: boj kann man phraseologisch als smrtni boj für 'Sterben, Agonie' brauchen und es kommt auch als Teil einiger Fachausdrücke vor, z. B. boj za obstanek 'Kampf um das Überleben' (Biologie) oder boj im Sinne von 'Wettbewerb' im Sport usw., während borba ausschließlich im Terminus borba za obstanek 'Kampf um das Überleben' in der Biologie verwendet wird. Metaphorisch wird für 'psychische, innere Konflikte' sowohl borba als auch boj gebraucht, für 'Wortgefechte' jedoch nur boj. Wegen seines Ursprungs ist borba in den neueren slowenischen Rechtschreibungshandbüchern in Ungnade gefallen: Slowenische Rechtschreibung (Slovenski pravopis; in der Folge SP) 1962: 140 zieht boj vor, doch verbietet nicht borba. Nach SP 1990, 135 ist vom Gebrauch von borba abzuraten.

\subsection{Das Textkorpus}

In Übereinstimmung mit den beschriebenen theoretischen Annahmen wurde für die Untersuchung Zorman 1997 ein Korpus von Texten gesammelt und eine Methode der Beschreibung von Synonymen auf allen drei Inhaltsebenen konzipiert. Das Korpus umfaßte $40 \mathrm{Mb}$ bzw. ungefähr 20000 maschinenschriftliche Seiten (insgesamt ca. 6 Millionen Wörter) von Texten aus allen Bereichen der geschriebenen slowenischen Gegenwartssprache. Die Zusammensetzung des Korpus war davon abhängig, daß die Texte wegen der gewählten Arbeitsmethode und wegen der relativ großen Menge auf einem Computermedium zugänglich sein mußten. Zur Zeit der Entstehung dieser Arbeit stand noch keine maschinenlesbare Sammlung von slowenischen Texten den Forschern zur Verfügung. Das Korpus besteht aus Texten, die schon in einer solchen Form notiert waren und für den Bedarf der Forschungsarbeit der Autorin von einigen Verfassern und Verlagsgesellschaften dankenswerterweise zur Verfügung gestellt wurden. In die Untersuchung wurden Texte aus einzelnen Jahrgängen slowenischer Zeitungen und Zeitschriften (überwiegend Delo, Mladina, Zdravje), fachlicher bzw. wissenschaftlicher Zeitschriften (Anthropos, Slavistična revija), 26 Monographien (Belletristik und fachliche Handbücher), Texte aus der Bibliographie der Universität Maribor (Izum) sowie einige unveröffentliche Texte (insbesondere private Korrespondenz) eingeschlossen. Alle Texte entstanden nach 1990 und von der 
hochsprachlichen Norm weichen nur wenige Texte aus der Jugendzeitschrift Špric und der Jugendzeitung $\check{Z}$ ab, die Elemente des Slangs aufweisen. Ursprünglich slowenische Texte sind stärker vertreten als übersetzte. Das Korpus erfaßt folgende sprachliche Varietäten: die Alltagssprache (ungefähr 15\%), die Pressesprache (30\%), die Fachoder populärwissenschaftliche Sprache (26\%), die wissenschaftliche Sprache (19\%) und die Literatursprache (10\%).

Die Arbeit mit einem Korpus von Texten ist streng empirisch. Die Methode ist induktiv und läßt weniger Platz für intuitive Beurteilungen, denn wir analysieren das, was tatsächlich vorkommt, und nicht etwa das, was nach unserer Meinung vorkommen könnte. Natürlich stellt sich die Frage, wann eine Sammlung groß genug für die Formulierung adäquater Feststellungen ist. Das Korpus umfaßt nur eine Untermenge aller Texte in einer Sprache, deshalb ist jede Feststellung nur mehr oder weniger wahrscheinlich und kann jederzeit revidiert werden. Aus diesem Grunde hat sich die Analyse nicht zum Ziel gesetzt, entgültige und unanfechtbare Urteile über einzelne konkrete Fälle der Synonymie abzugeben. Ihre Aufgabe ist es, zu beweisen, daß es bei der Synonymie nicht berechtigt ist, einfach über die Gleichheit oder Ähnlichkeit der Bedeutung zu urteilen (ungeachtet dessen, wie wir uns die "Bedeutung" und seine Gleichheit oder Ähnlichkeit erklären), denn die Verhältnisse sind ausgesprochen heterogen und abhängig von der jeweiligen Ebene der Beobachtung.

\subsection{Beispiele aus den analysierten Texten}

Die Leistungen des vorgeschlagenen Arbeitsverfahrens können anhand einiger Beispiele aus den analysierten Texten geschildert werden.

In den Beispielen (1) und (2) sind kuverta und ovojnica in redundanter Funktion.

(1) /.../ ali pa oddajte v nabiralnik Dela za križanke in rešitve, na dopisnico ali kuverto pa ne pozabite nalepiti našega kupona $/ . . . / 1$ ( $\% /$ oder werfen sie es in den Briefkasten für Kreuzworträtsel und Lösungen der Zeitung Delo, und vergessen sie nicht auf die Postkarte oder den Briefumschlag unseren Coupon aufzukleben /.../')

(2) /.../ 5. Posredovanje rezultatov in pritožb

(a) Rezultati kontrole so strogo zaupni in jih je treba posredovati zdravniku delegatu Komiteja za doping ali osebi, ki jo on imenuje, v zapečateni ovojnici.

(b) Dokazi, na osnovi katerih so dokončno ugotovili dopinško substanco, morajo biti na razpolago zdravniku delegatu ali njegovemu namestniku /.../2

(\%.../ 5. Übermittlung der Resultate und Beschwerden

(a) Die Kontrollresultate sind streng vertraulich und müssen dem delegierten Arzt des Komitees für Doping oder einer Person, welche dieser ernennt, in einem versiegelten Umschlag übermittelt werden.

41 Gesamter Text in Zorman 1997: 219.

42 Der Auszug stammt aus dem fachlichen Handbuch Sperryn, P. N. 1994. Šport in medicina. Übersetzt von J. Penca. Ljubljana: DZS. 
(b) Die Beweise, aufgrund welcher entgültig die Dopingsubstanz ermittelt wurde, müssen dem delegierten Arzt oder dessen Stellvertreter zur Verfügung stehen /.../')

In beiden Fällen geht es um die Bezeichnung eines Briefumschlags. Thematischer Kontext im Sinn eines Teilthemas des Textes ist in beiden Fällen eine Anweisung, wie die Informationen übertragen werden sollen. Der Text, aus welchem der Abschnitt stammt, ist im ersten Fall eine Benachrichtigung, im zweiten ein Reglement. Die Art des Textes ist zwar unterschiedlich, jedoch haben beide Texte manches hinsichtlich der Textnorm gemeinsam: Mistrik 1975: 190 ordnet beide den Texten des administrativen, benachrichtigenden Stils $z u$, bei beiden geht es um eine Information bzw. Beschreibung. Beide Texte sind objektiv - der Autor darf nicht anwesend sein, seine Absicht darf nicht bemerkt werden. Bei der Auswahl der lexikalischen Mittel (z. B. hinsichtlich der Zulässigkeit der Mehrdeutigkeit, des Gebrauchs der Metaphorik oder der Fachterminologie) gibt es zwischen den beiden Texttypen keine Unterschiede. Der wichtigste Unterschied liegt jedoch darin, daß das Reglement im rechtlichen Sinn verbindend ist, die Benachrichtigung hingegen nicht, was am deutlichsten bei der Wahl der modalen Mittel wird. Auch das Wissen, daß der erste Text in einer Zeitung veröffentlicht wurde, der zweite jedoch in einem fachlichen Handbuch, kann uns nicht weiterhelfen, weil wir beide Ausdrücke in allen sprachlichen Varietäten bzw. funktionellen Sprachen antreffen und beide können offensichtlich in redundanter Funktion auftreten. Infolge aller dieser Ähnlichkeiten könnte man leicht zu dem Schluß gelangen, daß kuverta und ovojnica als Bezeichnungen für einen Briefumschlag absolut synonym sind. Eine Untersuchung der Wahrheitsbedingungen oder die Substitution würde ergeben, daß sie in solchen Fällen völlig vertauschbar sind, daß sie sich aber dann, wenn sich ovojnica z. B. auf Gewebe (wie in sklepna ovojnica) bezieht, nicht gegeneinander austauschen lassen. Folglich handelt es sich um Synonyme, die in einer ihrer Bedeutungen sowohl im deskriptiven als auch expressiven Sinn übereinstimmen. Das Austauschen würde nicht einmal pragmatische Folgen nach sich ziehen, jedenfalls nicht solche, welche wir mit den anerkannten pragmatischen Methoden nachweisen könnten.

Weil aber das vorgeschlagene Verfahren für die Untersuchung der Synonyme induktiv ist, müssen wir auf ähnliche Weise, wie wir die oberen zwei Beispiele des Gebrauchs von kuverta und ovojnica beschrieben haben, den Gebrauch in einem weitaus größeren Korpus von Texten untersuchen. Dabei stellt sich jedoch heraus, daß auch solche stilistisch neutrale Glieder der Synonymenreihen in Texten verschiedene Wirkungen auslösen können, wie z. B. in den folgenden zwei Beispielen.

Beispiel (3) ist den ersten zwei Beispielen ziemlich ähnlich: ovojnica ist hier in der gleichen Bezeichnung und gleichem Kontext, und doch ist es nicht redundant:

(3) /.../ Prošnje bodo sprejemali samo ob ponedeljkih, sredah in petkih od 9. do 12. ure, potrjene vizume pa bo mogoče dobiti še istega dne po 15. uri. Slovenski državljani lahko zaprosijo za vizum osebno ali pošljejo po pošti potne liste, ki jim priložijo izpolnjene obrazce s svežo fotografijo in druge zahtevane dokumente ter ovojnico s svojim naslovom $/ . . .{ }^{43}$ ( $\% /$ Gesuche werden nur an Montagen, 
Mittwochen und Freitagen von 9 bis 12 Uhr angenommen, genehmigte Visa können schon am selben Tag nach 15 Uhr ausgehändigt werden. Slowenische Staatsangehörige können um ein Visum persönlich bitten oder per Post ihren Reisepaß schicken, dem die ausgefüllten Formulare mit einem neueren Paßfoto und andere benötigte Dokumente sowie ein Umschlag mit ihrer Addresse beiliegen /.../')

Der Unterschied zu den ersten zwei Beispiele liegt im Texttyp: Hier geht es um eine erweiterte Nachricht darüber, daß die amerikanische Botschaft in Ljubljana mit der Ausgabe von Visa begonnen hat. Die erweiterte Nachricht hat praktisch die gleiche Norm wie eine Nachricht - das ist eine äußerst schablonisierte und automatisierte publizistische Textsorte, bei der der Leser umso schneller über Ereignisse benachrichtigt werden will, und zwar will er Antworten auf die Fragen: Was, Wann, Wo, Wer, bei einer erweiterten Nachricht dazu noch Wie. Deshalb ist die Sprache sachlich und komprimiert, der Autor ist im Text nicht anwesend, seine Haltung ist neutral. Die Information, die für die Identifikation des Ereignisses nicht notwendig ist, stellt im oberen Fall die Beschreibung der Art und Weise dar, wie man um ein Visum über den Postweg bittet. Bei der Beschreibung dieser Vorgehensweise würden wir im Einklang mit der Textnorm (schablonisiert und automatisiert) Bezeichnungen erwarten, die in der amtlichen Umgebung gebraucht werden (z. B. novejšo ('neueres') anstatt svežo fotografijo ("frisches" Foto'), konkrete Benennungen anderer benötigter Dokumente und auch kuverta anstatt ovojnica). Für die Nachricht wäre wahrscheinlich auch die Formulierung sie können um ein Visum persönlich oder per Post bitten geeigneter anstatt sie können um ein Visum persönlich bitten oder sie schicken per Post die Reisepässe. Die gleiche Vorgehensweise des Autors können wir im weiteren Kontext des Textes betrachten, wo er schreibt das Amt für die Ausgabe von Reisepässen für amerikanische Staatsangehörige wird die Tätigkeit später aufnehmen, obwohl der Addressat eine Antwort auf die Frage Wann? erwartet. Der Text ist für den Addressaten hinsichtlich der Erwartungen beim Lesen der Nachricht nicht genügend redundant, deswegen kann der Leser z. B. zu dem Schluß gelangen, daß der Autor im Schreiben dieser Arten von Texten nicht genügend bewandert ist.

Wenn uns der Autor in diesem Fall etwas über sich mitgeteilt hat, können wir im Beispiel (4) die Wahl zwischen den Synonymen zu den Mitteln einordnen, die sein Verhältnis zum Addressaten indizieren - die Auswahl hat also die Funktion von sozialer Deixis:

\section{(4) Zdravo !}

Vesel potrjujem svojo udeležbo na raziskovalnem taboru na Kozjaku. Na vse kriplje nabiram potrebno kondicijo (telesno, umsko...), potrebno za delo v Troji skupini.

Vse dobro in lep pozdrav! 
R.P.

\section{7. 1991}

P. S.: Ker je "priloženo pismo" sestavljala le modra ovojnica, sem pismo napisal sam in ga poslal $v$ originalni ovojnici.44

('Hallo!

Mit Freude bestätige ich meine Teilnahme an dem Forschungslager auf dem Kozjak. Auf Teufel komm raus versuche ich die notwendige Kondition zu sammeln (körperliche, geistige...), die notwendig für die Arbeit in Deiner Gruppe ist.

Alles Gute und einen schönen Gruß!

R. P.

27. 7.1991

P. S.: Weil sich der "beiliegende Brief" nur aus einem blauen Umschlag zusammensetzt, habe ich den Brief selber geschrieben und ihn im Originalumschlag geschickt.')

Der Text ist der Brief, der zugleich Merkmale eines geschäftlichen und persönlichen Briefs aufweist - ist eine offizielle Anmeldung zur Teilnahme am Forschungslager, die aber nicht im streng formalen Stil geschrieben ist. Die Wahl des kommunikativen Musters ist durch das soziale Verhältnis zwischen dem Autor und dem Adressaten beeinflußt. Das Muster ist hier zugleich freundschaftlich (hieher gehört die Anrede Hallo, auf Teufel komm raus, Duzen..), und auch formal (bestätige die Teilnahme, in Deiner Gruppe...). Genau dieses Verhältnis bestimmt wahrscheinlich auch die Wahl zwischen ovojnica und kuverta. Die Norm der Alltagssprache ist - wie das Korpus zeigt - kuverta, und das Abweichen von der vorherrschenden Norm kann unter anderem ein Indikator des formalen Verhältnisses zwischen den Teilnehmern der Kommunikation sein.

Wegen der räumlichen Begrenzung ist es an dieser Stelle nicht möglich, weitere Möglichkeiten des funktionellen Wirkens mit Beispielen zu illustrieren. ${ }^{45}$ Die aufgeführten Beispiele zeigen hoffentlich, daß es nicht genügt, sich die Frage zu stellen, ob ein Wort ein anderes ersetzen könnte, sondern es ist notwendig, genau die Bedingungen zu beschreiben, unter welchen es ausgewählt wurde, und was und auf welche Weise es zum Sinn des Textes beigetragen hat.

44 Der Text stammt aus privater Korrespondenz und ist hier vollständig wiedergegeben.

45 Vgl. dazu die Tabellen 9-12 unter dem Punkt 4.4.3. 


\subsection{Erkenntnisse der Untersuchung}

Die Analyse des Gebrauchs von Musterbeispielen reiner (und totaler) Synonyme nach dem in Punkt 3.2 beschriebenen Modell macht es möglich, über die "Bedeutungsgleichheit" der untersuchten Ausdrücke folgendes Bild zu erstellen.

\subsubsection{Die Ebene der Bezeichnung}

a) Beide Glieder des Paares werden in den Texten für die Bezeichnung von verschiedenen Sachen gebraucht (hinsichtlich der Bezeichnung sind sie also polyvalent). Die Möglichkeiten für die Bezeichnungen sind, wie die Tabellen 1 und 2 zeigen, verschieden sowohl zwischen den einzelnen funktionellen Sprachen bei dem gleichen Glied wie auch zwischen beiden Gliedern in der gleichen funktionellen Sprache.

Tabelle 1: Vergleich der Bezeichnungen und die Frequenz nach den funktionellen Sprachen für das Paar kuverta - ovojnica

\begin{tabular}{|c|c|c|}
\hline & kuverta & ovojnica \\
\hline Frequenz & 6 & 9 \\
\hline \multirow[t]{5}{*}{ Bezeichnungen } & podkupnina 'Bestechungsgeld' & \\
\hline & plača 'Gehalt' & \\
\hline & pisemski ovitek 'Briefumschlag' & pisemski ovitek 'Briefumschlag' \\
\hline & pismo 'Brief' & pismo 'Brief' \\
\hline & & $\begin{array}{l}\text { kar nekaj ovija 'was etwas } \\
\text { umwickelt' }\end{array}$ \\
\hline
\end{tabular}

\begin{tabular}{l|l|l}
\hline PRESSESPRACHE & \multicolumn{2}{l}{} \\
\hline Frequenz & plača 'Gehalt' & 4 \\
\hline Bezeichnungen & ponudba 'Angebot' & \\
\hline & odločba 'Beschluß' & \\
\hline & $\begin{array}{l}\text { pregledati podatke 'Daten } \\
\text { durchsehen' }\end{array}$ & \\
\hline & tajen 'geheim' & \\
\hline & pisemski ovitek 'Briefumschlag' & pisemski ovitek 'Briefumschlag' \\
\hline & \multicolumn{2}{l}{ denar 'Geld' } \\
\hline
\end{tabular}

FACHSPRACHE

Biologie

\begin{tabular}{l|l|l}
\hline Frequenz & 0 & 8 \\
\hline Bezeichnungen & & $\begin{array}{l}\text { kar nekaj ovija 'was etwas } \\
\text { umwickelt' }\end{array}$ \\
\hline Medizin & 0 & 77 \\
\hline Frequenz & & $\begin{array}{l}\text { tkivo, ki kaj ovija 'Gewebe, das } \\
\text { etwas umwickelt' }\end{array}$ \\
\hline Bezeichnungen &
\end{tabular}




\begin{tabular}{|c|c|c|}
\hline & & $\begin{array}{l}\text { kar nekaj ovija 'was etwas } \\
\text { umwickelt' }\end{array}$ \\
\hline \multicolumn{3}{|l|}{ Informatik } \\
\hline Frequenz & 2 & 6 \\
\hline \multirow[t]{2}{*}{ Bezeichnungen } & pisemski ovitek 'Briefumschlag' & pisemski ovitek 'Briefumschlag' \\
\hline & & $\begin{array}{l}\text { kar nekaj ovija 'was etwas } \\
\text { umwickelt' }\end{array}$ \\
\hline \multicolumn{3}{|l|}{ Verwaltung } \\
\hline Frequenz & 2 & 2 \\
\hline \multirow[t]{2}{*}{ Bezeichnungen } & pisemski ovitek 'Briefumschlag' & pisemski ovitek 'Briefumschlag' \\
\hline & & $\begin{array}{l}\text { kar nekaj ovija 'was etwas } \\
\text { umwickelt' }\end{array}$ \\
\hline \multicolumn{3}{|c|}{ WISSENSCHAFTILICHE SPRACHE } \\
\hline Frequen $z$ & 0 & 9 \\
\hline Bezeichnung & & $\begin{array}{l}\text { črta, ki obdaja družino krivulj } \\
\text { 'Linie, die eine Familie von } \\
\text { Kurven umgibt' }\end{array}$ \\
\hline \multicolumn{3}{|c|}{ LITERATURSPRACHE } \\
\hline Frequenz & 3 & 23 \\
\hline \multirow[t]{4}{*}{ Bezeichnungen } & pisemski ovitek 'Briefumschlag' & pisemski ovitek 'Briefumschlag' \\
\hline & & $\begin{array}{l}\text { kar nekaj ovija 'was etwas } \\
\text { umwickelt' }\end{array}$ \\
\hline & & pismo 'Brief' \\
\hline & & denar 'Geld' \\
\hline \multicolumn{3}{|c|}{ SCHRIFTSPRACHE } \\
\hline Frequenz & 31 & 138 \\
\hline \multirow[t]{12}{*}{ Bezeichnungen } & plača 'Gehalt' & \\
\hline & podkupnina 'Bestechungsgeld' & \\
\hline & ponudba 'Angebot' & \\
\hline & odločba 'Beschluß' & \\
\hline & tajen 'geheim' & \\
\hline & \begin{tabular}{|l|}
$\begin{array}{l}\text { pregledati podatke 'Daten } \\
\text { durchsehen' }\end{array}$ \\
\end{tabular} & \\
\hline & pisemski ovitek 'Briefumschlag' & pisemski ovitek 'Briefumschlag' \\
\hline & pismo 'Brief' & pismo 'Brief' \\
\hline & & $\begin{array}{l}\text { kar nekaj ovija 'was etwas } \\
\text { umwickelt' }\end{array}$ \\
\hline & & $\begin{array}{l}\text { tkivo, ki kaj ovija 'Gewebe, das } \\
\text { etwas umwickelt' }\end{array}$ \\
\hline & & $\begin{array}{l}\text { črta, ki obdaja družino krivulj } \\
\text { 'Linie, die eine Familie von } \\
\text { Kurven umgibt' }\end{array}$ \\
\hline & & denar 'Geld' \\
\hline
\end{tabular}


Tabelle 2: Vergleich der Bezeichnungen und die Frequenz nach den funktionellen Sprachen für das Paar borba - boj

\begin{tabular}{|c|c|c|}
\hline & borba & boj \\
\hline Frequenz & 11 & 145 \\
\hline \multirow[t]{10}{*}{ Bezeichnungen } & $\begin{array}{l}\text { oborožen spopad 'bewaffneter } \\
\text { Zweikampf' }\end{array}$ & $\begin{array}{l}\text { oborožen spopad 'bewaffneter } \\
\text { Zweikampf' }\end{array}$ \\
\hline & $\begin{array}{l}\text { idejno nasprotovanje } \\
\text { 'Ideengegensatz' }\end{array}$ & $\begin{array}{l}\text { idejno nasprotovanje } \\
\text { 'Ideengegensatz' }\end{array}$ \\
\hline & prizadevanje 'Bestreben' & prizadevanje 'Bestreben' \\
\hline & $\begin{array}{l}\text { fizični spopad 'physischer } \\
\text { Zweikampf' }\end{array}$ & $\begin{array}{l}\text { fizični spopad 'physischer } \\
\text { Zweikampf' }\end{array}$ \\
\hline & $\begin{array}{l}\text { 2. svetovna vojna na naših tleh } \\
\text { '2. Weltkrieg auf unserem } \\
\text { Boden' }\end{array}$ & $\begin{array}{l}\text { 2. svetovna vojna na naših tleh } \\
\text { '2. Weltkrieg auf unserem } \\
\text { Boden' }\end{array}$ \\
\hline & & $\begin{array}{l}\text { verbalno nasprotovanje } \\
\text { 'verbaler Gegensatz' }\end{array}$ \\
\hline & & tekmovanje 'Wettkampf' \\
\hline & & preprečevanje 'Vorbeugung' \\
\hline & & $\begin{array}{l}\text { predvolilna kampanja } \\
\text { 'Wahlkampf' } \\
\end{array}$ \\
\hline & & $\begin{array}{l}\text { duhovni spopad 'geistiger } \\
\text { Zweikampf' }\end{array}$ \\
\hline \multicolumn{3}{|c|}{ PRESSESPRACHE } \\
\hline Frequenz & 4 & 256 \\
\hline \multirow[t]{8}{*}{ Bezeichnungen } & prizadevanje 'Bestreben' & prizadevanje 'Bestreben' \\
\hline & & $\begin{array}{l}\text { oborožen spopad 'bewaffneter } \\
\text { Zweikampf' }\end{array}$ \\
\hline & & $\begin{array}{l}\text { tekmovanje 'Wettkampf' } \\
\text { športno tekmovanje 'sportlicher } \\
\text { Wettkampf' } \\
\end{array}$ \\
\hline & & $\begin{array}{l}\text { predvolilna kampanja } \\
\text { 'Wahlkampf' } \\
\end{array}$ \\
\hline & & $\begin{array}{l}\text { idejno nasprotovanje } \\
\text { 'Ideengegensatz' }\end{array}$ \\
\hline & & preprečevanje 'Vorbeugung' \\
\hline & & preganjanje 'Bekämpfung' \\
\hline & & stavka 'Streik' \\
\hline
\end{tabular}

Philosophie

\begin{tabular}{l|l|l}
\hline Frequenz & 4 & 17 \\
\hline Bezeichnungen & tekmovanje 'Wettkampf' & \\
\hline & prizadevanje 'Bestreben' & prizadevanje 'Bestreben' \\
\hline & & $\begin{array}{l}\text { idejno nasprotovanje } \\
\text { 'Ideengegensatz' }\end{array}$ \\
\hline & & preprečevanje 'Vorbeugung' \\
\hline
\end{tabular}




\begin{tabular}{|c|c|c|}
\hline & & $\begin{array}{l}\text { 2. svetovna vojna na naših tleh } \\
\text { '2. Weltkrieg auf unserem } \\
\text { Boden' }\end{array}$ \\
\hline \multicolumn{3}{|l|}{ Psychologie } \\
\hline Frequenz & 13 & 35 \\
\hline \multirow[t]{7}{*}{ Bezeichnungen } & $\begin{array}{l}\text { oborožen spopad 'bewaffneter } \\
\text { Zweikampf' }\end{array}$ & \\
\hline & $\begin{array}{l}\text { fizični spopad 'physischer } \\
\text { Zweikampf' }\end{array}$ & \\
\hline & prizadevanje 'Bestreben' & prizadevanje 'Bestreben' \\
\hline & $\begin{array}{l}\text { idejno nasprotovanje } \\
\text { 'Ideengegensatz' }\end{array}$ & \begin{tabular}{|l} 
idejno nasprotovanje \\
'Ideengegensatz'
\end{tabular} \\
\hline & & $\begin{array}{l}\text { športno tekmovanje 'sportlicher } \\
\text { Wettkampf' }\end{array}$ \\
\hline & & agonija 'Agonie' \\
\hline & & $\begin{array}{l}\text { duhovni spopad 'geistiger } \\
\text { Zweikampf' }\end{array}$ \\
\hline \multicolumn{3}{|l|}{ Soziologie } \\
\hline Frequenz & 0 & 19 \\
\hline \multirow[t]{6}{*}{ Bezeichnungen } & & $\begin{array}{l}\text { oborožen spopad 'bewaffneter } \\
\text { Zweikampf' }\end{array}$ \\
\hline & & \begin{tabular}{|l|} 
idejno nasprotovanje \\
'Ideengegensatz' \\
\end{tabular} \\
\hline & & prizadevanje 'Bestreben' \\
\hline & & preprečevanje 'Vorbeugung' \\
\hline & & $\begin{array}{l}\text { fizični spopad 'physischer } \\
\text { Zweikampf' }\end{array}$ \\
\hline & & tekmovanje 'Wettkampf' \\
\hline \multicolumn{3}{|l|}{ Geschichte } \\
\hline & borba & boj \\
\hline Frequenz & 2 & 77 \\
\hline \multirow[t]{8}{*}{ Bezeichnungen } & $\begin{array}{l}\text { idejno nasprotovanje } \\
\text { 'Ideengegensatz', oborožen } \\
\text { spopad 'bewaffneter } \\
\text { Zweikampf' } \\
\end{array}$ & $\begin{array}{l}\text { idejno nasprotovanje } \\
\text { 'Ideengegensatz', oborožen } \\
\text { spopad 'bewaffneter } \\
\text { Zweikampf' } \\
\end{array}$ \\
\hline & & $\begin{array}{l}\text { oborožen spopad 'bewaffneter } \\
\text { Zweikampf' }\end{array}$ \\
\hline & & \begin{tabular}{|l|} 
idejno nasprotovanje \\
'Ideengegensatz' \\
\end{tabular} \\
\hline & & $\begin{array}{l}\text { 2. svetovna vojna na naših tleh } \\
\text { '2. Weltkrieg auf unserem } \\
\text { Boden' }\end{array}$ \\
\hline & & preprečevanje 'Vorbeugung' \\
\hline & & $\begin{array}{l}\text { fizični spopad 'physischer } \\
\text { Zweikampf' }\end{array}$ \\
\hline & & tekmovanje 'Wettkampf' \\
\hline & & prizadevanje 'Bestreben' \\
\hline
\end{tabular}




\begin{tabular}{|c|c|c|}
\hline \multicolumn{3}{|l|}{ Medizin } \\
\hline Frequenz & 5 & 50 \\
\hline \multirow[t]{4}{*}{ Bezeichnungen } & zdravljenje 'Heilung' & zdravljenje 'Heilung' \\
\hline & $\begin{array}{l}\text { preprečevanje bolezni } \\
\text { 'Krankheitsvorbeugung' }\end{array}$ & $\begin{array}{l}\text { preprečevanje bolezni } \\
\text { 'Krankheitsvorbeugung' }\end{array}$ \\
\hline & & prizadevanje 'Bestreben' \\
\hline & & $\begin{array}{l}\text { športno tekmovanje 'sportlicher } \\
\text { Wettkampf' }\end{array}$ \\
\hline \multicolumn{3}{|l|}{ Verwaltung } \\
\hline Frequenz & 13 & 35 \\
\hline \multirow[t]{6}{*}{ Bezeichnungen } & prizadevanje 'Bestreben' & prizadevanje 'Bestreben' \\
\hline & tekmovanje 'Wettkampf' & tekmovanje 'Wettkampf' \\
\hline & $\begin{array}{l}\text { idejno nasprotovanje } \\
\text { 'Ideengegensatz' }\end{array}$ & $\begin{array}{l}\text { idejno nasprotovanje } \\
\text { 'Ideengegensatz' }\end{array}$ \\
\hline & & preprečevanje 'Vorbeugung' \\
\hline & & $\begin{array}{l}\text { 2. svetovna vojna na naših tleh } \\
\text { ' } 2 \text {. Weltkrieg auf unserem } \\
\text { Boden' }\end{array}$ \\
\hline & & $\begin{array}{l}\text { oborožen spopad 'bewaffneter } \\
\text { Zweikampf' }\end{array}$ \\
\hline \multicolumn{3}{|c|}{ WISSENSCHAFTLICHE SPRACHE } \\
\hline Frequenz & 1 & 0 \\
\hline Bezeichnung & $\begin{array}{l}\text { oborožen spopad 'bewaffneter } \\
\text { Zweikampf' }\end{array}$ & \\
\hline \multicolumn{3}{|c|}{ LITERATURSPRACHE } \\
\hline Frequenz & 6 & 14 \\
\hline \multirow[t]{7}{*}{ Bezeichnungen } & rotenje 'Beschwörung' & \\
\hline & $\begin{array}{l}\text { zavzemanje 'Eintreten für } \\
\text { etwas' }\end{array}$ & \\
\hline & $\begin{array}{l}\text { fizični spopad 'physischer } \\
\text { Zweikampf' }\end{array}$ & $\begin{array}{l}\text { fizični spopad 'physischer } \\
\text { Zweikampf' }\end{array}$ \\
\hline & $\begin{array}{l}\text { duhovni spopad 'geistiger } \\
\text { Zweikampf' }\end{array}$ & $\begin{array}{l}\text { duhovni spopad 'geistiger } \\
\text { Zweikampf' }\end{array}$ \\
\hline & prizadevanje 'Bestreben' & prizadevanje 'Bestreben' \\
\hline & & agonija 'Agonie' \\
\hline & & preprečevanje 'Vorbeugung' \\
\hline \multicolumn{3}{|c|}{ SCHRIFTSPRACHE } \\
\hline Frequenz & 56 & 672 \\
\hline \multirow[t]{5}{*}{ Bezeichnungen } & $\begin{array}{l}\text { zavzemanje 'Eintreten für } \\
\text { etwas' }\end{array}$ & \\
\hline & rotenje 'Beschwörung' & \\
\hline & $\begin{array}{l}\text { oborožen spopad 'bewaffneter } \\
\text { Zweikampf' }\end{array}$ & $\begin{array}{l}\text { oborožen spopad 'bewaffneter } \\
\text { Zweikampf' }\end{array}$ \\
\hline & $\begin{array}{l}\text { idejno nasprotovanje } \\
\text { 'Ideengegensatz' }\end{array}$ & $\begin{array}{l}\text { idejno nasprotovanje } \\
\text { 'Ideengegensatz' }\end{array}$ \\
\hline & prizadevanje 'Bestreben' & prizadevanje 'Bestreben' \\
\hline
\end{tabular}




\begin{tabular}{l|l|l}
\hline & $\begin{array}{l}\text { fizični spopad 'physischer } \\
\text { Zweikampf' }\end{array}$ & $\begin{array}{l}\text { fizicni spopad 'physischer } \\
\text { Zweikampf' }\end{array}$ \\
\hline & $\begin{array}{l}\text { duhovni spopad 'geistiger } \\
\text { Zweikampf' }\end{array}$ & $\begin{array}{l}\text { duhovni spopad 'geistiger } \\
\text { Zweikampf' }\end{array}$ \\
\hline & $\begin{array}{l}\text { 2. svetovna vojna na naših tleh } \\
\text { '2. Weltkrieg auf unserem } \\
\text { Boden' }\end{array}$ & $\begin{array}{l}\text { 2. svetovna vojna na naših tleh } \\
\text { '2. Weltkrieg auf unserem } \\
\text { Boden' }\end{array}$ \\
\hline & tekmovanje 'Wettkampf' & tekmovanje 'Wettkampf' \\
\hline & zdravljenje 'Heilung' & zdravljenje 'Heilung' \\
\hline & $\begin{array}{l}\text { preprečevanje bolezni } \\
\text { 'Krankheitsvorbeugung' }\end{array}$ & $\begin{array}{l}\text { preprečevanje (bolezni) } \\
\text { '(Krankheits)vorbeugung' }\end{array}$ \\
\hline & & $\begin{array}{l}\text { verbalno nasprotovanje } \\
\text { 'verbaler Gegensatz' }\end{array}$ \\
\hline & & $\begin{array}{l}\text { predvolilna kampanja } \\
\text { 'Wahlkampf' }\end{array}$ \\
\hline & & $\begin{array}{l}\text { sportno tekmovanje 'sportlicher } \\
\text { Wettkampf' }\end{array}$ \\
\hline & & preganjanje 'Bekämpfung' \\
\hline & & agonija 'Agonie' \\
\hline & & stavka 'Streik' \\
\hline
\end{tabular}

Die im Korpus belegten Möglichkeiten für die Bezeichnung stimmen recht gut mit den entsprechenden Bedeutungserklärungen der einzelnen Wörter im SSKJ überein. Bei kuverta stimmen die Bezeichnungen für 'Briefumschlag', 'Gehalt' und 'Bestechungsgeld' mit den entsprechenden Paraphrasen im SSKJ überein, das SSKJ erwähnt jedoch nicht zwei im Korpus zu beobachtenden Weisen der metonymischen Bezeichnung (Teil für Ganzheit: 'Brief', und Verpackung für Inhalt: 'Angebot, Beschluß') sowie zwei phraseologische Verbindungen (biti zaprt $v$ kuverti 'verschlossen sein im Kuvert/Umschlag' für 'geheim' und odpreti kuverto 'Kuvert öffnen' für 'Daten durchsehen').

Bei ovojnica stimmen die Bezeichnungen 'Briefumschlag', 'was etwas umwickelt' und 'Gewebe, das etwas umwickelt' mit den entsprechenden Paraphrasen für die 1., 2. und 3. Bedeutung im SSKJ überein. Im Korpus sind auch alle terminologischen Arten der Verwendung außer der medizinischen und veterinären plodova ovojnica 'die Schafhaut' sowie zoologischen ovojnica 'Hundebandwurm' vertreten. Außerdem fehlen im Korpus auch Beweise für den phraseologischen Gebrauch von ovojnica für 'Gehalt/Einkommen' und 'Bestechungsgeld'. Im SSKJ dagegen sind die metonymische Verwendungen von ovojnica für 'Brief', 'Preisgeld' und 'Geld' (d. h. Teil : Ganzes, Verpackung : Inhalt) nicht erwähnt, welche wir im Korpus finden.

Bei borba stimmen die Bezeichnungen größtenteils mit der 1., 2. und 3. Bedeutung im SSKJ überein; in der oberen Tabelle ist die 3. lexikalische Bedeutung ('Bestreben zum Erreichen einer Absicht') genauer untergliedert hinsichtlich der Wirkung des Kontextes, und zwar auf: prizadevanje 'Bestreben', zdravljenje 'Heilung', preprečevanje (bolezni) '(Krankheits)vorbeugung', tekmovanje 'Wettkampf', 
zavzemanje 'Eintreten (für etwas)'. In der Tabelle sind mit den entsprechenden Paraphrasen auch die Bezeichnungen aufgeführt, welche wir im SSKJ dem Illustrationsmaterial entnehmen: duhovni spopad 'geistiger Zweikampf' für den im Wörterbuch erwähnten übertragenden Gebrauch doživlja hude notranje borbe 'durchlebt einen schweren inneren Kampf' sowie 2. svetovna vojna '2. Weltkrieg' für die Wortverbindung narodnoosvobodilna borba 'Volksbefreiungskampf'. Im Korpus gibt es nur für den 'Wahlkampf' (volilna borba) keinen Nachweis, der vom SSKJ erwähnt wird, dagegen ist es nicht möglich, aus dem Material im SSKJ die Verwendung des Ausdrucks borba als Bezeichnung für einen unbewaffneten 'physischen Zweikampf' herauszulesen.

In gleichem Maß und auf gleiche Weise stimmen auch die Erkenntnisse des SSKJ mit der vorliegenden Untersuchung des Wortes boj überein, nur daß bei der terminologischen Verwendung in der Geschichte anstatt des im Wörterbuch aufgeführten investiturni boj 'investiturischer Kampf' im Korpus ikonoklastični boji 'ikonoklastische Kämpfe' zu verzeichnen ist. Daraus geht zweierlei hervor: 1. das SSKJ führt als Bedeutungserklärung der behandelten lexikalischen Einheiten eine Synthese der Möglichkeiten für die Bezeichnungen auf und 2. die Größe des Korpus darf aufgrund der Übereinstimmungen mit dieser repräsentativen Beschreibung der slowenischen Sprache als ausreichend gewertet werden.

b) Die Übersicht der charakteristischen Determinatoren (ein wenig vereinfacht können wir auch von typischen Kollokationen sprechen) in Tabelle 3 und 4 zeigt bei beiden Paaren nur teilweise Übereinstimmung. Wenn wir diese Kollokationen im Sinne der Determinatoren von Coseriu untersuchen, können wir über das bloße Dokumentieren hinausgehen und mit deren Hilfe lexikalische Varianten aufdecken (verschiedene "Bedeutungen" eines Wortes - siehe Identifikatoren) sowie Eigenschaften und Besonderheiten, welche die Sprecher Sachen zuschreiben (Explikatoren und Spezifikatoren). Weil diese Operationen nach Coseriu 1975 die Integrierung der aktuellen Erkenntnis mit dem vorherigen Wissen ermöglichen, können wir auf der Ebene des Sinns im Zusammenhang mit der Funktion des Textes das Integrieren des Außersprachlichen in die sprachliche Nachricht beobachten (z. B. die Gründe betrachten für die Wahl der syntagmatisch ausgedrückten Information des Typs mesečna kuverta anstatt der entsprechenden paradigmatischen Struktur plaža 'Gehalt'). Damit wird ein immer noch unerforschtes Gebiet der Synonymwahl für funktionelle Untersuchungen aufgeschlossen. 
Tabelle 3: Vergleichende Übersicht der charakteristischen Determinatoren bei kuverta und ovojnica

\begin{tabular}{|c|c|c|}
\hline & kuverta & ovojnica \\
\hline Explikatoren & $\begin{array}{l}\text { modra kuverta 'blaues Kuvert' } \\
\text { zaprta kuverta 'verschlossenes } \\
\text { Kuvert' } \\
\text { zalepljena kuverta 'verklebtes } \\
\text { Kuvert' } \\
\end{array}$ & $\begin{array}{l}\text { debela ovojnica 'dicker } \\
\text { Umschlag' }\end{array}$ \\
\hline Spezialisatoren & bančna kuverta 'Bankkuvert' & $\begin{array}{l}\text { ovojnica poljubnega telesa } \\
\text { 'Umschlag eines beliebigen } \\
\text { Körpers' } \\
\text { ovojnica za naslednjo raven } \\
\text { 'Umschlag für die nächste } \\
\text { Ebene' }\end{array}$ \\
\hline Spezifikatoren & $\begin{array}{l}\text { zmečkana kuverta 'zerknittertes } \\
\text { Kuvert' } \\
\text { uniformirane kuverte } \\
\text { 'unifomierte Kuverte' } \\
\text { kuverta z... 'Kuvert mit...' } \\
\text { kuverte, v katerih... 'Kuverte, in } \\
\text { denen...' }\end{array}$ & $\begin{array}{l}\text { modra ovojnica 'blauer } \\
\text { Umschlag' } \\
\text { zapečatena ovojnica } \\
\text { 'versiegelter Umschlag' } \\
\text { fibrozna ovojnica 'fibröser } \\
\text { Umschlag' } \\
\text { zabrazgotinjena ovojnica } \\
\text { 'vernarbter Umschlag' } \\
\text { poliuretanska ovojnica } \\
\text { 'polyurethaner Umschlag' } \\
\text { ovojnica iz čvrste plastike } \\
\text { 'Umschlag aus festem } \\
\text { Kunststoff' } \\
\end{array}$ \\
\hline Identifikatoren & $\begin{array}{l}\text { mesečna kuverta 'Monatskuvert } \\
=\text { Gehalt' } \\
\text { plačilna kuverta } \\
\text { 'Zahlungskuvert = Gehalt' } \\
\text { kuverte s plačami } \\
\text { 'Gehaltskuverte = Gehalt' } \\
\text { kuverta s pisanjem } \\
\text { 'Schreibkuverte = Brief' }\end{array}$ & $\begin{array}{l}\text { ovojnica magnetofonskega } \\
\text { traku } \\
\text { 'Magnetophonbandumschlag' } \\
\text { pisemska ovojnica } \\
\text { 'Briefumschlag' } \\
\text { sklepna ovojnica } \\
\text { 'Gelenkumschlag = } \\
\text { Gelenkkapsel' } \\
\text { ovojnica kite 'Sehnenumschlag } \\
\text { = Sehnenüberzug' } \\
\text { mišična ovojnica } \\
\text { 'Muskelumschlag = } \\
\text { Muskelhaut' } \\
\text { kostna ovojnica } \\
\text { 'Knochenumschlag = } \\
\text { Knochenhaut' }\end{array}$ \\
\hline
\end{tabular}

Die Explikatoren (moder 'blau', zaprt 'verschlossen', zalepljen 'verklebt') zeigen, daß die Eigenschaften von kuverta hauptsächlich die Farbe und das, daß es zugeklebt/verschlossen werden kann, sind. Bei ovojnica ist das Adjektiv debel 'dick' wahrscheinlich der einzige Explikator im Korpus, denn nur diese Eigenschaft können wir als gemeinsam allen oder zumindestens der Mehrheit der Umschläge werten 
(natürlich auch mit dem entsprechenden Antonym ausgedrückt oder nicht besonders ausgedrückt wegen des neutralen Grades dieser Eigenschaft). Die Adjektive moder 'blau' und zalepljen 'verklebt', zapečaten 'versiegelt', zaprt 'verschlossen', die bei kuverta die Eigenschaft betonen, treten bei ovojnica in der Funktion von Spezifikatoren auf - sei es als distinktiver oder informativer. Die Spezifikatoren, die ovojnica determinieren, bestimmen besondere Eigenschaften, die kleinere Klassen innerhalb der Klasse der ovojnica eingrenzen. Wir können sie aufgliedern in solche, die sich auf das äußere Aussehen (insbesondere Farbe) beziehen, Material, aus welchem ein bestimmter Umschlag besteht (Papier, Plastik, menschliches Gewebe) und die Funktion, die ein Umschlag ausübt (für die Aufbewahrung von Geld, die Pflege von Kontakten mit anderen, den Schutz von Sachen...). Die Ambiguität bei kuverta wird nur von den Identifikatoren des Typs mesečna/plačilna kuverta (wörtlich 'Monats-/Gehaltskuvert' für 'Gehalt') sowie kuverta s pisanjem (wörtlich 'Schreibkuvert' für 'Brief') begrenzt. Bei ovojnica treten in dieser Rolle konkrete Sachen auf, die einen Umschlag haben: Das sind Briefe und verschiedene andere Gegenstände, zu denen ein Umschlag gehört, obwohl die Unterscheidung von der ersten Gruppe manchmal fragwürdig ist.

Tabelle 4: Vergleichende Übersicht der charakteristischen Determinatoren bei borba und boj

\begin{tabular}{|c|c|c|}
\hline & borba & $b o j$ \\
\hline Exsplikatoren & $\begin{array}{l}\text { oborožena borba 'bewaffneter } \\
\text { Kampf' } \\
\text { totalna borba 'totaler Kampf' } \\
\text { enakovredna borba } \\
\text { 'gleichwertiger Kampf' } \\
\text { brezobzirna borba } \\
\text { 'rücksichtsloser Kampf' }\end{array}$ & $\begin{array}{l}\text { oborožen boj 'bewaffneter Kampf' } \\
\text { hud boj 'schlimmer Kampf' } \\
\text { zagrizeni boji 'verbissener Kampf' } \\
\text { razdiralni boji 'zerstörerischer Kampf' } \\
\text { težak boj 'schwerer Kampf' } \\
\text { lahek boj 'leichter Kampf' } \\
\text { oster boj 'scharfer Kampf' } \\
\text { zaostren boj 'verschärfter Kampf' } \\
\text { srditi boji 'verbissene Kämpfe' } \\
\text { silovit boj 'gewaltiger Kampf' } \\
\text { veliki boji ' 'große Kämpfe' } \\
\text { neenak boj 'ungleicher Kampf' } \\
\text { krajši boj 'kurzer Kampf' } \\
\text { dolgotrajen boj 'langhaltender Kampf' } \\
\text { uspešen boj 'erfolgreicher Kampf' } \\
\text { nesmiseln boj 'unsinniger Kampf' } \\
\text { brezupen boj 'hoffnungsloser Kampf' }\end{array}$ \\
\hline Spezifikatoren & $\begin{array}{l}\text { borba za obstanek 'Kampf ums } \\
\text { Überleben' } \\
\text { borba za obstoj 'Kampf ums } \\
\text { Überleben' } \\
\text { borba z dogmatskimi silami } \\
\text { 'Kampf gegen Dogmatiker' } \\
\text { borba z aidsom 'Kampf gegen } \\
\text { Aids' } \\
\text { borba proti aidsu 'Kampf gegen } \\
\text { Aids' }\end{array}$ & $\begin{array}{l}\text { boj za obstanek 'Kampf ums Überleben' } \\
\text { boj za obstoj 'Kampf ums Überleben' } \\
\text { boj med spoloma 'Geschlechterkampf' } \\
\text { boj proti aidsu 'Kampf gegen Aids' } \\
\text { boj proti bolezni 'Kampf gegen Krankheit' } \\
\text { boj proti muslimanom 'Kampf gegen } \\
\text { Moslems' } \\
\text { ikonoklastični boji 'ikonoklastische Kämpfe' } \\
\text { boj zoper reformatorje 'Kampf gegen die } \\
\text { Reformatoren' }\end{array}$ \\
\hline
\end{tabular}




\begin{tabular}{|c|c|c|}
\hline & $\begin{array}{l}\text { borba proti bolezni 'Kampf } \\
\text { gegen Krankheit' } \\
\text { osvobodilna borba } \\
\text { 'Befreiungskampf' } \\
\text { borba za delovno mesto 'Kampf } \\
\text { um einen Arbeitsplatz' } \\
\text { borba za prestol 'Kampf um den } \\
\text { Thron' } \\
\text { borba za pravice slov. manjšin } \\
\text { 'Kampf um die Rechte der } \\
\text { slowenischen Minderheiten' } \\
\text { borba delavskega razreda } \\
\text { 'Kampf der Arbeiterklasse' } \\
\text { borba proti določenim željam } \\
\text { 'Kampf gegen bestimmte } \\
\text { Wünsche' } \\
\text { borba za preživetje 'Kampf ums } \\
\text { Überleben' } \\
\text { borba za zaščito živali 'Kampf } \\
\text { um den Tierschutz' } \\
\text { borba za naklonjenost vodje } \\
\text { 'Kampf um die Gunst des } \\
\text { Führers' } \\
\text { borba sindikatov 'Kampf der } \\
\text { Gewerkschaften' } \\
\text { borba s kačo 'Kampf mit der } \\
\text { Schlange' } \\
\text { borba z levom 'Kampf mit dem } \\
\text { Löwen' } \\
\text { borba proti medvedu 'Kampf } \\
\text { gegen den Bären'lange' }\end{array}$ & $\begin{array}{l}\text { boj zoper Turke 'Kampf gegen die Türken' } \\
\text { boj proti kajenju 'Kampf gegen das Rauchen' } \\
\text { nacionalni boj 'nationaler Kampf' } \\
\text { frakcijski boji 'Fraktionskämpfe' } \\
\text { strankarski boji 'Parteienkämpfe' } \\
\text { politični boj 'politischer Kampf' } \\
\text { verski boj 'Glaubenskampf' } \\
\text { interesni boji 'Interessenskampf' } \\
\text { boj proti kriminalu 'Kampf gegen } \\
\text { Kriminalität' } \\
\text { boj proti inflaciji 'Kampf gegen die Inflation' } \\
\text { boj za svobodo 'Freiheitskampf' } \\
\text { boji v Čečeniji 'Kämpfe in Tschetschenien' } \\
\text { boj proti komunizmu 'Kampf gegen den } \\
\text { Kommunismus' } \\
\text { boj za avtonomijo 'Kampf um Autonomie' } \\
\text { boj za oblast 'Machtkampf' } \\
\text { boj za lastnino 'Kampf um Eigentum' } \\
\text { boj za identiteto 'Kampf um Identität' } \\
\text { naslednji boj 'nächster Kampf' } \\
\text { zaporedni boj 'aufeinanderfolgender Kampf' } \\
\text { boj za golo preživetje 'Kampf ums nackte } \\
\text { Überleben' }\end{array}$ \\
\hline Identifikatoren & $\begin{array}{l}\text { razredna borba 'Klassenkampf' } \\
\text { borba proti okupatorju 'Kampf } \\
\text { gegen Okkupator' } \\
\text { konkurenčna borba } \\
\text { 'Konkurrenzkampf' } \\
\text { poulična borba 'Straßenkampf' } \\
\text { narodnoosvobodilna borba } \\
\text { 'Volksbefreiungskampf' } \\
\text { borba od blizu 'Nahkampf' } \\
\text { borba z bajoneti 'Kampf mit } \\
\text { Bajonetten' } \\
\text { borba za gradnjo proge 'Kampf } \\
\text { um den Bau einer Strecke' }\end{array}$ & $\begin{array}{l}\text { razredni boj 'Klassenkampf' } \\
\text { boj z okupatorjem 'Kampf mit dem } \\
\text { Okkupator' } \\
\text { konkurenčni boj 'Konkurrenzkampf' } \\
\text { poulični boj 'Straßenkampf' } \\
\text { narodnoosvobodilni boj } \\
\text { 'Volksbefreiungskampf' } \\
\text { notranji boj 'innerer Kampf' } \\
\text { krvav boj 'blutiger Kampf' } \\
\text { partizanski boj 'Partisanenkampf' } \\
\text { idejni boj 'Ideenkampf' } \\
\text { intelektualni boj 'intellektueller Kampf' } \\
\text { boj za naslov svetovnega prvaka 'Kampf um } \\
\text { den Weltmeistertitel' } \\
\text { boj proti fašizmu 'Kampf gegen Faschismus' } \\
\text { sportni boj 'sportlicher Kampf' } \\
\text { predvolilni boj 'Wahlkampf' } \\
\text { volilni boj 'Wahlkampf' } \\
\text { gladiatorski boj 'Gladiatorkampf' } \\
\text { boj za pravo refleksijo 'Kampf um die wahre } \\
\text { Reflexion' } \\
\text { smrtni boj 'Todeskampf' }\end{array}$ \\
\hline
\end{tabular}




\begin{tabular}{|l|l|}
\hline & $\begin{array}{l}\text { petelinji boji 'Hahnenkampf' } \\
\text { boji na zahodni fronti 'Kämpfe an der } \\
\text { Westfront' } \\
\text { boj s kilogrami 'Kampf mit Kilogrammen' } \\
\text { boji z minometi 'Kämpfe mit Minenwerfern' } \\
\text { parlamentarni boj 'parlamentarischer Kampf' } \\
\text { sindikalni boj 'Gewerkschaftskampf' } \\
\text { zakulisni boj 'Kampf hinter den Kulissen' }\end{array}$ \\
\hline
\end{tabular}

Die Unterscheidung zwischen den einzelnen Typen von Determinatoren, die zusammen mit den Lexemen borba und boj auftreten, war oft zweifelhaft. Bei der Einreihung der Determinatoren in einzelne Gruppen wurde zum entscheidenden Kriterium die Unterscheidung zwischen Beispielen, wo schon der Determinator selbst die Form/Art des Kampfes bestimmt (d. h. die potentielle Mehrdeutigkeit eingrenzt, folglich ist er als Identifikator gebraucht), und Beispielen, wo für eine solche Bestimmung ein zusätzliches Wirken der Umfelder nötig ist. In solchen Fällen können wir die Determinierung als Zugabe von Zügen verstehen, die nicht Teil der Bedeutung des Zeichens sind, sondern Besonderheiten bezeichnen (Spezifikatoren). Fragwürdig sind Spezialisatoren, wo eine Entscheidung gefällt werden müßte, ob man von einer einheitlichen Klasse borba bzw. boj sprechen kann, von denen wir einen Gesichtspunkt mit der Spezialisierung von den restlichen Gesichtspunkten abgrenzen können, ohne daß wir damit zugleich schon die lexikalische Variante bestimmen würden (vgl. in diesem Sinne z. B. Kampf ums Überleben, Machtkampf, Kampf um den zweiten Platz). Die Frage bleibt offen für weiteres Nachdenken und aus diesem Grunde sind Spezialisatoren in der Tabelle nicht gesondert aufgeführt.

Bei der Annahme der oberen Kriterien können wir auf der Grundlage der im Korpus notierten Explikatoren zu den Eigenschaften von borba und boj den Gebrauch (oder Nicht-Gebrauch) von Waffen (die Waffen können verschiedener Art sein, die Art der Waffe ist ein Identifikator, der die lexikalische Variante bestimmt), den Stärkegrad (brezobzirna borba 'rücksichtsloser Kampf', hud/težak/lahek/zaostren... boj 'schlimmer/schwerer/leichter/verschärfter... Kampf') sowie das Kräfteverhältnis zwischen den Gegnern (enakovredna borba 'gleichwertiger Kampf', neenak boj 'ungleicher Kampf') zählen. Bei boj decken die Explikatoren auch die zeitliche Dimension (krajši/dolgotrajen boj 'kürzerer/langanhaltender Kampf') und die Dimension des Resultats (nesmiseln boj 'unsinniger Kampf', boj $z$ mlini na veter 'Kampf mit Windmühlen', brezupen boj 'hoffnungsloser Kampf') auf, was wir bei borba im Korpus nicht vorfinden; unter den möglichen Gründen dafür dürfen wir jedoch nicht die niedrige Frequenz dieses Wortes übersehen. Unter den Spezifikatoren finden wir sowohl bei borba als auch bei boj solche, die ein Ziel bestimmen (osvobodilna borba 'Befreiungskampf', borba za naklonjenost vodje 'Kampf um die Gunst des Führers'...; boj za svobodo 'Freiheitskampf', boj za lastnino/preživetjel identiteto 'Kampf um Eigentum/Überleben/ Identität'...), dann solche, die einen Gegner bestimmen (in beiden Fällen kann das ein Lebewesen, eine Idee, eine Krankheit, eine ideologische oder andersartige Gruppe sein: borba $z$ dogmatskimi 
silami 'Kampf gegen Dogmatiker'; boj med spoloma 'Kampf zwischen den Geschlechter', boj proti muslimanom 'Kampf gegen Moslems', nacionalni boj 'nationaler Kampf') oder eine negative gesellschaftliche Erscheinung wie Alkoholismus, Kindersterblichkeit, Blockeinteilung der Welt, Korruption... Die Besonderheit von boj liegt darin, daß es zusammen mit Spezifikatoren verwendet wird, die auf eine frequentative Wiederholung hinweisen (zaporedni boji 'aufeinanderfolgende Kämpfe', naslednji boj 'nächster Kampf', novi boji 'neue Kämpfe'...) sowie zusammen mit Spezifikatoren, die einen Ort bestimmen, wo sich der Kampf abwickelt, inwieweit sie zugleich nicht die lexikalischen Varianten bedingen (vgl. z. B. zakulisni boj 'Kampf hinter den Kulissen' : boji v Čečeniji 'Kämpfe in Tschetschenien'). Zu den Identifikatoren gehören ohne Zweifel Waffenarten (borba $z$ bajoneti 'Kampf mit Bajonetten'; boji z minometi 'Kämpfe mit Minenwerfern'), in gleicher Funktion können auch Kategorien auftreten, die bei den Spezifikatoren aufgeführt sind (Ziel, Gegner, Ort), jedoch nur in Fällen, wo davon unbedingt eine bestimmte Art der borba oder boj abhängt (konkurenčna borba/boj 'Konkurrenzkampf', poulična borba/boj 'Straßenkampf', borba od blizu 'Nahkampf', medfevdalna borba 'zwischenfeudaler Kampf', borba za gradnjo proge 'Kampf um den Bau einer Strecke'; razredni boj 'Klassenkampf', petelinji boj 'Hahnenkampf', partizanski boj 'Partisanenkampf', boj za pravo refleksijo 'Kampf um die wahre Reflexion', predvolilni boj 'Wahlkampf', smrtni boj 'Agonie', boji na zahodni fronti 'Kämpfe an der Westfront', parlamentarni boj 'parlamentarischer Kampf' ...).

Im Rahmen der Regionen treten Politik, Marxismus und Biologie (Darvinismus) in der Funktion des Bereiches auf, sowohl bei borba als auch bei boj (Machtkampf, Klassenkampf und Kampf um das Überleben sind in diesen Bereichen vertraute Elemente der Lebenswelt oder des Wissens der Sprecher). Unterschiede sind jedoch in der Umgebung zu finden. Während boj nicht an eine bestimmte Umgebung gebunden ist, wird bei borba auf der Sinnebene mehrmals das Wissen genutzt, daß dieser Ausdruck von bestimmten sozialen Gruppen verwendet wird, insbesondere von Aktivisten, Revolutionären oder Angehörigen der ehemaligen Jugoslawischen Volksarmee. Genauso kann er eine soziale Schicht evozieren, die mit der Norm der slowenischen Sprache nicht vertraut ist. Eine spezifische Region stellt dagegen bei boj der Sport dar.

c) Die Präferenzen bei der Wahl der einzelnen Glieder sind in verschiedenen funktionellen Sprachen unterschiedlich (siehe Tabelle 5, 6). Errechnet sind sie auf der Grundlage der relativen Häufigkeit der Wahl zwischen den einzelnen Gliedern. Aus den Daten über die Präferenzen können wir im Zusammenhang mit der Funktion der Wahl im Text (siehe Punkt 4.4.3 weiter unten) die Norm der einzelnen funktionellen Sprachen beurteilen. 
Tabelle 5: Präferenzen in verschiedenen funktionellen Sprachen und die relative Häufigkeit der Wahl zwischen kuverta und ovojnica

\begin{tabular}{|l|l|l|l|}
\hline funktionelle Sprache & Bezeichnung & Präferenzen & Anteil in \% \\
\hline Alltagssprache & $\begin{array}{l}\text { pisemski ovitek } \\
\text { 'Briefumschlag' }\end{array}$ & ovojnica & 63 \\
\hline Pressesprache & $\begin{array}{l}\text { pisemski ovitek } \\
\text { 'Briefumschlag' }\end{array}$ & kuverta & 70 \\
\hline Verwaltungssprache & $\begin{array}{l}\text { pisemski ovitek } \\
\text { 'Briefumschlag' }\end{array}$ & kuverta & 66 \\
\hline Literatursprache & $\begin{array}{l}\text { pisemski ovitek } \\
\text { 'Briefumschlag' }\end{array}$ & ovojnica & 85 \\
\hline
\end{tabular}

Die Tabelle 5 zeigt, daß in der Alltagssprache sowohl kuverta als auch ovojnica gebraucht werden. Relativ häufiger tritt zwar ovojnica auf, jedoch hat diese Auswahl selten eine redundante Funktion. ${ }^{46}$ Die Norm gibt wohl kuverta den Vortritt. Die Erkenntnisse der Analyse auf der Ebene der Bezeichnung stimmen gänzlich mit der Beschreibung dieses Sprachtyps in Pogorelec 1986 überein: Der Sprachtyp erlaubt zwar ein beliebiges Verhältnis der lexikalischen Elemente zu dem Bezeichneten (vgl. dazu die metonymischen Benennungen in Tabelle 1), jedoch ist die semantische Ebene einheitlich. Die Verständlichkeit ist situationsbedingt, die bei geschriebenen Texten natürlich mit einem Redekontext geschaffen werden muß: vgl. dazu z. B. ovojnica magnetofonskega traku 'Umschlag eines magnetophonischen Bandes' in der Tabelle 3. In der Pressesprache wird häufiger kuverta verwendet, die Norm ist jedoch aus den analysierten Daten nicht erkennbar. Beide Ausdrücke werden nämlich in diesem Sprachstil meistens funktionell gebraucht. Die vorwiegend metonymischen Bezeichnungen (s. Tabelle 1) beweisen das willkürliche Verhältnis der lexikalischen Elemente zum Bezeichneten, die Verständlichkeit kann durch die Aktualisierung gegeben sein. In der Computersprache können wir auf der Grundlage der statistischen Daten auf die Präferenzen von ovojnica schließen, während der Norm etwa kuverta entspricht (die Auswahl von ovojnica ist in den analysierten Beispielen nie redundant). Hinsichtlich des Typs ist das Verhältnis der lexikalischen Einheiten zum Bezeichneten von der Konvention bestimmt, die Metapher dient dabei als Veranschaulichung. In der Verwaltungssprache sind Präferenzen für die Wahl von kuverta bemerkbar. Das Korpus ist für das Feststellen der Norm dieser Sprache entscheidend zu klein, gleiches gilt für den Typ. In der Literatursprache wird ovojnica häufiger gebraucht, was wohl auch in Einklang mit der Norm dieser Sprache ist (hier ist die Auswahl von kuverta funktionell). Der Typ läßt eine Mehrdeutigkeit (vgl. die Bezeichnungen in der Tabelle 1) und ein willkürliches Verhältnis der lexikalischen Einheiten zu dem Bezeichneten zu. Die Klarheit ist mit der Struktur des literarischen Werkes und seinen literarischen den Beispielen aus den Texten begründet, die an dieser Stelle nicht aufgeführt werden können. $\mathrm{Zu}$ den Feststellungen über Präferenzen und Norm vgl. Zorman 1997: $111 \mathrm{f}$. und 170. 
Aktualisierungen bestimmt. In den übrigen funktionellen Sprachen gibt es keine Möglichkeit für die Identität in der Bezeichnung bei den Lexemen kuverta und ovojnica (s. Tabelle 1), deshalb ist es nicht möglich, über Präferenzen zu sprechen.

Tabelle 6: Präferenzen in verschiedenen funktionellen Sprachen und die relative Häufigkeit der Wahl zwischen borba und boj

\begin{tabular}{|c|c|c|c|}
\hline $\begin{array}{l}\text { funktionelle } \\
\text { Sprache }\end{array}$ & Bezeichnung & Präferenzen & Anteil in \% \\
\hline Alltagssprache & $\begin{array}{l}\text { oborožen spopad 'bewaffneter Zweikampf' } \\
\text { idejno nasprotovanje 'Ideengegensatz' } \\
\text { prizadevanje 'Bestreben' } \\
\text { fizični spopad 'physischer Zweikampf' } \\
\text { 2. svetovna vojna }\end{array}$ & $\begin{array}{l}b o j \\
b o j \\
b o j \\
b o j \\
b o r b a\end{array}$ & $\begin{array}{l}97 \\
97 \\
62 \\
66 \\
60\end{array}$ \\
\hline Pressesprache & prizadevanje 'Bestreben' & $b o j$ & 96 \\
\hline $\begin{array}{l}\text { Fachsprache - } \\
\text { Philosophie }\end{array}$ & prizadevanje 'Bestreben' & $b o j$ & 71 \\
\hline $\begin{array}{l}\text { Fachsprache - } \\
\text { Psychologie }\end{array}$ & prizadevanje 'Bestreben' & $b o j$ & 57 \\
\hline $\begin{array}{l}\text { Fachsprache - } \\
\text { Geschichte }\end{array}$ & $\begin{array}{l}\text { idejno nasprotovanje 'Ideengegensatz', oborožen } \\
\text { spopad 'bewaffneter Zweikampf' }\end{array}$ & $b o j$ & 84 \\
\hline $\begin{array}{l}\text { Fachsprache - } \\
\text { Medizin }\end{array}$ & $\begin{array}{l}\text { zdravljenje 'Heilung' } \\
\text { preprečevanje 'Vorbengung' }\end{array}$ & $\begin{array}{l}b o j \\
b o j\end{array}$ & $\begin{array}{l}90 \\
84\end{array}$ \\
\hline $\begin{array}{l}\text { Verwaltungs- } \\
\text { sprache }\end{array}$ & $\begin{array}{l}\text { idejno nasprotovanje 'Ideengegensatz' } \\
\text { prizadevanje 'Bestreben' } \\
\text { tekmovanje 'Wettkampf' }\end{array}$ & $\begin{array}{l}b o j \\
b o j \\
b o j\end{array}$ & $\begin{array}{l}66 \\
68 \\
90\end{array}$ \\
\hline Literatursprache & $\begin{array}{l}\text { fizični spopad 'physischer Zweikampf' } \\
\text { duhovni spopad 'geistiger Zweikampf' } \\
\text { prizadevanje 'Bestreben' }\end{array}$ & $\begin{array}{l}\text { boj } \\
? \\
?\end{array}$ & $\begin{array}{l}87 \\
50 \\
50\end{array}$ \\
\hline
\end{tabular}

In allen Systemen der geschriebenen Sprache sind Präferenzen für die Wahl des Wortes boj zu bemerken, welches auch spürbar häufiger in der redundanten Funktion auftritt. Das heißt, daß boj wohl auch mit der Norm der entsprechenden Systeme zusammenfällt. Die einzige Ausnahme stellt die häufige Wahl von borba für die Bezeichnung des 2. Weltkrieges in der Alltagssprache dar, weil aber diese Wahl redundant nur im Rahmen bestimmter Arten von Texten ist, stimmt wahrscheinlich boj auch in diesem Fall mit der Norm überein. Gleich ist die Norm auch für die Bezeichnung einer physischen oder geistigen Auseinandersetzung in der Literatursprache, wo es nicht möglich ist, auf der Grundlage von Belegen im Korpus Präferenzen zu bestimmen, doch ist borba anscheinend immer funktionell gebraucht.

\subsubsection{Bedeutungsebene}

a) Auf der Ebene der Bedeutung, d. h. des Inhalts im sprachlichen System, sind die Verhältnisse zwischen beiden Gliedern unterschiedlich in verschiedenen funktionellen Sprachen (siehe Tabelle 7, 8). 
Tabelle 7: Identifizierung von Einheiten in den Systemen funktioneller Sprachen für kuverta und ovojnica

\begin{tabular}{|l|l|}
\hline funktionelle Sprache & strukturelle Beziehung \\
\hline Alltagssprache & Oppositionen \\
\hline Pressesprache & Invariante \\
\hline Fachsprache & Diversitäten/Oppositionen \\
\hline wissenschaftliche Sprache & Diversitäten \\
\hline Literatursprache & Oppositionen \\
\hline
\end{tabular}

Tabelle 8: Identifizierung von Einheiten in den Systemen funktioneller Sprachen für borba und $b o j$

\begin{tabular}{|l|l|}
\hline funktionelle Sprache & strukturelle Beziehung \\
\hline Alltagssprache & Invariante \\
\hline Pressesprache & Oppositionen \\
\hline Fachsprache & Diversitäten/Oppositionen \\
\hline Literatursprache & Oppositionen \\
\hline
\end{tabular}

Die Identifizierung von Einheiten mit Hjelmslevs Kommutationprobe beweist, daß borba und boj vom Gesichtspunkt des Inhalts eine einzige Invariante nur in der Alltagssprache darstellen, kuverta und ovojnica jedoch nur in der Pressesprache (nicht berücksichtigt wurden selbstverständlich Eigennamen, Termini sowie Einheiten der wiederholten Rede). In der Pressesprache sind borba und boj Oppositionen wegen des Gebrauchs von boj für die Bezeichnung eines sportlichen Wettkampfes und in der Literatursprache wegen des Gebrauchs der gleichen Einheit für die Bezeichnung des Sterbens, der Agonie (smrtni boj). In den Fachsprachen treten zwar beide Einheiten auf, die Entscheidung, ob es sich um Oppositionen oder Diversitäten handelt, ist jedoch auf der Grundlage der Belege im Korpus aus folgenden zwei Gründen ungewiß: Diese zwei Wörter werden in den Texten oft außerhalb ihrer Region gebraucht und borba tritt oft in ursprünglich gesprochenen Texten auf (siehe Zorman 1997: 171). Die Umformung dieser Texte in die schriftliche Form sowie die Wahl von borba in ursprünglich geschriebenen Texten beweist in vielen Fällen eine niedrige Stufe der expressiven Kompetenz des Autors (vgl. ebd.). Bei dem Paar kuverta - ovojnica ist der Unterschied in der Form verbunden mit dem Unterschied im Inhalt in der Alltagssprache sowie in der Literatursprache in Fällen, wo die lexikalische Einheit ovojnica für die Bezeichnung dessen gebraucht wird, was etwas umwickelt, jedoch geht es hierbei nicht um einen Brief (vgl. z. B. ovojnica revije 'Umschlag einer Zeitschrift'). Die Einheiten sind also Oppositionen. In der Fachsprache richtet sich das Verhältnis je nach der Fachrichtung. In der Sprache der Medizin oder Biologie tritt selbstverständlich nur ovojnica auf (z. B. mišična ovojnica 'Muskelhaut', sklepna ovojnica 'Gelenkkapsel'). Hier sind die beiden Einheiten nicht vergleichbar, denn sie gehören verschiedenen Systemen an. Die Mannigfaltigkeit dieser Verhältnisse beweist, 
daß die Annahme, daß z. B. zwei Ausdrücke im Slowenischen überall "absolut synonym" sind, viel zu vereinfacht ist. Wenn wir ausschließlich die Beziehungen im System berücksichtigen, wäre dies bei den behandelten Paaren nur in dem Fall von Invarianz zulässig.

b) Die Erforschung der kategoriellen Bedeutung, der Motiviertheit und der möglichen Assoziationen zwischen den Wörtern deckt beim Paar kuverta - ovojnica einen Unterschied im Ursprung auf. Kuverta ist mit dem Deklinationssuffix - $a$ aus dem französischen couvrir, couvert gebildet, welches für die Bezeichnung des Briefumschlags auch in anderen Sprachen verwendet wird. Wegen seines Ursprungs kann es vom Sprachpurismus gefährdet werden. Ovojnica ist dagegen mit dem Suffix -nica aus dem Postverbal ovoj zu oviti 'winden, wickeln' abgeleitet. Die Wurzel können wir bis zum indogermanischen *uei- zurückverfolgen (Skok 1973: $600 \mathrm{f}$ ), deshalb können wir ovojnica zu den echten slowenischen Wörtern zählen. Das Suffix selbst dient zur Bildung von Nomina weiblichen Geschlechts und hat nach Bajec 1950: 102-5 keine spezifische Bedeutung. Nach Toporišič 1984: 124 ff. wird es für die Ableitung von Substantiven weiblichen Geschlechts gebraucht, die den Agens, Gegenstand, Ort usw. bezeichnen. So ist in den Texten, wo eine von diesen lexikalischen Einheiten gebraucht wird, die latent vorhandene Möglichkeit gegeben, daß sich bei kuverta der fremde Ursprung aktualisiert, bei ovojnica jedoch die Assoziationen mit oviti, ovijati, ovoj sowie mit irgendeiner von Toporišič angeführten Bedeutungsgruppe von Substantiven auf -nica oder sogar mit Deminutiven auf $-i c a{ }^{47}$

Borba und boj sind Nomina actionis. Borba gehört zum Verb boriti se, borim se 'kämpfen', das als primäres oder denominales Verb sonst allgemein slawisch ist, aber im Slowenischen jedoch nur neuschriftsprachlich belegt (vgl. Bezlaj 1977: 34, Berneker 1908-1913: 76, Skok 1971: 189). Obwohl -ba im Slowenischen ein immer noch produktives Formans für deverbale Nomina ist, hält Bajec 1950: 78 das Wort borba für einen Serbokroatismus. Im Gegensatz dazu ist es bei boj nicht möglich, den einheimischen Ursprung in Frage zu stellen: Das Wort ist mit dem Deklinationssuffix aus der o-Stufe derselben Wurzel, wie ihn das allgemeinslawische, und auch slowenische Verb biti, bijem 'schlagen' aufweist, gebildet (Bezlaj ebd. 23, Berneker ebd. 68, Skok ebd. 161 ff.). Keine von den beschriebenen Bildungweisen ist mit der spezifischen Bedeutung verbunden, deshalb sind Assoziationen dieses Typs in den Texten ausgeschlossen, es kann jedoch zu Assoziationen im Rahmen der Wortfamilie kommen. Bei borba geht es um Assoziationen mit dem oben erwähnten Verb boriti se, borim se und allen Ableitungen davon (s. Bezlaj, 1. zit.) sowie um Assoziationen mit den Komposita des Typs bikoborba 'Stierkampf', rokoborba 'Ringkampf' usw. Boj hat eine noch größere Wortfamilie als borba (vgl. die Angaben in den oben erwähnten etymologischen Wörterbüchern). Einen Unterschied zwischen den beiden Ausdrücken gibt es auch in der instrumentalen Bedeutung (weibliches : männliches Geschlecht); als 
Beispiel der funktionellen Ausnutzung dieses Unterschiedes siehe Zorman 1997: 137, Beispiel (72).

c) Die Bedeutung der behandelten Wörter wurde mit einer Computeranalyse der Distribution nach der Methode von H. J. Heringer untersucht sowie schematisch in der Form eines Bedeutungsfeldes vorgestellt. Mit Hilfe der Kondensate aus den Redekontexten wurde nicht der Inhalt der Bedeutung beschrieben, sondern nur der Platz identifiziert, den eine lexikalische Einheit im Rahmen des Systems einnimmt. Weil die Feststellungen über die Bedeutung der untersuchten Einheiten, wie bereits erwähnt, in einem besonderen Artikel vorgestellt werden, sind sie in der vorliegenden Übersicht weggelassen worden.

\subsubsection{Die Ebene des Sinnes}

a) Redundante Funktion der Auswahl

Kuverta wird in den Texten in $29 \%$ aller Vorkommen redundant gebraucht, und zwar ohne Ausnahme als Bezeichnung für einen Briefumschlag in Kontexten über die Korrespondenz. Ein anderer thematischer Kontext (z. B. Geld oder Amtsgeschäfte) kann auch bei dieser Bezeichnung schon zu den Evokationen beitragen, die unten in Tabelle 9 aufgezeigt sind.

Ovojnica wird in fast $70 \%$ der Fälle $(69,5 \%)$ redundant gebraucht, jedoch muß ein solcher Stand im Korpus dem zahlenmäßigen Vorherrschen von populärwissenschaftlichen medizinischen Texten (55\% der Fälle) zugerechnet werden. Mit der Ausnahme eines einzigen Falles, wo ovojnica in redundanter Funktion als Bezeichnung für 'Briefumschlag' in einem Amtstext verwendet wird (Beispiel (2) oben), wird es in allen anderen Fällen in solcher Funktion als Bezeichnung für 'was etwas umwickelt' gebraucht. Andere Fälle der Verwendung von ovojnica für die Bezeichnung eines 'Briefumschlags' zeigen auf eine funktionelle Ausnutzung der Bezeichnung. Diese kann die Beziehung Autor - Adressat oder Autor - Thema indizieren oder auf eine geringere Stufe der expressiven Kompetenz des Autors weisen; solche Fälle wären im Sinn der interpersonellen Rhetorik (z. B. Leech 1990) erklärbar. Eine zusätzliche Möglichkeit für ein solches Ausnutzen der Bezeichnung ist die Betonung eines bestimmten Gesichtspunktes einer Sache, welcher zum Inferieren hinführt. Einzelheiten daraus sind aus Tabelle 10 ersichtlich.

Borba können wir in den behandelten Texten eine redundante Funktion nur in zwei Fällen (3,5\% aller Fälle) zuschreiben. Im ersten Fall tritt es als Bezeichnung für den 2. Weltkrieg in Slowenien in einem Verzeichnis von Abkürzungen in einem fachlichen Werk auf (das Verzeichnis ist auf der Grundlage älterer Dokumente erstellt), ${ }^{48}$ im zweiten Fall wird es metasprachlich gebraucht (als Beispiel für abzuratenden Gebrauch, übernommen nach der slowenischen Rechtschreibung (Slovenski pravopis 1990: 135). In allen anderen Fällen wird die Wahl funktionell auf der Sinnebene (siehe Tabelle 11). 
Boj steht in redundanter Funktion in ungefähr $55 \%$ der Fälle, und zwar als Bezeichnung für einen physischen oder bewaffneten Zweikampf in allen Arten von Texten, als Bezeichnung für den 2. Weltkrieg in Slowenien (narodnoosvobodilni boj 'Volksbefreiungskampf') in fachlichen und alltagssprachlichen Texten, die vor einigen Jahren entstanden, wenn wir sie von dem entsprechenden zeitlichen Gesichtspunkt beurteilen, in der Publizistik auch als Bezeichnung für einen sportlichen Wettkampf und in bestimmten Fällen für einen Wahlkampf oder ein bestimmtes Bestreben. Redundant wird boj auch als Fachterminus gebraucht (natürlich in Verbindung mit spezifischen Determinatoren) in entsprechenden Fachtexten. In den restlichen Fällen erhält die Wahl einen funktionellen Wert - siehe Tabelle 12.

Die angeführten Daten beweisen, daß in den Texten jedes beliebige Glied einer Synonymenreihe in redundanter Funktion auftreten kann. Der entscheidende Faktor für eine redundante oder funktionelle Wirkung der Wahl zwischen den Gliedern der Synonymenreihen, also für das Integrieren außersprachlicher Elemente in eine sprachliche Nachricht, ist der Text mit seiner Norm und Funktion. Wenn die Norm des Textes nur eine bestimmte Wahl zuläßt, dann kann nur der Ausdruck redundant sein, der mit der Norm zusammenfällt. Wenn aber die Wahl frei ist, dann ist die funktionelle Wirkung schon vorgesehen. In diesem Fall hängt vom Verfasser des Textes ab, ob er die Möglichkeit nutzen wird, vom Adressaten aber, ob er sie in die Interpretation des Textes einbezieht oder nicht.

b) Funktioneller Gebrauch der Auswahl

Die Tabellen 9-12 zeigen einige Arten der funktionellen Wirkung von Synonymen und die entsprechenden Mittel dazu.

Tabelle 9: Funktioneller Gebrauch von kuverta

\begin{tabular}{|l|l|}
\hline WIRKUNGSMITTEL & FUNKTION \\
\hline MULTIPLE/METAPHORISCHE/ & $\begin{array}{l}\text { Negieren des Inhalts } \\
\text { METONYMISCHE } \\
\text { BEZEICHNUNG }\end{array}$ \\
\hline REGION & $\begin{array}{l}\text { Integrieren des Wissens, daß jeder Umschlag etwas enthält } \\
\text { geöffnet werden dürfen, daß verschlossene Umschläge nicht }\end{array}$ \\
\hline $\begin{array}{l}\text { Evozieren der Region und Meinungen über die Umgebung } \\
\text { - amtliche Umgebung } \\
\text { - Bürokratie } \\
\text { - Arbeiterklasse } \\
\text { - Unterschicht }\end{array}$ \\
\hline ASSOZIATIONEN MIT & kuverta = 'Bestechungsgeld' \\
ZEICHEN IM SYSTEM & \\
\hline
\end{tabular}


Tabelle 10: Funktioneller Gebrauch von ovojnica

\begin{tabular}{|l|l|}
\hline WIRKUNGSMITTEL & FUNKTION \\
\hline $\begin{array}{l}\text { MULTIPLE/METAPHORISCHE} \\
\text { METONYMISCHE }\end{array}$ & $\begin{array}{l}\text { Integrieren des Wissens, daß ein Inhalt eingewickelt ist } \\
\text { Negieren des Inhalts } \\
\text { der Umschlag bewahrt, schützt den Inhalt }\end{array}$ \\
\hline DIVERSITÄT & $\begin{array}{l}\text { Indiziert das Verhältnis Autor - Adressat } \\
\text { wirkt störend auf den Adressaten }\end{array}$ \\
\hline REGION & $\begin{array}{l}\text { Evozieren der Umgebung } \\
\text { - Mittelschicht } \\
\text { - Fachleute }\end{array}$ \\
\hline $\begin{array}{l}\text { ASSOZIATIONEN MIT } \\
\text { ZEICHEN IM SYSTEM }\end{array}$ & oviti, ovijati 'umwickeln', zaviti 'einwickeln', ovoj 'Einband' \\
\hline
\end{tabular}

Aus dem Vergleich der Tabellen ist ersichtlich, daß das Wissen, welches bei kuverta und ovojnica integriert werden kann, teilweise unterschiedlich ist: Texte, in denen ovojnica verwendet wird, erlauben manchmal die Integrierung des Wissens, daß das, was wir umwickeln (in Umschläge tun), sicher, geschützt, aber auch wichtig, wertvoll ist. Bei kuverta muß man hin und wieder wissen, daß geschlossene Kuverts von niemandem außer dem Addressaten geöffnet werden dürfen, deshalb kann der Leser zum Schluß gelangen: Das, von dem im Text die Rede ist, ist geheim. Ein Unterschied besteht auch in der Region, welche von beiden Zeichen evoziert werden kann: kuverta evoziert eine amtliche und bürokratische Umgebung, die Arbeiterklasse und untere soziale Schichten, die Texte verlangen aber auch das Integrieren des Wissens und der Meinung, welche wir von diesen Schichten haben, was die Autoren als Stütze für ihre Argumente ausnutzen; ovojnica hingegen kann die Mittelschicht und Fachleute evozieren. Daneben hat kuverta die Fähigkeit, Assoziationen mit 'Bestechungsgeld' auch in Texten hervorzurufen, wo dieses Wort nicht als Bezeichnung dafür verwendet wird. Dagegen ruft ovojnica Assoziationen mit seiner Wortfamilie hervor (s. oben Punkt 4.4.2 b)), wobei der Leser des Textes sein Wissen darüber aktualisieren könnte, was normalerweise eingewickelt bzw. im Einband aufbewahrt wird - etwas, was gut aufbewahrt, vor Schäden geschützt werden muß... Damit erlauben beide Ausdrücke sehr unterschiedliche Inferenzen bzw. Rückschlüsse kuverta negative, ovojnica jedoch Inferenzen über die Sicherheit, den Schutz...

Tabelle 11: Funktioneller Gebrauch von borba

\begin{tabular}{|l|l|}
\hline WIRKUNGSMITTEL & FUNKTION \\
\hline MULTIPLE/METAPHORISCHE & Integrieren des Wissens über physische Kämpfe \\
/ & - Schmerz, Schläge \\
METONYMISCHE & Integrieren der Meinungen über bewaffnete Zusammenstöße \\
BEZEICHNUNG & - Kriegszustand, Gefahr \\
& - Brutalität, Opfer \\
& - starkes Engagement \\
& Integrieren des Wissens/der Meinungen über Gegner \\
& Inferieren des Nichtgutheißens \\
\hline
\end{tabular}




\begin{tabular}{|l|l|}
\hline DIVERSITÄT & Mangel expressiver Kompetenz \\
\hline REGION & $\begin{array}{l}\text { Integrieren des Wissens der Fachrichtungen } \\
\text { - Marxismus } \\
\text { - Darvinismus } \\
\text { Evozieren der Umgebung und Meinungen über sie } \\
\text { - aktivistische, revolutionäre } \\
\text { - ehemalige Jugoslawische Volksarmee }\end{array}$ \\
\hline $\begin{array}{l}\text { ASSOZIATIONEN MIT } \\
\text { ZEICHEN IM TEXT }\end{array}$ & Wissen über Stier-, Ringkämpfe, Kämpfe in Arenen \\
\hline $\begin{array}{l}\text { ASSOZIATIONEN MIT } \\
\text { TEICHEN IM ANDEREN }\end{array}$ & $\begin{array}{l}\text { ältere Fachtexte } \\
\text { politischer Appell }\end{array}$ \\
\hline $\begin{array}{l}\text { ASSOZIATIONEN MIT } \\
\text { ZEICHEN IM SYSTEM }\end{array}$ & weibliches Geschlecht \\
\hline
\end{tabular}

Tabelle 12: Funktioneller Gebrauch von $b o j$

\begin{tabular}{|l|l|}
\hline WIRKUNGSMITTEL & FUNKTION \\
\hline MULTIPLE/METAPHORISCHF & Integrieren des Wissens über physische und bewaffnete Kämpfe \\
- starkes Engagement \\
METONYMISCHE & - Gebrauch von nichterlaubten Mittel \\
- Brutalität, Opfer \\
Integrieren der Meinungen über Kämpfe \\
- unangenehm, schlimm \\
Integrieren des Wissens über den Gegner
\end{tabular}

Der Vergleich beider Tabellen zeigt, daß das Wissen, welches bei borba und $b o j$ integriert wird, ähnlich ist, es gibt aber wichtige Unterschiede in der Region: Neben den Regionen, die sich überdecken, ist bei borba die Möglichkeit für das Evözieren einer aktivistischen, revolutionären Umgebung, der gehaßten Jugoslawischen Volksarmee sowie die Zugehörigkeit zur sozialen Mittelschicht ohne entsprechende Sprachbildung gegeben. Alles das - wie die behandelten Beispiele zeigen - nutzen die Autoren der Texte zu ihrem Vorteil, manchmal jedoch rufen sie wegen ihrer Ungeschicktheit ungewollt unerwünschte Evokationen hervor. Der Einfluß der ursprünglich gesprochenen Texte ist bei borba sehr eindeutig, für ein genaueres Folgern über die Funktion der Wahl in solchen Fällen wäre die Kenntnis vom Stand in der gesprochenen Sprache notwendig. Eine andere erkennbare Kategorie der Texte, in welchen es zum Hervorrufen ungewünschter Evokationen kommt, sind Übersetzungen aus fremden Sprachen ins Slowenische. Ziemlich viele Texte, in welchen borba auftritt, zeigen auch sonst eine niedrigere Stufe der expressiven Kompetenz des Autors. 


\section{Schlußfolgerungen}

\subsection{Beurteilung des Wertes der vorgeschlagenen Methode}

Die unter Punkt 3 vorgeschlagene Methode für die Untersuchung von Synonymen bietet die Möglichkeit für eine Ursachen-Folgen-Beobachtung der Beziehungen auf drei Ebenen des Sprachinhalts: Bezeichnung, Bedeutung und Sinn, welche sonst von verschiedenen Zweigen der Sprachwissenschaft getrennt beschrieben werden Lexikologie, Semantik, Stilistik und Pragmatik. Im Rahmen der Semantik ermöglicht sie die Erforschung der Faktoren, die sowohl von der syntagmatischen wie auch von der paradigmatischen Semantik erforscht werden, zugleich aber auch das Beschreiben der Wirkungen auf dem Niveau der Einheit Text, was sonst in den Rahmen der Textlinguistik gehören würde. Bei der Annahme von zwei Hypothesen:

1. daß in verschiedenen sprachlichen Varietäten verschiedene Wörter für die Bezeichnung derselben Sache bestehen, und

2. daß empirisch begründete und zumindest annähernd wahrscheinliche Schlüsse über den Zustand in der Sprache nur auf der Grundlage einer systematischen Beschreibung der Bedingungen und Arten der Verwendung in einer umso größeren Zahl von tatsächlichen Texten gezogen werden dürfen und das natürlich nicht aus dem Kontext entrissen,

hat sich die Forschung von der intuitiven Beurteilung der potentiellen Verwendungsweisen außer dem situativen Rahmen zur Beschreibung der folgenden Beziehungen bewegt:

- Zeichen - Objekt,

- Zeichen - Zeichen,

- Zeichen - Kontext im weitesten Sinne des Wortes,

- Zeichen - Zeichen in anderen Texten.

Damit hat sich die Beobachtung der Synonyme im Kontext mit der Beschreibung im System vereint. Die Erkenntnisse der einen und der anderen Vorgehensweise waren hauptsächlich als unvereinbar betrachtet worden, die vorgeschlagene Methode dagegen ermöglicht das Aufdecken von systemeigenen Charakteristika auf der Grundlage der Beschreibung der Synonyme in der Rede. Der Text als besonderer Faktor des Sprechens, der mit seiner Form und Funktion ein Folgen der Norm eines bestimmten Texttyps fordert, ermöglicht das Erforschen von zwei verschiedenen Funktionen, welche dabei das Wort hat. Einerseits geht es um die schon von ehedem anerkannte Funktion, daß das Wort für die Bezeichnung von Sachen verwendet wird, anderseits um die noch völlig unerforschte Funktion des Wortes als Beitrag zum Sinn des Textes. Die Kategorie des Textes und das Bewußtsein des Einflusses der Norm auf die Verfassung von Texten ermöglichen, daß wir erneut auch das Problem der sog. absoluten Synonymie untersuchen, das ohne entsprechenden funktionellen Untersuchungen unlösbar zu sein scheint. 
In welchem Maß die unter Punkt 4.4 beschriebenen Resultate der Analyse dem tatsächlichen Zustand in der Sprache entsprechen, ist eine empirische Frage. Die Erkenntnisse über die Musterbeispiele würden die Autorin und wahrscheinlich auch den Leser enttäuschen - über die behandelten Synonyme ist eigentlich nichts derartiges entdeckt, was nicht schon Teil des intuitiven Wissens kompetenter Sprecher der slowenischen Sprache sein würde. Jedoch müssen wir uns dessen bewußt sein, daß das eigentlich der Beweis furr die Angemessenheit der Methode ist. Ihr Wert liegt darin, daß sie dem Sprachwissenschaftler, den die inhaltliche Ähnlichkeit zweier Ausdrücke interessiert, als Werkzeug für eine relativ objektive Behandlung mehrerer Schichten desselben Problems dienen könnte, ohne daß er bei der Suche einer Antwort nur von der Introspektion und eigener Intuition abhängig wäre. Eine objektive Beschreibung der sprachlichen Realität und die Anerkennung der Mannigfaltigkeit des Problems sind die Zusicherung, daß die Frage, was für ein Unterschied zwischen $x$ und $y$ besteht, dem wir wie einen roten Faden zusammen durch praktisch jedes Nachdenken über Synonyme nachstellen können, nicht mehr ein Gefühl von Hilflosigkeit oder Ungewißheit wegen der unterschiedlichen möglichen Antworten hervorrufen würde.

\subsection{Empfehlungen für die weitere Synonymenforschung}

Bei der Annahme, daß die unter dem Punkt 4.4 besprochenen Erkenntnisse der Untersuchung richtig sind, lassen sich daraus noch einige über die erörterten Musterbeispiele hinausgehenden Vermutungen über die Synonymie ableiten, die im Folgenden als empfehlenswert für die zukünftige Forschung aufgeführt werden.

a) Die weitverbreitete Meinung, daß die niedrigere Frequenz einer der Glieder der Synonymenreihe Merkmal einer stilistischen und gefühlsmäßigen Spezialisierung ist, gilt zu revidieren. Der Grund für eine bestimmte Wirkung dieses Typs ist nicht die Frequenz selbst, weil diese schon durch die Norm bestimmt ist. Die Norm beeinflußt zwar die Wirkung, jedoch in der Weise, daß funktionell eigentlich jedes beliebige Glied gebraucht werden kann. Die Angabe über die Frequenz ist danach für das Feststellen der stilistischen und gefühlsmäßigen Spezialisierung unbrauchbar.

b) In der Synonymenreihe ist nicht immer ein bestimmtes Glied markiert, das andere hingegen unmarkiert. Das Verhältnis markiert : unmarkiert gehört nicht zur Synonymenreihe. Das ist kein strukturelles Verhältnis, sondern ein Textverhältnis.

c) Selbst wenn wir im Fall sog. absoluter Synonymie eine völlige Bedeutungsgleichheit bzw. Invarianz im Rahmen eines bestimmten Sprachsystems beweisen können, kann unseren Erwartungen hinsichtlich der Angemessenheit der Wahl im Text nur ein Glied eines solchen Paares oder Reihe entsprechen. Unsere Erwartungen sind von der angeeigneten Stufe expressiver Kompetenz abhängig, die jedoch bei verschiedenen Sprechern unterschiedlich ist, außerdem tragen dazu noch unsere Überzeugungen über die Funktion des Textes sowie andere subjektive Faktoren bei. Es ist klar, daß die Beurteilungen über die Angemessenheit und damit auch die Interpretierung des Textes von verschiedenen Sprechern nicht übereinstimmen können. 
d) Eine zufällige Beobachtung, die leider im Rahmen dieser Arbeit nicht systematisch geprüft werden konnte, scheint für die funktionelle textlinguistische Untersuchung der Synonymie interessant zu sein. In bezug auf die Norm des Textes können Texte in zwei Typen unterteilt werden:

1. Texte, die eine bestimmte, der Norm entsprechende Wahl des Ausdruckes fordern, und

2. Texte, bei denen die Auswahl frei ist und die Möglichkeit für die funktionelle Wirkung durch die Wahl in der Norm schon vorausgesetzt ist.

Die Betrachtung der tatsächlichen Vorgehensweisen bei der Textverfassung verlangt jedoch eine weitere Untergliederung beider Typen in mehrere Untertypen: $\operatorname{ad} 1)$ :

a) Texte, in denen die Wahl tatsächlich mit der Norm zusammenfällt,

b) Texte, in denen die Norm augenscheinlich wegen der mangelnden Stufe der Kompetenz für die Gestaltung von Texten verletzt wird, ${ }^{49}$ und

c) Texte, in denen es keine Beweise für die mangelnde expressive Kompetenz gibt; jedoch weicht die Wahl des Ausdrucks trotzdem von den Erwartungen ab. Die Verfasser verletzen die Norm wohl gewollt, mit bestimmter Absicht, die mit einer Analyse des gesamten Textes normalerweise nicht besonders schwer erkennbar ist, obwohl sie nicht explizit im Redekontext ausgedrückt ist. Wenn ein solches Vorgehen zugleich im Gegensatz mit der Funktion des Textes steht, dann können wir das wohl eine Form von Manipulation durch Sprache nennen.

ad 2):

a) Texte, in denen die funktionelle Wirkung der außersprachlichen Elemente die Argumentation unterstützt. In solchen Fällen ist der Parallelismus auf der Ebene des Sprachlichen und der Ebene des Außersprachlichen bemerkbar - die explizit angeführten Argumente scheinen denen zu gleichen, zu welchen der Adressat mit impliziten, durch die Wahl ausgelösten Schlußfolgerungen kommen kann;

b) auch in nichtargumentativen Texten ist mit ähnlicher Vorgehensweise wie unter Punkt a) eine Möglichkeit für die evaluative Einstellung erreicht (oder zumindest angeboten), die wir hinsichtlich des Texttyps eigentlich nicht erwarten würden. Die sprachlichen Mittel dafür und die diesbezügliche Funktion unterschiedlicher Texttypen sind noch lange nicht genügend erklärt (z. B. völlig neutrale Wörter und Texte mit vorwiegender Informationsfunktion);

c) in verschiedenen Texttypen kann die Synonymwahl selbstverständlich auch den von der Stilistik anerkannten Funktionen dienen (z. B. Personen-, Milieu- oder Zeitcharakterisierung, Gradation, Betonen verschiedener Aspekte usw.). Diese Funktionen sind schon lange Gegenstand der Untersuchung, was für den Typ c) unter 
Punkt 1 und die Typen a) sowie b) unter Punkt 2, die wahrscheinlich eine ziemlich neue Betrachtungsweise darstellen, nicht der Fall ist.

Die Liste der Möglichkeiten, die sich im Feld der Synonymforschung auf der Grundlage der Sprachtheorie Coserius ergeben, kann beliebig fortgeführt werden, doch sollen die aufgezählten Möglichkeiten als Beweis genügen, daß die Wahl der erwähnten theoretischen Grundlage für die Behandlung verschiedener Gesichtspunkte der Synonymie angemessen und aussichtsvoll ist.

\section{Quellen- und Literaturverzeichnis}

Apresjan, Ju. D. 1966. Analyse distributionnelle des significations et champs sémantiques structurés. Languages 1, 44-74. Paris: Didier/Larousse.

Bajec, A. 1950. Besedotvorje slovenskega jezika. I. Izpeljava samostalnikov. Ljubljana: Slovenska akademija znanosti in umetnosti.

Battaglia, S. 1991. Überlegungen zu einer gebrauchstheoretischen Beschreibung von Adjektiven. In: Sprache - Kommunikation - Informatik. Akten des 26. Linguistischen Kolloquiums, Pozna 1991, Bd. 2, 657-665.

Beaugrande, R. A. de, W. U. Dressler. 1992. Uvod v besediloslovje. Ljubljana: Park.

Berneker, E. 1908-1913. Slavisches etymologisches Wörterbuch I. Heidelberg: Winter.

Bezlaj, F. 1977. Etimološki slovar slovenskega jezika I. Ljubljana: Slovenska akademija znanosti in umetnosti, Inštitut za slovenski jezik.

Bickmann, H.-J. 1978. Synonymie und Sprachverwendung. Tübingen: Niemeyer.

Cooper, D. E. 1974. Synonymie. In: Ratio 15, 253-263.

Coseriu, E. 1967. Lexikalische Solidaritäten. In: Poetica 1, 293-303.

Coseriu, E. 1970. Einführung in die strukturelle Betrachtung des Wortschatzes. Tübingen: Narr.

Coseriu, E. 1971. Sprache. Strukturen und Funktionen. 2. verbesserte Aufl. Tübingen: Narr.

Coseriu, E. 1973. Die Lage in der Linguistik. Innsbruck: Institut für Sprachwissenschaft.

Coseriu, E. 1974. Synchronie, Diachronie und Geschichte. München: Fink.

Coseriu, E. 1975. Sprachtheorie und allgemeine Sprachwissenschaft. München: Fink.

Coseriu, E. 1985. Textlinguistik. 2., durchgesehene Aufl. Darmstadt: Wissenschaftliche Buchgesellschaft.

Coseriu, E. 1992. Einführung in die allgemeine Sprachwissenschaft. 2. Aufl. Tübingen: Francke.

Dubois, J. 1964. Distribution, ensemble et marque dans le lexique. In: Cahiers de lexicologie 4, 5-16.

Ducrot, O. 1988. Izrekanje in izrečeno. Ljubljana: Škuc, Znanstveni Inštitut Filozofske fakultete.

Eckert, R. von. 1968. Zur Darstellung der Synonymie mit Hilfe der Distributionsmodelle und einige Schlußfolgerungen daraus für den russischen Sprachunterricht. In: Wissenschaftliche Zeitschrift der Karl-Marx-Universität. Gesellschafts- und Sprachwissenschaftliche Reihe 17, 129-132. 
Evens, M. W. et al. 1980. Lexical-semantic Relations: A Comparative Survey. Carbondale, USA, Edmonton, Canada: Linguistic Research Inc.

Filipec, J. 1961. Česká synonyma z hlediska stylistiky a lexikologie. Praha: Československá akademie věd.

Flydal, L. 1951. Remarques sur certains rapports entre le style et l'état de la langue. In: Norsk tidsskrift for sprogvidenskap 16, 240-257.

Gabka, K. 1967. Zur Abgrenzung lexikalischer, morphologischer und syntaktischer Synonymie. In: Zeitschrift für Slawistik 12, 727-734.

Gauger, H.-M. 1972. Zum Problem der Synonyme. Tübingen: Narr.

Gauger, H.-M. 1972a. Die Wörter und ihr Kontext. Ein Beitrag zu den Synonymen. In: Neue Rundschau 83, 432-450.

Harris, R. 1973. Synonymy and Linguistic Analysis. Oxford: Blackwell.

Harris, Z. S. 1970. Papers in Structural and Transformational Linguistics. DordrechtHolland: Reidel.

Heringer, H. J. 1992. Distributionelle Semantik. Ein Arbeitspapier. Unveröffentlichtes Manuskript.

Hjelmslev, L. 1980. Prolegomena teoriji jezika. Zagreb: GZS.

Hurford, J. R., B. Heasley. 1983. Semantics: a coursebook. Cambridge etc.: Cambridge University Press.

Katz, J. J., J. A. Fodor. 1963. The Structure of a Semantic Theory. In: Language 39, 170-210.

Kmecl, M. 1976. Mala literarna teorija. Ljubljana: Borec.

Koch, W. A. 1963. Zur Homonymie und Synonymie. Eine kritische Zusammenfassung. In: Acta Linguistica 13, 65-93.

Košir, M. 1988. Nastavki za teorijo novinarskih vrst. Ljubljana: DZS.

Leech, G. 1990. Principles of pragmatics. 7th impression. London, New York: Longman.

Levinson, S. C. 1983. Pragmatics. Cambridge etc.: Cambridge University Press.

Lyons, J. 1975. Einführung in die moderne Linguistik. 4., unveränderte Aufl. München: Beck.

Lyons, J. 1980-1983. Semantik. München: Beck.

Lyons, J. 1981. Language, Meaning and Context. London: Fontana/Collins.

Mates, B. 1950. Synonymity. In: University of California Publications in Philosophy 25, 201-226.

Mel'čuk, I. A., A. K. Žolkovskij. 1970. Towards a Functioning 'Meaning-Text' Model of Language. In: Linguistics 57, 10-47.

Mistrík, J. 1975. Žánre vecnej literatúry. Bratislava: Slovenské pedagogické nakladatel'stvo.

Nida, E. A. 1975. Componential Analysis of Meaning. The Hague, Paris: Mouton.

Pogorelec, B. 1986. Znanstveno besedilo, njegove jezikoslovne prvine in slog. In: Vidovič-Muha, A. (Hrsg.): Slovenski jezik v znanosti 1. Ljubljana: Univerza Edvarda Kardelja v Ljubljani, Filozofska fakulteta, Znanstveni inštitut, 11-22.

Quine, W. V. O. 1960. Word and Object. Cambridge, Mass.: M. I. T. Press. 
Quinne, W. V. O. 1976. Das Bedeutungsproblem in der Linguistik. In: Bense, E., P. Eisenberg, H. Haberland (Hrsg.): Beschreibungmethoden des amerikanischen Strukturalismus. 1. Aufl. München: Hueber, 332-345.

Schiffrin, D. 1994. Approaches to Discourse. Oxford UK, Cambridge USA: Blackwell.

Schirn, M. 1975. Identität und Synonymie. Stuttgart-Bad Cannstatt: FrommannHolzboog.

Skalička, V. 1941. Problémy stylu. In: Slovo a slovesnost 7, 191-197.

Skok, P. 1971-1974. Etimologijski rječnik hrvatskoga ili srpskoga jezika. Zagreb: Jugoslavenska akademija znanosti i umjetnosti.

Slovar slovenskega knjižnega jezika I-V. 1970-1991. Ljubljana: DZS.

Slovenski pravopis. 1, Pravila. 1990. Ljubljana: DZS.

Slovenski pravopis. 1962. Ljubljana: DZS.

$\mathrm{SP}=$ Slovenski pravopis

Sparck Jones, K. 1986. Synonymy and Semantic Classification. Edinburgh: Edinburgh University Press.

SSKJ = Slovar slovenskega knjižnega jezika

Toporišič, J. 1984. Slovenska slovnica. Pregledana in razširjena izd. Maribor: Obzorja. Toporišič, J., Gjurin, V. (Hrsg.). 1981. Slovenska zvrstna besedila. Ljubljana: Univerza Edvarda Kardelja v Ljubljani, Filozofska fakulteta.

Ullmann, S. 1967. Grundzüge der Semantik. Berlin: de Gruyter.

Ungeheuer, G. 1969. Paraphrase und syntaktische Tiefenstruktur. In: Folia Linguistica 3, 178-227.

Wunderlich, D. 1980. Arbeitsbuch Semantik. Königstein/Ts.: Athenäum.

Zorman, M. 1997. Nekateri strukturalno-funkcionalni odnosi med členi sinonimnih vrst v slovenščini. Unveröffentlichte Doktorarbeit. Ljubljana: Filozofska fakuteta.

Zvegincev, V. A. 1963. Zamečanija o leksičeskoj sinonimii. In: Voprosy teorii i istorii jazyka. Sbornik v čest' prof. B. A. Larina. Leningrad: Izd. Leningradskogo univ., 127-142.

Povzetek

NEKAJ O STRUKTURI IN FUNKCIJI SINONIMOV

Spoznanje, da so odkritja različnih semantičnih šol o problemu sinonimije nezdružljiva, in da so mnenja o sinonimih prepogosto utemeljena le $z$ introspekcijo in intuitivnim zavedanjem kompetentnih govorcev nekega jezika, zahteva, da raziskovanje sinonimije zasnujemo na koherentni semantični teoriji ter empirični analizi rabe sinonimov $v$ dejanskih besedilih.

$\mathrm{V}$ delu je na takih osnovah (Coserijeva strukturalno-funkcionalna terija jezika ter korpus slovenskih besedil) predstavljen model za opisovanje sinonimov, ki vključuje različne semantične metode, primerne za raziskovanje treh ravnin vsebine: oznake, pomena in smisla. $\mathrm{V}$ duhu modela sta analizirana dva para slovenskih sinonimov: kuverta - ovojnica ter borba - boj.

Analizirani so odnosi znak - stvar, znak - znak (strukturalni odnosi), znak - kontekst $v$ najširšem smislu ter znak - znaki $v$ drugih besedilih, torej odnosi, ki jih sicer ločeno proučujejo sintagmatska in paradigmatska semantika, besediloslovje ter pragmatika. Opisovanje strukturalnih odnosov sloni na računalniški analizi distribucije v besedilih (metoda $\mathrm{H}$. J. Heringerja), proučevanje funkcionalnega vidika problema pa na opazovanju norme in funkcije besedila. Upoštevani sta dve funkciji besede: beseda kot oznaka za določeno stvar ter njen prispevek $\mathrm{k}$ smislu besedila. 
Rezultati analize se ujemajo s semantičnimi razlagami in intuitivnim védenjem kompetentnih govorcev slovenskega jezika, zato predlagano metodo nemara smemo šteti za primerno orodje za relativno objektivno obravnavo več vidikov problema vsebinske enakosti/podobnosti med izrazi. Če dopuščamo, da se ugotovitve o proučenih parih sinonimov ujemajo $z$ dejanskim stanjem $v$ jeziku in besedilih, je na njihovi osnovi mogoče postaviti nekatere dogme o sinonimih pod vprašaj, nadaljnje raziskovanje pa usmeriti v še neraziskane funkcije sinonimov kot npr. podpora argumentaciji, vplivanje na vrednotenje $s$ stilno nevtralnimi izrazi, manipuliranje $z$ jezikom, socialna deiksa itd. 